\title{
Rheumatic patients at work : a study of labour force participation and its determinants in rheumatoid arthritis, ankylosing spondylitis, and juvenile chronic arthritis
}

Citation for published version (APA):

Chorus, A. M. J. (2004). Rheumatic patients at work : a study of labour force participation and its determinants in rheumatoid arthritis, ankylosing spondylitis, and juvenile chronic arthritis. [Doctoral Thesis, Maastricht University]. Universiteit Maastricht. https://doi.org/10.26481/dis.20040507ac

Document status and date:

Published: 01/01/2004

DOI:

10.26481/dis.20040507ac

Document Version:

Publisher's PDF, also known as Version of record

Please check the document version of this publication:

- A submitted manuscript is the version of the article upon submission and before peer-review. There can be important differences between the submitted version and the official published version of record. People interested in the research are advised to contact the author for the final version of the publication, or visit the DOI to the publisher's website.

- The final author version and the galley proof are versions of the publication after peer review.

- The final published version features the final layout of the paper including the volume, issue and page numbers.

Link to publication

\footnotetext{
General rights rights.

- You may freely distribute the URL identifying the publication in the public portal. please follow below link for the End User Agreement:

www.umlib.nl/taverne-license

Take down policy

If you believe that this document breaches copyright please contact us at:

repository@maastrichtuniversity.nl

providing details and we will investigate your claim.
}

Copyright and moral rights for the publications made accessible in the public portal are retained by the authors and/or other copyright owners and it is a condition of accessing publications that users recognise and abide by the legal requirements associated with these

- Users may download and print one copy of any publication from the public portal for the purpose of private study or research.

- You may not further distribute the material or use it for any profit-making activity or commercial gain

If the publication is distributed under the terms of Article 25fa of the Dutch Copyright Act, indicated by the "Taverne" license above, 


\title{
Rheumatic patients at work
}

\author{
A study of labour force participation and its \\ determinants in rheumatoid arthritis, ankylosing \\ spondylitis, and juvenile chronic arthritis
}


Financial support for the studies in this thesis was obtained from the Ministry of Public Health, Welfare and Sports and from the Dutch Arthritis Association (Het Reumafonds). Additional financial support for the printing of this thesis by the Dutch Arthritis Association (Het Reumafonds), the department of Internal Medicine, division of Rheumatology, University Hospital Maastricht, and TNO Prevention and Health is gratefully acknowledged.

Cover design: 'Hokjesgeest' by Dolph Paulsen, www.anymation.nl, Zeist Layout: Jaap van der Plas, TNO Prevention and Health, Leiden Printed by: Drukkerij De Bink B.V., Leiden

ISBN nummer: 90-5986-058-6

\section{Q 2004, A.M.J. Chorus}

All rights reserved. No part of this book may be reproduced, stored in a retrieval system, or transmitted in any form or by any means, electronic, mechanical, photocopying, recording, or otherwise, without prior permission, in writing of the author, or, when appropriate, of the publishers of the publications. 


\title{
Rheumatic patients at work
}

\author{
A study of labour force participation and its \\ determinants in rheumatoid arthritis, ankylosing \\ spondylitis, and juvenile chronic arthritis
}

PROEFSCHRIFT

ter verkrijging van de graad van doctor aan

de Universiteit Maastricht,

op gezag van de Rector Magnificus, Prof, mr. G.P.M.F. Mols,

volgens het besluit van het College van Decanen,

in het openbaar te verdedigen

op vrijdag 7 mei 2004 om 14.00 uur

door

Astrid Maria Jacoba Chorus

geboren te Munstergeleen 


\section{Promotor:}

Prof.dr. Sj, van der Linden

\section{Beoordelingscommissie:}

Prof. dr. F.J.N. Nijhuis (voorzitter)

Prof. dr. J.Th.M. van Eijk

Prof, dr. W, van Mechelen (Vrije Universiteit Amsterdam)

Prof, dr. J.J. Rasker (Universiteit Twente)

Prof. dr. ir. C.P. van Schayck 


\section{Contents}

\section{Page}

1 General introduction

2 Quality of life and work in patients with rheumatoid arthritis and ankylosing spondylitis of working age

3 Labour force participation among patients with rheumatoid arthritis

4 Employment, work disability, and work days lost in patients with ankylosing spondylitis: a cross sectional study of Dutch patients

5 Work factors and behavioural coping in relation to withdrawal from the labour force in patients with rheumatoid arthritis.

6 Employment perspectives of patients with ankylosing spondylitis

7 Labour force participation, career related problems, and job handicaps in adults with juvenile chronic arthritis

Samenvatting

Dankwoord 

General introduction 



\section{Background}

Hippocrates first recognised rheumatic diseases, at least as partially joint diseases, in the fourth century before Christ. The term 'rheuma' was probably introduced in the first century after Christ to indicate a flow of pain through the joints. ${ }^{1}$ In mediaeval times Baillou, a Parisian physician, was the first to conceptualise rheumatism as a musculoskeletal syndrome. The term rheumatic disease does not have a clear boundary and nowadays more than 100 different conditions are labelled as rheumatic diseases. ${ }^{2}$ Nevertheless, despite differences in clinical features, they have in common that they are responsible for a sizeable amount of health care use and disability, with studies showing that $27-40 \%$ of long-term disability is attributable to musculoskeletal disorders. ${ }^{2-4}$

For many people, the word rheumatism conjures up an image of grandparents with the minor aches and pains inevitably associated with ageing. The reality is that theumatic disease can be found at every stage of life. It is ironic that, with the exception of osteoarthritis, the other most common types of rheumatic diseases, such as rheumatoid arthritis, systemic lupus erythematosus, ankylosing spondylitis, often begin in working age. ${ }^{5}$ Juvenile chronic arthritis occurs before the age of 16 , and can lead to long-term physical and psychosocial disability, including work disability. ${ }^{6}$

In many industrialised countries work disability is a substantial problem for persons with rheumatic diseases, and a challenge in terms of social and health policy. ${ }^{7, \theta}$ The costs of work disability are usuallyi high, and generally higher than the costs of medical treatment. 3,9-11 In the Netherlands, an estimated 200000 people of working age are affected by chronic rheumatic diseases. They include 6000 persons with JCA during childhood. In total, this is $2 \%$ of the entire population of working age. ${ }^{12,13}$

Patients and their families are faced with a loss of income at the same time as substantial medical care costs. ${ }^{14-16}$ In the Netherlands, no estimates are available of financial losses incurred by individuals and their families due to lost wages. Out-of-pocket costs incurred by rheumatic patients have been estimated at 0.9 billion euros. This is twice as much as the costs of people without not chronic illnesses. ${ }^{13}$ Moreover, not only does work provide income and social status, it is also valued for its social support and social distraction outside the family. In general, work was found to have positive effects on the well-being and quality of life of the chronically ill. ${ }^{17}$

At the societal level, employers have to deal with productivity loss and the resultant higher insurance premiums. Governments have to control economic costs of disabilities in people of working age who receive support from the social security system (and, in particular, the system for disability pensions). In the Netherlands, rheumatic diseases account for an 
estimated $6 \%$ of the total direct medical costs and about $15 \%$ of the costs due to work disability payments, ${ }^{13,10}$

Risk factors that affect participation in the labour force by rheumatic patients can be useful. in determining whether and how rates can be changed.' For people with theumatic diseases, the physical demands of a job need to be matched to the physical capacity of the individual involved. ${ }^{19}$ Since risk factors exist at both the level of the individual and the societal level, international comparison of studies is hampered by cultural differences, different economic conditions, and different social security systems.

In the last decade, reducing work disability in people with chronic diseases has attracted increased attention in public health and socioeconomic policy in the Netherlands. Nevertheless, only a few academics have looked at work related issues in rheumatic diseases. Furthermore, scientific information is limited about the importance of work and the actual work situation of Dutch patients with rheumatic diseases, as well as factors that may have an effect in that respect. Where information is available - in case of rheumatoid arthritis - it was found that about $40 \%$ of Dutch academic hospital patients with rheumatoid arthritis left the labour force within four years after diagnosis. ${ }^{20,21}$

\section{Aim and research questions}

The aim of this study is to increase the understanding of work related quality of life and participation in the labour force among Dutch patients with rheumatic diseases and to provide scientific evidence as support for modifiable determinants in the development of effective vocational counselling and rehabilitation strategies.

The following research questions were therefore addressed:

1. What is the importance of paid work for the quality of life of patients with rheumatic diseases?

2. To what extent do patients with rheumatic diseases participate in the labour force, and what is their labour market position compared to peers in the general population? 


\section{Which determinants of early withdrawal from the labour force can be identified, and what is the relative importance of some of those determinants?}

\section{Which problems do adult patients with a history of childhood rheumatic disease encounter in the labour market?}

\section{Research design}

This section provides a rough outline of the methods used. A more detailed description will be given in subsequent chapters.

In 1996, TNO Prevention and Health instigated, in co-operation with TNO Work and Employment and the division of Rheumatology, department of Internal Medicine of the University Hospital of Maastricht, a study of "Labour force participation and its determinants in patients with rheumatic diseases". This cross sectional study looked at patients with rheumatic diseases. It made use of a self-administered questionnaire comprising validated measurements of sociodemographics, disease status and outcome, work history and current work situation.

\section{Recruitment of study population}

This thesis looks at three groups. of patients with different, clinically-confirmed rheumatic diagnoses. To recruit patients for our study, we approached rheumatologists working in a nationwide geographical sample of at least 15 practices. This spread enables us to obtain large enough samples of patients. Eligible patients were randomly selected from participating practices using the national Standardised Diagnosis Register of Rheumatic diseases (SDR), a representative database with information about the diagnosis of the patient population by $80 \%$ of all rheumatologists in the Netherlands. ${ }^{22}$ After this sampling procedure, the participating rheumatologists invited their patients by letter to participate in the present study. Patients willing to participate filled out an informed consent form, in which they also were asked to indicate their present employment status, before sending it to TNO. They then received a questionnaire adapted to their current work situation.

In 1996, data on sociodemographics, disease status and outcome, work history and current work situation were obtained from 1056 patients with rheumatoid arthritis (RA) aged 16-59 years (62\% of the initial cohort) and from 104 patients with juvenile chronic arthritis (JCA) 16-35 years of age (50\% of the initial cohort). Both study groups were recruited from patient populations of 35 rheumatologists working in 17 practices. In 1997 , 
data were obtained from 658 patients with ankylosing spondylitis (AS) 16-59 years of age ( $60 \%$ of the initial cohort). This study group was recruited from patient populations of 34 rheumatologists working in 15 practices.

\section{Outline of thesis}

The chapters in this thesis seek to answer the research questions listed in the section 'Aim and research questions'. Chapter 2 investigates the relative contribution of paid work to the physical and mental health related quality of life in patients with RA and AS (question 1). Chapters 3 and 4 address research question 2. Chapter 3 describes labour force participation rates of patients with RAs and subgroups of patients with RA compared with rates of peers in the general population. Chapter 4 describes participation in the labour force of patients with AS compared to the general population. Chapters 5 and 6 deal with research question 3: the identification of determinants of early withdrawal from the labour force and their relative importance for introduction to vocational rehabilitation practice. In Chapter 5, modifiable determinants of early withdrawal from the labour force are identified for patients with RA, and placed in a multivariate context. In line with the methods used in Chapter 5, the determinants of early withdrawal from the labour force for patients with AS are examined in Chapter 6. Chapter 7 describes labour force participation rates and the labour market position of adult patients with JCA (question 4). Chapters 2 to 7 of this thesis were originally written as separate articles for publication in scientific journals. There is therefore some overlap between chapters, especially in the description of the methodology, Chapter 8 contains the summary and conclușions, and places them in perspective. 


\section{References}

1. Copeman WSC, Scott JT. Historical. In: Scott JC, editor. Copeman's textbook of the rheumatic diseases. Edinburgh: Churchill Livingstone, 1980:3-24.

2. Sangha O. Epidemiology of rheumatic diseases. Rheumatology 2000;39:3-12.

3. Yelin E, Callahan LF. The economic cost and social and psychological impact of musculoskeletal conditions. National Arthritis Data Work Groups. Arthritis Rheum $1995 ; 38: 1351-62$.

4. Hill AG, Parsons J, Taylor A, Leach G. Health Related Quality of life in a population sample with arthritis. J Rheumatol 1999;26:2029-35.

5. Schiaffino KM, Brady TJ. Psychosocial aspects. In: Wegener ST, Belza BL, Gall EP, editors. Clinical care in the rheumatic diseases. Georgia: American College of Rheumatology, 1996:15-8.

6. Erlandson D. Juvenile rheumatoid arthritis. In: Logigian M, Ward J, editors. Pediatric Rehabilitation: A team Approach for Thearpists. Boston: Little Brown and Co., 1989.

7. Allaire SH. Update on work disability in rheumatic diseases. Curr Opin Rheumatol 2001;13:93-8.

8. Allaire SH. Work disability. In: Wegener ST, Belza BL, Gall EP, editors. Clinical care in the rheumatic diseases. Georgia: American College of Rheumatology, 1996: 141-5.

9. Pugner KM, Scott DI, Holmes JW, Hieke K. The costs of rheumatoid arthritis: an international long-term view. Semin Arthritis Rheum 2000;29:305-20.

10. Allaire SH, Prashker MJ, Meenan RF. The costs of rheumatoid arthritis. Pharmacoeconomics $1994 ; 6: 513-22$.

11. Cooper NJ. Economic burden of rheumatoid arthritis: a systematic review. Rheumatology (Oxford) 2000;39:28-33.

12. Miedema HS. Reuma in Nederland (Rheumatic diseases in the Netherlands). Leiden: TNO Prevention and Health, 1997.

13. Chorus AMJ, Reuma in Nederland: de cijfers, actualisering 2000 (Rheumatic diseases in the Netherlands: key figures, update 2000). Leiden: TNO Prevention and Health, 2001.

14. Newhall-Perry K, Law N], Ramos B, Sterz M, Wong. WK, Bulpitt KJ et al. Direct and indirect costs associated with the onset of seropositive rheumatoid arthritis. Western Consortium of Practicing Rheumatologists. J Rheumatol 2000;27:1156-63.

15. Yelin E. The earnings, income, and assets of persons aged 51-61 with and without musculoskeletal conditions. J Rheumatol 1997;24:2024-30. 
16. Gabriel SE, Crowson CS, Campion ME, O'Fallon WM. Indirect and nonmedical costs among people with rheumatoid arthritis and osteoarthritis compared with nonarthritic controls. J Rheumatol 1997;24:43-8.

17. Warr P. Work, unemployment and mental health. Oxford: Clarendon Press, 1987.

18. Polder J, Takken J, Meerding WJ, Kommer GJ, Stokx U. Kosten van ziekten in Nederland: de zorgeuro ontrafeld (Cost of illnesses in The Netherlands: the euro of care disentangled). Bilthoven: Rijksinstituut voor Volksgezondheid en Milieu, 2002.

19. Shanahan EM, Smith MD. Rheumatoid arthritis, disability and the workplace. Bailliere's Best Pract Res Clin Rheumatol 1999;13:675-88.

20. Doeglas D, Suurmeijer T, Krol B, Sanderman R, van Leeuwen M, van Rijswij̣k M. Work disability in early rheumatoid arthritis. Ann Rheum Dis 1995;54:455-60.

21. Albers JM, Kuper HH, van Riel PL, Prevoo ML, van 't H, van Gestel AM et al. Socioeconomic consequences of rheumatoid arthritis in the first years of the disease. Rheumatology 1999;38:423-30.

22. Miedema HS, Linden SM vd, Rasker J3, Valkenburg HA. A national database of patients visiting rheumatologists in the Netherlands: The Standard Diagnosis Register of Rheumatic Diseases. A report and preliminary analysis. $\mathrm{Br}$ ] Rheumatol 1998;37:55561. 
Quality of life and work in patients with rheumatoid arthritis and ankylosing spondylitis of working age 


\section{Abstract}

\section{Objectives}

To investigate the relationship between work and quality of life (QOL) in patients with rheumatoid arthritis (RA) and ankylosing spondylitis (AS) aged 16-59.

\section{Methods}

1056 patients with RA and 658 patients with AS were included. Data were obtained by a postal questionnaire, included several generic and disease related QOL instruments. Separate dimensions and physical and mental summary scores from the SF-36 were compared. Stepwise multiple regression was performed to study the relationship between work and physical and mental health related QOL, including disease related factors, coping, and fatigue.

\section{Results}

Physical health related QOL was reported to be worse, and mental health related QOL better, in RA than in AS in people of working age. No differences between RA and AS were found in somatic pain, physical role functioning, social functioning, emotional role functirsinfy, vidilty, or generál 'healith perception; nor were there any significant differences in fatigue and behavioural coping styles. Work was positively associated with physical health related. QOL in both groups, and after disease characteristics, was the most important determinant. No association was found with mental health related QOL.

\section{Conclusions}

Although physical health related QOL was worse in RA patients, the impact on several dimensions of health related QOL in patients with RA and AS of working age under rheumatological care was comparable. Patients with RA and AS experienced similar limitations in physical role functioning, including work. Work is an important independent external determinant of physical health related QOL, but not of mental health related QOL. 


\section{Introduction}

Rheumatoid arthritis (RA) and ankylosing spondylitis (AS) are two common types of inflammatory rheumatic disease. In the Netherlands patients are usually referred to rheumatologists by general practitioners. ${ }^{1}$ RA is characterised by chronic, symmetric, and erosive synovitis of peripheral joints. Any joint may be affected, but those most commonly involved are the metacarpophalangeal or proximal interphalangeal joints of the hand, and the metatarsophalangeal and proximal interphalangeal joints of the feet, wrists, knees and elbows. The disease causes decreased hand function and decreased mobility. Onset of RA reaches a peak between the ages of 40 and 50 and it is two to three times more prevalent in women than in men. ${ }^{2}$ AS predominantly affects the axial skeleton with sacroiliac joint involvement (sacroiliitis) as its hallmark, causing decreased spinal mobility. Onset is usually before the age of 40 . Clinically, AS is three times more prevalent in men.

Daily pain, stiffness, fatigue, and physical disability are common features of both RA and AS. ${ }^{3-5}$ These problems, and the way patients cope with them, can affect their quality of life $(\mathrm{QOL}){ }^{2,6} \mathrm{RA}$ is traditionally considered to be a disease with a major impact on all aspects of QOL. ${ }^{2}$ The burden of iliness of AS is less well defined than for RA. It is often said that AS has a moderately severe impact on QOL because many patients maintain good functional ability, and most patients manage to maintain paid employment. ${ }^{6-9}$ However, in a previous study we found that age and sex adjusted participation in the labour force was also reduced in AS compared to reference data from the general population of working age. ${ }^{10}$ So work disability can be a major problem in both patients with RA and AS, with a potentially negative effect on wellbeing and QOL. Only one study makes a direct comparison of the consequences of RA and AS. That study found that groups of patients with RA and AS matched. for age and sex had similar amounts of disability, pain, and reduced wellbeing. This contradicts the consensus view." However, there was no assessment of the relationship between work and QOL.

Having a paid job can have positive effects on the wellbeing and QOL of people of working age. ${ }^{12}$ Because both diseases tend to strike when people are of working age and, it is expected that these positive effects also apply to patients with RA and AS. On the other hand, holding down a paid job may require a lot of energy from people with chronic disease, and this may have negative effects on health status. Research on rheumatic diseases has shown that health related QOL is influenced by the main disease disability pathway and factors external to this pathway, such as education and psychosocial 
characteristics. ${ }^{7,13}$ However, the relative contribution of work to the QOL of patients with RA and AS is not known.

The objectives of this study were, therefore, to compare the QOL of patients with RA and AS of working age who were receiving rheumatological care, and to study the effect of work on the health related $\mathrm{QOL}$ in a multivariate context.

\section{Methods}

\section{Patient population}

The present study was conducted in a Dutch nationwide group of 1056 patients with RA and 658 patients with AS aged 16-59 years, as diagnosed. by a rheumatologist. Eligible patients were selected using the national Standardised Diagnosis Register of Rheumatic Diseases (SDR), a representative database with information about diagnoses of the patient population made by $80 \%$ of all rheumatologists in the Netherlands. ${ }^{1}$ For each diagnosis group, recruitment and data collection were conducted separately, using different geographically representative samples of theumatology practices throughout the Netherlands. In 1996 a random sample of patients with RA aged 16-59 was selected from 17 practices (52\% of all practices participating in the SDR in 1996, accounting for $37 \%$ of all SDR rheumatologists, in other words $30 \%$ of all rheumatologists in the Netherlands). In 1997 a random sample of AS patients aged 16-59 was selected from 15 practices ( $42 \%$ of all practices participating in the SDR in 1997, accounting for $34 \%$ of all SDR rheumatologists, in other words $27 \%$ of all rheumatologists in the Netherlands). All patients were contacted by their own rheumatologist, and 1056 patients with RA and 658 patients with AS. (62\% and $60 \%$ of the initial cohorts respectively) agreed to participate. All patients filled out a self administered questionnaire on demographics, work related characteristics, disease specific and general health related instruments to assess QOL, coping, and fatigue. The design has also been described in detail elsewhere. ${ }^{10,14}$

\section{Demographics, work and disease related characteristics}

The demographic variables were age, sex, and highest attained level of education (primary; secondary; higher vocational/university). Work is defined as having paid employment (yes/no). Disease related characteristics included were age at time of diagnosis, disease duration, comorbidity (at least one comorbid condition versus none), and a measure for disease activity. Disease activity was assessed by different validated disease-specific measures. The Rheumatoid Arthritis Disease Activity Index (RADAI) was used for patients with RA and the Bath Ankylosing Spondylitis Disease Activity Index 
(BASDAI) was used for patients with AS. ${ }^{15,16}$ Both the RADAI and the BASDAI may range from 0 to 10 , and higher scores indicate more disease activity.

\section{Quality of life}

Information about health related $\mathrm{QOL}$ was obtained with a validated Dutch translation of the SF-36. ${ }^{17}$ The SF-36 contains 36 items, organised into eight multi-item scales covering the dimensions physical functioning, physical role functioning, social functioning, emotional role functioning, mental health, vitality, bodily pain, and general health. One additional item pertains to health transition. On the basis of these separate subscales, component summary scores can be calculated to provide a global measure of physical (PCS) and mental functioning (MCS). ${ }^{18,19}$ The scales and summary scores may vary from 0-100, with lower scores indicating a worse health status.

\section{Coping}

Coping styles were assessed with the Dutch validated Coping with Rheumatic Stressors (CORS) instrument. ${ }^{20.21}$ The CORS measures eight coping styles for the most important stressors of inflammatory rheumatic diseases-namely pain, limitations, and dependence. Three scales relate to pain: comforting cognitions ( 9 items), decreasing activities ( 8 items), and diverting attention ( 8 items). Three scales measure styles of coping with limitations: optimism (5 items), pacing-for example, adapting one's level of activity (10 items), and creative solution seeking ( 8 items). Two scales refer to dependence: making an effort to accept one's level of dependency (6 items) and showing consideration (7 items). For each item, patients report how often they made use of that particular coping effort on an interval scale ranging from 1 to 4 . Higher scores indicate more frequent use.

\section{Fatigue}

The Multidimensional Fatigue Inventory (MFI) was used to assess fatigue. It measures five dimensions: general fatigue, physical fatigue, reduced motivation, reduced activity, and mental fatigue. The MFI has been validated and tested in previous studies of chronically ill people, including patients with AS. ${ }^{22,23}$ Each dimension of the MFI has four items that have a positive or negative focus. Each item is scored on a five-point scale ranging from "yes, that is true" to "no, that is not true". A summary score was calculated for each dimension, varying from 4 to 20 . Higher scores indicate more fatigue.

\section{Data analysis}

First, statistically significant differences in demographics, work related and disease related characteristics between both disease groups were examined. Because it is well known that 
age and sex differ significantly between RA and AS, all differences in demographics, work related variables and disease related variables were controlled for age and sex. Continuous variables were subjected to an analysis of variance (ANCOVA). Nominal or ordinal data were submitted to logistic regression analysis. Secondly, mean scores and standard deviations were calculated for the separate dimensions and the physical and mental component summary scores of the SF-36, for the different behavioural coping styles, and for the dimensions of fatigue for men and women for each disease sample. Differences between groups were tested using an analysis of variance, including age and educational level as covariates (ANCOVA). A Bonferroni correction was made to account for multiple group comparison ( $k=4)$, using a significance level of $p=0.05 / 4$.

Finally, a multiple stepwise regression analysis was. conducted to investigate the relation between work and health related QOL in RA and AS in combination with demographics, disease related characteristics, coping styles, and fatigue. As outcome measures for QOL, we used the physical and the mental component summary scores of the SF-36 to reduce the number of statistical comparisons and therefore the role of chance. These summary scores have proved useful in most studies and better than the best SF-36 scale. ${ }^{19}$ Independent variables in the regression analysis were introduced stepwise in five blocks of variables to test for mediation. In the first block, age in years, sex, and educational level (the three ordinal categories) were entered into the model. In the second block, employment (a paid job $\vee$ no paid job) was added. In the third block, disease duration, disease activity, and comorbidity (one or more comorbid conditions $v$ none) were included. In the fourth block, coping styles (continuous variables) were introduced. Finally, as advised by the developers of the instrument, the general fatigue dimension (continuous) of the MFI was added as an indicator of fatigue. ${ }^{23}$ To avoid multicollinearity in the model in other words interrelatedness between the independent variables, we introduced a tolerance threshold of 0.6 , meaning that a variable is included in the model if the variance shared by another independent variable is $40 \%$ or less. ${ }^{24}$ The change in the percentage of explained variance (incremental $R^{2}$ ) and the partial correlation coefficients after each step are reported as results of the regression analyses. A partial correlation is the correlation of the independent variable with the outcome (PCS or MCS) after correction for all the other independent variables in the model. The total $R^{2}$ is also reported. All statistical analyses were performed with the statistical package SPSS for Windows, release 11.0.1. 


\section{Results}

Table 2.1 Demographic characteristics of the patients with RA and AS

\begin{tabular}{|c|c|c|c|c|c|}
\hline & RA & & AS & & p Value \\
\hline Number of patients & 1056 & & 658 & & \\
\hline Men*, $\%$ & 27.7 & & 70.1 & & $<0.001$ \\
\hline Age* (Years), mean (SD) & 49.0 & $(8.3)$ & 43.5 & $(9.4)$ & $<0.001$ \\
\hline Men & 50.5 & $(7.5)$ & 44.0 & $(9.3)$ & $<0.001$ \\
\hline Women & 48.4 & $(8.4)$ & 42.5 & $(9.5)$ & $<0.001$ \\
\hline \multicolumn{6}{|l|}{ Highest attained level of education, totals, "w } \\
\hline Primary school & 49.1 & & 41.7 & & 0.082 \\
\hline Secondary school & 38.8 & & 36.9 & & \\
\hline High vocational school/university & 12.1 & & 19.4 & & \\
\hline \multicolumn{6}{|l|}{ Highest attained level of education, mens. \% } \\
\hline Primary school & 52.7 & & 40.7 & & 0.018 \\
\hline Secondary school & 34.5 & & 36.7 & & \\
\hline High vocational school/university & 12.8 & & 22.6 & & \\
\hline \multicolumn{6}{|l|}{ Highest attained level of education, womens, \$ } \\
\hline Primary school & 48.1 & & 44.1 & & 0.305 \\
\hline Secondary school & 40.4 & & 44.1 & & \\
\hline High vocational school/university & 11.9 & & 11.8 & & \\
\hline Paid employment\$, \$ & 35.7 & & 64.0 & & 0.003 \\
\hline Men & 56.7 & & 70.7 & & 0.157 \\
\hline Women & 27.7 & & 48.2 & & 0.003 \\
\hline Work disability \$ (fuily or partially), $\$$ & 40.3 & & 32.4 & & $<0,001$ \\
\hline Men & 59.5 & & 34.1 & & $<0,001$ \\
\hline Women & 33.1 & & 28.4 & & 0.144 \\
\hline Age at diagnosis 2 (years), mean ( $S D$ ) & 37.2 & $(10.6)$ & 31.3 & $(9,4)$ & $<0,001$ \\
\hline Men & 39.6 & $(9.2)$ & 31.2 & $(9.5)$ & $<0.001$ \\
\hline Women & $3 \times 3$ & $\sin \alpha 1$ & sta & 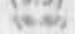 & พ.M. \\
\hline visease duration\$ (years), mean (SD) & 11.9 & (9.1) & 12.3 & $(8.0)$ & $<0.001$ \\
\hline Men & 11.1 & (7.9) & 12.8 & $(8.4)$ & $<0.001$ \\
\hline Women & 12.3 & $(9.1)$ & 11.0 & $(7.0)$ & 0.320 \\
\hline Disease activity (RADAI, 0-10), mean (SD) & 4.2 & $(2.2)$ & & & \\
\hline Men & 4.2 & $(2.2)$ & & & \\
\hline Women & 4.2 & $(2.1)$ & & & \\
\hline Disease activity (BASDAI, 0-10), mean (SD) & & & 3.9 & $(2,4)$ & \\
\hline Men & & & 3.7 & (2.4) & \\
\hline Women & & & 4.4 & $(2.4)$ & \\
\hline Comorbidity\$, \% & 47.4 & & 40.1 & & 0.316 \\
\hline Men & 45.9 & & 37.7 & & 0.717 \\
\hline Women & 47.9 & & 45.7 & & 0.203 \\
\hline \multicolumn{6}{|l|}{ Duration of morning stiffness (min), totals, \% } \\
\hline $0-14$ & 26.6 & & 36.1 & & $<0.001$ \\
\hline $15-29$ & 18.8 & & 22.2 & & \\
\hline $30-59$ & 26.0 & & 24.6 & & \\
\hline $60-119$ & 13.9 & & 16.6 & & \\
\hline$\geq 120$ & 14.7 & & 0.3 & & \\
\hline \multicolumn{6}{|l|}{ Duration of morning stiffness (min), mens, $\%$} \\
\hline $0-14$ & 24,8 & & 36.0 & & $<0.001$ \\
\hline $15-29$ & 17.2 & & 24.0 & & \\
\hline $30-59$ & 23.7 & & 24.7 & & \\
\hline $60-119$ & 16.6 & & 15.1 & & \\
\hline$\geq 120$ & 17.7 & & 0.2 & & \\
\hline \multicolumn{6}{|l|}{ Duration of morning stiffness ( $\mathrm{min}$ ), womens, \% } \\
\hline $0-14$ & 27.3 & & 36.3 & & 0.001 \\
\hline $15-29$ & 19.4 & & 17.9 & & \\
\hline $30-59$ & 26.9 & & 25.3 & & \\
\hline $60-119$ & 12.9 & & 20.0 & & \\
\hline$\geq 120$ & 13.6 & & 0.5 & & \\
\hline
\end{tabular}

- Univariately tested; $\$$ multivariately tested to adjust for age and sex (if applicable); \# multivariately tested to adjust for sex-differences (if applicable). Correlation between current age and age at diagnosis was 0.64 . 
Table 2.1 lists the demographic characteristics of the patients with RA and AS of working age. The age and sex distributions of the patients with RA and of patients with AS are significantly different. Slightly more than one quarter of the patients with RA and more than two thirds of the patients with AS were male. The mean age was 49.0 years for RA and 43.5 years for AS. Men and women with RA were significantly older than their AS counterparts. The educational level among male patients with RA was lower than among male patients with AS. Fewer patients with RA than patients with AS were in paid employment, especially women. Mean age at diagnosis was 37.2 years for RA and 31.3 years for AS $(p<0.001)$. The mean disease duration for men and women with RA was lower than for AS. In these working age groups, there was no significant difference in comorbidity between the samples as shown by the prevalence and mean number of comorbid conditions.

Table 2.2 presents mean scores and standard deviations for separate dimensions, together with summary scores for QOL questionnaires, various behavioural coping styles, and dimensions of fatigue and the results of the ANCOVA tests for differences between male and female patients separately controlled for age and educational level.

Overall, the physical component scores were more favourable in AS than in RA, merely because patients with RA reported more problems with physical functioning, such as running, climbing stairs, washing and dressing. Other components of physical health related QOL - physical role functioning, bodily pain and vitality - were not found to vary between the diseases. However, there was a sex related difference: women reported lower scores than men.

The mental component scores were more favourable in RA than in AS because of significantly better mental health in men with RA. There was no statistically significant difference between the diseases for other components of mental health related QOL (social functioning and emotional role functioning).

With the exception of the dependence coping style "accepting", there were statistically significant differences for all other coping styles. These differences tended to be more sexspecific than disease-specific, Regardless of the disease, women reported significantly more frequent use of the pain coping styles "decreasing activity" and "diverting attention" and of the limitations coping style "pacing" than men. The limitations coping style "creative solutions" was used with significantly higher frequency by women with RA than by men with AS. Finally, the dependence coping style "consideration" was reported significantly more often by women with RA than by men with RA. 
Table 2.2 Quality of life, coping, and fatigue of male and female patients with RA and AS

\begin{tabular}{|c|c|c|c|c|c|}
\hline & \multicolumn{2}{|c|}{ Rheumatoid arthritis } & \multicolumn{2}{|c|}{ Ankylosing spondylitis } & \multirow[b]{2}{*}{ p Value } \\
\hline & $\begin{array}{l}\text { Men } \\
(n=292)\end{array}$ & $\begin{array}{l}\text { Women } \\
(n=764)\end{array}$ & $\begin{array}{l}\text { Men } \\
(n=461)\end{array}$ & $\begin{array}{l}\text { Women } \\
(n=197)\end{array}$ & \\
\hline \multicolumn{6}{|l|}{$\begin{array}{l}\text { Quality of Life (SF-36, } \\
\text { range 0-100), mean (SD) }\end{array}$} \\
\hline Physical functioning & $52.7(27.4)^{2.3}$ & $47,9(26.3)^{1.24}$ & $67.8(24.1)^{2,2.4}$ & $61.3(23.1)^{23}$ & $<0.001$ \\
\hline Physical role functioning & $49.3(42.9)^{2}$ & $42.9(45.5)^{3}$ & $60.0(41.5)^{2}$ & $51.4(40.4)$ & $<0.001$ \\
\hline Social functioning & $74.7(24.2)^{2}$ & $71.6(25.2)^{03}$ & $76.3(23.8)^{2}$ & $72.7(25.1)$ & 0.008 \\
\hline Emotional role functioning & $76.7(38.9)$ & $73.8(42.9)^{3}$ & $81.2(33.6)^{2}$ & $75.2(36.0)$ & 0.038 \\
\hline Mental health & $74,3(17,4)^{2.14}$ & $71.4(19.2)^{4}$ & $72.4(18.2)^{1}$ & $70.5(17.7)^{i}$ & $<0,001$ \\
\hline Vitality & $56.1(20.1)^{2.4}$ & $52.4(20.2)^{1}$ & $54,6(20.1)$ & $51.0(17.8)^{1}$ & 0.005 \\
\hline Bodily pain. & $53.8(21.7)^{24}$ & $51.0(20.9)^{1.3}$ & $57.4(20.4)^{24}$ & $50.9(20.6)^{1.3}$ & 0.001 \\
\hline General heaith & $50.0(21.8)$ & $51.2(22.3)$ & $53.4(22.2)$ & $51.8(21.7)$ & 0.582 \\
\hline PCS* & $35.7(10.6)^{23}$ & $34.3(10.7)^{1.4}$ & $40.2(9.9)^{1.24}$ & $37.8(9.4)^{2.3}$ & $<0.001$ \\
\hline MCS** & $51.8(10.3)^{3 / 4}$ & $50.2(11.9)$ & $49.4(10.1)^{1}$ & $49.0(9.7)^{3}$ & 0.002 \\
\hline \multicolumn{6}{|l|}{$\begin{array}{l}\text { Coping (CORS), } \\
\text { mean (SD) }\end{array}$} \\
\hline \multicolumn{6}{|l|}{ Pain coping style: } \\
\hline comforting cognition $(9-36)$ & $26.7(4.8)$ & $27.2(4.7)$ & $26.6(4.9)$ & $27.3(4.3)$ & 0.012 \\
\hline decreasing activity (8-31) & $18.6(4.7)^{24}$ & $19.4(4.3)^{1.3}$ & $17.8(5.0)^{2.4}$ & $19.5(4.5)^{1.4}$ & $<0.001$ \\
\hline diverting attention (8-30) & $17.7(4.3)^{2}$ & $18.7(4.5)^{\mathrm{D}}$ & $17.2(4.4)^{2.4}$ & $18.8(4.2)^{3}$ & $<0.001$ \\
\hline \multicolumn{6}{|l|}{ Limitations coping style: } \\
\hline optimism (5-20) & $15.2(3.0)$ & $15.4(3.7)$ & $14.7(3.2)$ & $15.2(2.6)$ & 0.027 \\
\hline pacing $(10-40)$ & $27.1(6.5)^{2}$ & $27.7(6.1)^{1.3}$ & $25.0(6.6)^{2.4}$ & $26.2(5.6)^{3}$ & $<0.001$ \\
\hline creative solutions (8-32) & $20.3(5.1)$ & $20.8(5.0)^{3}$ & $19.7(5.0)^{2}$ & $19.9(4.5)$ & 0.020 \\
\hline \multicolumn{6}{|l|}{ Dependence coping style: } \\
\hline accepting (6-24) & $14.2(4.2)$ & $13.8(4.0)$ & $13.0(4.0)$ & $13.0(3.7)$ & 0.576 \\
\hline consideration $(7-28)$ & $18.7(3.4)^{2}$ & $19.3(3.5)^{1}$ & $18.7(3.7)$ & $19.4(3.0)$ & 0.010 \\
\hline \multicolumn{6}{|l|}{$\begin{array}{l}\text { Fatigue (MFI range } \\
4-20 \text { ), mean (SD) }\end{array}$} \\
\hline General fatigue & $12.3(4.2)^{2.4}$ & $13.2(4.5)^{t .3}$ & $12.4(4.2)^{24}$ & $13.4(3.9)^{13}$ & $<0.001$ \\
\hline Physical fatigue & $12.4(4.1)$ & $12.5(4.1)$ & $11.8(4.0)$ & $12.4(3.6)$ & 0.168 \\
\hline Activity & $10.7(4.1)$ & $10.7(4.3)$ & $9.9(4.0)$ & $10.1(3.8)$ & 0.173 \\
\hline Motivation & $9.7(3.5)$ & $9.7(3.8)$ & $9.3(3.6)$ & $9.3(3.6)$ & 0.369 \\
\hline Mental fatigue & $8.7(3.9)$ & $8.7(4.4)$ & $8.8(3.9)$ & $9.1(3.9)$ & 0.433 \\
\hline
\end{tabular}

Note: Group comparison with Bonferroni correction ( $P<0.05)$ : 1 different from male patients with RA: 2 different from female patients with RA; 3 different from male patients with $A S ; 4$ different from female patients with AS. "PCS: Physical Component Summary; **MCS: Mental Component Summary 
There was less difference between the four groups for fatigue, with the exception of the dimension "general fatigue", which was reported significantly worse by women than by men, irrespective of the disease.

\section{Relationship between work and physical health related QOL for RA and AS}

Table 2.3 lists the results of the stepwise multiple regression analysis of determinants of physical health related QOL in patients with RA and AS. In RA, the demographic variables, explained $6 \%$ of the variance in the PCS score, with age, sex, and educational level as significant determinants. In AS, these variables explained $12 \%$ of the variance. Adding work status to the model significantly increased the explained variance by $8 \%$ in the RA sample and by $13 \%$ in the AS sample (patients with a paid job had better physical health related $\mathrm{QOL}$ ). Introducing disease related variables increased the explained variance by $39 \%$ in RA and $27 \%$ in AS. In RA, all variables contributed significantly to the model, while. in AS only disease activity contributed significantly. Adding the coping styles explained. another $6 \%$ of the variance in RA and another $5 \%$ in AS. In the final step, general fatigue was entered and this slightly increased the explained variance in RA by $3 \%$ and in AS by $2 \%$. After this last step, disease activity was found to be most closely related to physical health related QOL (patients who reported a higher disease activity had worse physical health related $\mathrm{QOL})$.

All variables included in the final model explained. $62 \%$ of the variance in physical health related QOL of patients with RA and $59 \%$ of the variance in patients with AS. A high correlation with other independent variables for RA meant that the pain coping style "comforting cognition" and the limitations coping style "pacing" were not included in the model. Variables not included for AS were the pain coping style "diverting attention" and the limitations coping styles "optimism" and "pacing". In the final multivariate model, the relationship between work status and physical health related QOL was still significant in both samples.

\section{Relationship between work en mental health related QOL for RA and AS}

Table 2.4 lists the results of the stepwise multiple regression analysis of determinants of mental health related quality of life in patients with RA and AS. In RA, the demographic variables explained only $3 \%$ of the variance in the MCS score. In patients with AS, this was even less: only $1 \%$ of the explained variance. Adding the variable for work status slightly increased the explained variance in RA by $2 \%$ and in AS by $5 \%$. The disease related variables explained $6 \%$ of the variance in RA and $10 \%$ of the variance in AS, with disease activity and comorbidity as significant determinants. Adding the coping styles explained $10 \%$ of the variance in RA and $7 \%$ of the variance in AS. In particular, the 
cognitive coping styles "optimism" for coping with limitations in RA (patients with RA who were more optimistic when dealing with limitations had a better mental health related QOL) and "comforting cognition" for coping with pain in AS were the most significant determinants.

All variables included in the model together explained $25 \%$ of the variance in the MCS score for RA and $30 \%$ of the variance for AS. In this model, the same variables for RA and AS in the analysis on physical health related QOL were excluded to avoid multicollinearity. In the final model, the relationship between work and mental health related QOL was no longer significant in either RA or AS.

\section{Discussion}

Direct comparison of the consequences for patients with RA and AS is difficult because of different age and sex distributions. However, labour force participation and working ability were identified. as a significant problem in both diseases. ${ }^{10,14}$ Our study therefore provided a unique opportunity to compare patients with RA and AS directly in the productive stage of life. This might be of relevance to further priorities and planning for health care, because the working ability of rheumatic patients is receiving increasing attention from society as a whole, as well as from rheumatology practice. ${ }^{25}$

Our study shows that physical health related QOL was reported to be worse in patients with RA compared to patients with AS of working age, although physical role functioning, one of the components of physical health related QOL, was similar for both diseases. Mental health related QOL was reported to be more favourable in RA than in AS, although social role functioning was quite similar. In addition, the level of fatigue and the way patients cope with stressors of the disease were also similar for patients with RA and AS of working age. Our findings confirm the conclusion of Zink et al. that RA and AS in patients receiving rheumatological care generate similar amounts of disability, pain and impact on wellbeing. ${ }^{11}$ In addition, we found that the impact on the participation level, as indicated by physical role functioning and social functioning in these patients of working age, is also similar. 
Table 2.3 Stepwise multiple regression analysis of determinants of physical health related QOL of patients with rheumatoid arthritis and ankylosing spondylitis

\begin{tabular}{|c|c|c|c|c|c|c|c|c|c|c|}
\hline \multirow[b]{3}{*}{ Blocks } & \multicolumn{5}{|c|}{ Rheumatoid arthritis } & \multirow{2}{*}{\multicolumn{5}{|c|}{\begin{tabular}{|l|} 
Ankylosing spondylitis \\
Partial correlation"
\end{tabular}}} \\
\hline & \multicolumn{3}{|c|}{ Partial correlation" } & & & & & & \\
\hline & $\overrightarrow{\mathrm{U}}$ & $\begin{array}{l}N \\
\text { जิ } \\
\text { जी }\end{array}$ & 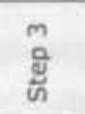 & $\begin{array}{l}\text { v } \\
\text { कै }\end{array}$ & in & के & $\begin{array}{l}N \\
\text { 워 } \\
\text { Wn }\end{array}$ & m & 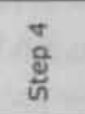 & in \\
\hline 1 Demographics & & & & & & & & & & \\
\hline Age & $-0.19^{t}$ & $-0.10^{6}$ & -0.01 & -0.00 & -0.02 & $-0.14^{k}$ & $-0.08^{*}$ & -0.05 & -0.05 & -0.06 \\
\hline Sex & $-0.11^{6}$ & -0.00 & -0.01 & -0.02 & 0.01 & $-0.10^{x}$ & -0.03 & 0.02 & 0.02 & 0.03 \\
\hline Educational level & $0.11^{*}$ & 0.02 & -0.05 & -0.06 & -0.04 & $0.29^{2}$ & $0.22^{2}$ & $0.14^{t}$ & $0.16^{\circ}$ & $0.13^{\circ}$ \\
\hline 2 Work & & & & & & & & & & \\
\hline Paid employment & & $0.29^{\mathrm{F}}$ & $0.19^{b}$ & $0.11^{\circ}$ & $0.11^{b}$ & & $0.38^{5}$ & $0.29^{c}$ & $0.19^{t}$ & 0.19 \\
\hline $\begin{array}{l}3 \text { Disease related } \\
\text { characteristics }\end{array}$ & & & & & & & & & & \\
\hline Disease duration & & & $-0.11^{5}$ & $-0.10^{\circ}$ & $-0.11^{\circ}$ & & & 0.00 & 0.00 & 0.00 \\
\hline Disease activity & & & $-0.66^{\mathrm{c}}$ & $-0.66^{6}$ & $-0.56^{\circ}$ & & & -0.59 & $-0.54^{t}$ & $-0.44^{5}$ \\
\hline Comorbidity & & & $-0.09^{6}$ & $-0.08^{t}$ & -0.06 & & & -0.07 & $-0.06^{\circ}$ & -0.04 \\
\hline 4 Coping & & & & & & & & & & \\
\hline $\begin{array}{l}\text { Pain coping styles: } \\
\text { - comforting cognition }\end{array}$ & & & & - & 8 & & & & & \\
\hline - decreasing activities & & & & $-0.23^{5}$ & -0.17 & & & & -0.01 & -0.01 \\
\hline - diverting attention & & & & $0.10^{6}$ & $0.08^{*}$ & & & & $\begin{array}{r}-0.27 \\
0.08\end{array}$ & $\begin{array}{r}-0.23 \\
0.07\end{array}$ \\
\hline $\begin{array}{l}\text { Limitations } \\
\text { coping styles: }\end{array}$ & & & & & & & & & & \\
\hline •optimism & & & & 0.07 & 0.03 & & & & - & - \\
\hline "pacing & & & & - & - & & & & - & \\
\hline -creative solutions & & & & $-0.10^{\circ}$ & $-0.12^{b}$ & & & & 0,07 & \\
\hline $\begin{array}{l}\text { Dependence } \\
\text { coping styles: }\end{array}$ & & & & & & & & & -0.07 & $-0.09^{\circ}$ \\
\hline - accepting & & & & $-0.14^{5}$ & $-0.16^{5}$ & & & & 0.03 & -0.04 \\
\hline - considering others & & & & -0.03 & 0.02 & & & & -0.04 & -0.03 \\
\hline 5 Fatigue & & & & & & & & & & \\
\hline General fatigue & & & & & $-0.29^{c}$ & & & & & $-0.24^{\mathrm{F}}$ \\
\hline Total $R^{2}$ & 0.06 & 0.14 & 0.53 & 0.59 & 0.62 & 0.12 & 0.25 & 0.52 & 0.57 & 0.59 \\
\hline Incremental $R^{2}$ & $0.06^{6}$ & $0.08^{c}$ & $0.39^{6}$ & 0.06 & $0.03^{e}$ & $0.12^{2}$ & $0.13^{t}$ & 0.27 & $0.05^{6-}$ & $0.02^{t}$ \\
\hline
\end{tabular}

${ }^{2} p<0.05 ;{ }^{b} p<0.01 ; \mathrm{p}<0.001 ; \phi$ Partial correlation coefficients of independent variables after adjustment of the other independent variables in the model 
Table 2.4 Stepwise multiple regression analysis of determinants of mental health related QOL of patients with rheumatoid arthritis and ankylosing spondylitis

\begin{tabular}{|c|c|c|c|c|c|c|c|c|c|c|}
\hline \multirow[b]{3}{*}{ Blocks } & \multicolumn{5}{|c|}{ Rheumatoid arthritis } & \multicolumn{5}{|c|}{ Ankylosing spondylitis } \\
\hline & \multicolumn{5}{|c|}{ Partial correlation" } & \multicolumn{5}{|c|}{ Partial correlation" } \\
\hline & $\frac{\vec{g}}{\mathrm{~g}}$ & $\begin{array}{l}N \\
\text { Q⿱艹 } \\
\text { ñ }\end{array}$ & $\begin{array}{l}m \\
\text { ڤั } \\
\text { जิ }\end{array}$ & $\frac{\nabla}{8}$ & $\begin{array}{l}\text { n } \\
8 \\
\text { กิ }\end{array}$ & है & $\begin{array}{l}\text { N } \\
\text { g⿱⺈ }\end{array}$ & $\begin{array}{l}m \\
8 \\
\frac{8}{8}\end{array}$ & है & 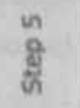 \\
\hline \multicolumn{11}{|l|}{1 Demographics } \\
\hline Age & 0.05 & $0.09^{*}$ & $0.12^{\circ}$ & 0.07 & 0.05 & -0.01 & 0.02 & 0.02 & 0.01 & 0.00 \\
\hline Sex & $-0.08^{*}$ & -0.03 & $=0.03$ & -0.04 & -0.02 & 0.00 & 0.04 & 0.08 & 0.06 & 0.07 \\
\hline Educational level & $0.16^{t}$ & $0.12^{t}$ & $0.10^{b}$ & $0.11^{\circ}$ & 0.13 & $0.12^{\mathrm{b}}$ & 0.07 & 0.07 & -0.00 & +0.03 \\
\hline \multicolumn{11}{|l|}{2 Work } \\
\hline Paid employment & & $0,14^{t}$ & $0.08^{*}$ & 0.06 & 0.06 & & $0.21^{k}$ & $0.14^{b}$ & 0.07 & 0.06 \\
\hline \multicolumn{11}{|l|}{$\begin{array}{l}3 \text { Disease related } \\
\text { characteristics }\end{array}$} \\
\hline Disease duration & & & -0.01 & -0.02 & -0.03 & & & 0.07 & 0.06 & 0.07 \\
\hline Disease activity & & & $-0.22^{x}$ & $-0.18^{8}$ & 0.07 & & & $-0.30 \mathrm{r}$ & $-0.23^{5}$ & $-0.09^{*}$ \\
\hline Comorbidity & & & $-0.08^{t}$ & $-0.07^{t}$ & -0.06 & & & $-0.09^{k}$ & -0.05 & -0.07 \\
\hline \multicolumn{11}{|l|}{4 Coping } \\
\hline \\
\hline $\begin{array}{l}\text { - comforting cognition } \\
\text { - decreasing activities }\end{array}$ & 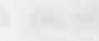 & & & $-0.10^{\circ}$ & 0.05 & & & & $0.2 z^{i}$ & $0.20^{b}$ \\
\hline - diverting attention & & & & 0.00 & -0.02 & & & & $-0.12^{\prime \prime}$ & -0.07 \\
\hline \multirow{2}{*}{\multicolumn{11}{|c|}{$\begin{array}{l}\text { Limitations } \\
\text { coping styles: }\end{array}$}} \\
\hline & & & & & & & & & & \\
\hline - optimism & & & & $0.24^{\mathrm{e}}$ & $0.21^{\epsilon}$ & & & & 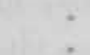 & - \\
\hline - creative solutions & & & & $0.08^{4}$ & 0.07 & & & & -0.02 & -0.04 \\
\hline \multicolumn{11}{|l|}{$\begin{array}{l}\text { Dependence } \\
\text { coping styles: }\end{array}$} \\
\hline - accepting & & & 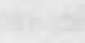 & 0.07 & 0.06 & & & & 0.08 & 0.07 \\
\hline - considering others & & & & -0.06 & -0.05 & & & & -0.02 & -0.01 \\
\hline \multicolumn{11}{|l|}{5 Fatigue } \\
\hline General fatigue & & & & & $-0.21^{5}$ & & & & & -0.29 \\
\hline Total $R^{2}$ & 0.03 & 0.05 & 0.11 & 0.21 & 0.25 & 0.01 & 0.06 & 0.16 & 0.23 & 0.30 \\
\hline Incremenca! $R^{2}$ & $0.03^{c}$ & $0.02^{t}$ & $0.06^{5}$ & $0.10^{5}$ & $0.04^{c}$ & $0.01^{4}$ & 0.05 & $0.10^{\circ}$ & 0.07 & 0.07 \\
\hline
\end{tabular}

" $p<0.05 ; p<0.01 ; p<0.001 ;$ p Partial cọrrelation coefficients of independent variables after adjustment of the other independent variables in the model 
As stated before, it might be expected that work provides social status and income and might be valued for its social support and social distraction. ${ }^{12}$ We found a positive association between work and physical health related QOL in both patient groups. Furthermore, after disease related factors, work was the most important contributing factor. In RA, work explained $8 \%$ of the total explained variance of $62 \%$. In AS, this was $13 \%$ of the total variance of $59 \%$. So work contributed considerably and might be an important factor in positively influencing patients' perception of their physical performance.

On the other hand, we did not find any association between work and mental health related quality of life in the two patient groups. The most important mediating factors in this relationship were cognitive coping styles. Because both models only explained less than $30 \%$ of the variance, we think that the unexplained variance probably reflects unmeasured, non-disease related psychosocial factors such as self esteem, support and appreciation at the workplace and social support outside the workplace.

A number of conceptual and methodological constraints of the study merit attention. We performed a secondary analysis on data collected. primarily in order to study work disability in RA and in AS separately, as part of a larger framework in which work disability was being studied in several other chronic diseases as well. Selection bias (non-response bias) may have affected the observed results. After two reminders had been sent, the response rate was $62 \%$ in the RA sample and $60 \%$ in the AS sample. Although not high, this is an average rate for studies with postal questionnaires in the Netherlands. A randomised trial of various design and mailing routines for questionnaires in an open population generated an even lower response rate $(40-56 \%),{ }^{26}$ Owing to privacy tegislation in the Netherlands, we could not: perform an extensive non-response analysis. When the SDR was examined, we did not find any significant differences for age and sex between participants and non-participants in either sample. ${ }^{9.14}$ We therefore conclude that our results are at least representative for patients with RA and AS of working age who are receiving specialised care from rheumatologists. It is estimated that $25 \%$ of the total RA population and $40 \%$ of the AS population in the Netherlands are monitored by rheumatologists.'

Conceptually, a generic QOL instrument, the SF-36, was chosen to enable comparison between the patient samples. However, the SF=36 has only a few items relevant to upper extremity function, an important disabling aspect in RA. The disease-specific instruments included to measure functional limitations, the Health Assessment Questionnaire (HAQ) in RA and the Bath Ankylosing Spondylitis Functional Index (BASFI) in AS were closely 
correlated to the physical functioning dimension of the SF-36 $(r>8) .{ }^{10.14 .27}$ We therefore conclude that the SF-36 is a valid instrument for measuring physical functioning and comparing different aspects of health related QOL in patients with RA and AS. Moreover the SF-36 captures a wider range of disability in RA and AS, in which comorbidity may also play an important role.

Our regression analysis aimed at assessing the relative contribution of work to health related QOL, in combination with demographics, disease related characteristics, behavioural coping, and fatigue, considered separately and independently. However, some of these factors are unlikely to act independently, being more likely to interact with other characteristics in a given patient. Our analyses did not consider any of these complex interactions. We were primarily interested in the association between work and health related QOL in combination with other important determinants. Moreover, the cross sectional design of our study does not allow us to state that there is a causal relationship between work and physical health related QOL. There is a distinct possibility that patients with a better physical condition are more likely to be in paid employment, despite the fact that we controlled for disease duration, disease activity and coping. However, it is also known that patients with comparable levels of disease activity can differ greatly in the way they perceive their health, and therefore work might be an important factor that positively influences patient's perceived physical condition.

In conclusion, although physical health related QOL in patients with RA was worse than in patients with AS aged 16-59, the impact on several other dimensions was quite similar. Patients with RA or AS reported the same level of problems for role functioning, including performing a paid job. Moreover, work is an important independent external factor that contributes significantly, together with disease related factors, to physical health related $\mathrm{QOL}$ in both patients with RA and AS receiving rheumatological care. Work was not a significant independent factor for mental health related QOL.

\section{Acknowledgements}

For helping in reçuititing patients we gratefully thank all rheumatologists and their assistants at the following rheumatology centres: Jan van Breemeninstituut Amsterdam, Sint Antoniusziekenhuis Nieuwegein, Rode Kruisziekenhuis Den Haag, Bosch Medicentrum Den Bosch, Sint Laurentiusziekenhuis Roermond, Sint Jansgasthuis Weert, Groene Hartziekenhuis Gouda, Albert Schweitzerziekenhuis Dordrecht, Kennemer Gasthuis locatie 
Deo Haarlem, Lievensberg Ziekenhuis Bergen op Zoom, Tweesteden Ziekenhuis Tilburg, Rijnstate Ziekenhuis Arnhem, Medisch Centrum Leeuwarden, St. Maartenskliniek Nijmegen, Medisch Spectrum Twente Enschede, Leids Universitair Medisch Centrum Leiden, Academisch Ziekenhuis Groningen, Gelderse Vallei Wageningen, Ziekenhuis. Hilversum, Beatrixziekenhuis Gorinchem and Academisch Ziekenhuis Maastricht. 


\section{References}

1. Miedema HS, Linden SM vd, Rasker 3], Valkenburg HA. A national database of patients visiting rheumatologists in the Netherlands: The Standard Diagnosis Register of Rheumatic Diseases. A report and preliminary analysis. Br J Rheumatol 1998;37:55561.

2. Pincus T. Rheumatoid arhritis. In: Wegener ST, Beiza BL, Gall E.P., editors. Clinical Care in the Rheumatic Diseases. Atlanta: American College of Rheumatology, 1996:147-56.

3. Utsinger PD, Zvaifler NJ, Ehrlich GE. Rheumatoid arthritis, etiology, diagnosis, and treatment. Philadelphia: JB Lippincott CO, 2000.

4. Calin A. The individual with ankylosing spondylitis: defining disease status and the impact of the illness. Br J Rheumatol 1995;34:663-72.

5. Ward MM. Health-related quality of life in ankylosing spondylitis: a survey of 175 patients. Arthritis Care Res 1999;12:247-55.

6. Gall V. Spondyloarthropathies. In: Wegener ST, Belza BL, Gall E.P., editors. Clinical Care in the Rheumatic Diseases. Atlanta: American College of Rheumatology, 1996:171-5.

7. Dalyan M, Guner A, Tuncer S, Bilgic A, Arasil T. Disability in ankylosing spondylitis. Disabil Rehabil 1999;21:74-9.

8. Guillemin F, Briancon S, Pourel J, Gaucher A. Long-term disability and prolonged sick leaves as outcome measurements in ankylosing spondylitis. Possible predictive factors. Arthritis Rheum 1990;33:1001-6.

9. Boonen $A$, de Vet $H$, Heijgde $D$ van der, Linden $S$ van der. Work status and its determinants among patients with ankylosing spondylitis. A systematic literature review. J Rheumatol 2001;28:1056-62.

10. Boonen $A$, Chorus $A$, Miedema $H_{k}$ van der Heijde $D$, van der Tempel $H$, van der Linden S. Employment, work disability, and work days lost in patients with ankylosing spondylitis: a cross sectional study of Dutch patients. Ann Rheum Dis 2001;60:353-8.

11. Zink A, Braun J, Listing J, Wollenhaupt J. Disability and handicap in rheumatoid arthritis and ankylosing spondylitis--results from the German rheumatological database. German Collaborative Arthritis Centers. J Rheumatol 2000;27:613-22.

12. Warr P. Work, unemployment and mental health. Oxford: Clarendon Press, 1987.

13. Escalante A, Rincon A del. How much disability in rheumatoid arthritis is explained by rheumatoid arthritis? Arthritis Rheum 1999;42:1712-21. 
14. Chorus AMJ, Miedema HS, Wevers CWJ, Linden SM vd. Labour force participation among rheumatoid arthritis patients. Ann Rheum Dis 2000;59:549-54.

15. Mason JH, Anderson JJ, Meenan RF, Haraison KM, Lewis-Stevens D, Kaine JL. The rapid assessment of disease activity (RADAR) questionnaire: Validity and sensitivity to change of a patient self-report measure of joint count and clinical status. Arthritis Rheum 1992;35:156-62.

16. Calin A, Nakache JP, Gueguen A, Zeidler H, Mielants H, Dougados M. Defining disease activity in ankylosing spondylitis: is a combination of variables (Bath Ankylosing Spondylitis Disease Activity Index) an appropriate instrument? Rheumatology 1999;38:878-82.

17. Aaronson NK, Muller M, Cohen PD, Essink-Bot ML, Fekkes M, Sanderman R et al. Translation, validation, and norming of the Dutch language version of the SF-36 Health Survey in community and chronic disease populations. J Clin Epidemiol 1998;51:1055-68.

18. Sprangers MA, de Regt EB, Andries F, van Agt HM, Bijl RV, de Boer JB et al. Which chronic conditions are associated with better or poorer quality of life? J Clin Epidemiol 2000;53:895-907.

19. Ware JEJ, Kosinski M, Bayliss MS, McHorney CA, Rogers WH, Raczek A. Comparison of methods for the scoring and statistical analysis of SF-36 health profile and summary measures: summary of results from the Medical Outcomes Study. Med Care $1995 ; 33: 264-79$.

20. Van Lankveld W, Pad Bosch P van het, Putte L van, Näring G, van der Staak C. Disease-specific stressors, in rheumatoid arthritis: coping and well- being. $\mathrm{Br} \mathrm{J}$ Rheumatol 1994;33:1067-73.

21. Van Lankveld. W, Näring G, van der Staak C, Pad Bosch P van het, Putte L van. Stress caused by rheumatoid arthritis: relation among subjective stressors of the disease, diseașe status, and well-being. J Behav Med 1993;16:309-21.

22. Smets EM, Garssen B, Bonke B, De Haes JC. The Multidimensional Fatigue Inventory (MFI) psychometric qualities of an instrument to assess fatigue. J Psychosom Res 1995; 39:315-25.

23. Van Tubergen A, Coenen J, Landewé R, Spoorenberg A, Chorus A, Boonen A et al: Assessment of fatigue in patients with ankylosing spondylitis: a psychometric analysis. Arthritis Rheum 2002;47:8-16.

24. Hazard Munro B. Statistical Methods for Health Care Research. 3 ed. Philadelphia: Lippincott-Raven Publishers, 1997. 
25. Buck PD de, Amstel RJ van, Buijs PC, Maasen JH, van Dijk FJ, Hazes JM et al, Communication between Dutch rheumatologists and occupational physicians in the occupational rehabilitation of patients with rheumatic diseases. Ann Rheum Dis 2002;61:62-5.

26. Eaker S, Bergstrom R, Bergstrom A, Adami HO, Nyren O. Response rate to mailed epidemiologic questionnaires: a population-based randomized trial of variations in design and mailing routines. Am J Epidemiol 1998;147:74-82.

27. Bijlsma JWJ, Oude Heuvel CHB, Zaalberg A. Development of the Dutch questionnaire capacities of daily life (VDF) of patients with rheumatoid arthritis. J Rehabilitation Sciences $1990 ; 2: 71-4$. 



\section{Labour force participation among rheumatoid arthritis patients}




\section{Abstract}

\section{Objectives}

To assess work history and labour force participation (LFP) among patients with rheumatoid arthritis (RA) in the Netherlands.

\section{Methods}

A random sample of 1056 patients with RA aged 16-59 years from 17 rheumatology practices in the Netherlands was examined. Data on disease status and outcome were obtained by a questionnaire including standardised instruments, such as the Rapid Assessment of Disease Activity in Rheumatology (RADAR) and RAND-36 questionnaires. Labour force participation was defined as having a paid job.

\section{Results}

Of the study group with a mean disease duration of 12 years, $35.7 \%$ held a paid job (men: $56.7 \%$; women $27.7 \%$ ). When standardised for age, sex and educational level, the labour force participation of patients, with RA was $61.2 \%$ compared with $65.5 \%$ for the general population, which was not statistically significant. Disease duration of six years and more. wusา vegactiverý assocrácé 'with'iádour tórce participation.

\section{Conclusions}

After controlling for the confounding effects of age, sex and education, the labour force participation of patients with RA in the Netherlands is only slightly lower than that of the general population. 


\section{Introduction}

Paid employment has an important role in daily life, and this is true aiso for people with chronic diseases. Work provides not only social status and income but is also valued for its social support and social distraction. Having a paid job can have positive effects on wellbeing and quality of life. ${ }^{1.2}$ On the other hand, maintaining work may require a lot of extra energy of people with chronic diseases, which might have negative effects on their health and work status.

One of the chronic diseases prevalent in those of working age is rheumatoid arthritis (RA). In the Netherlands, estimates of the prevalence indicate that between $0.7 \%$ and $0.9 \%$ of the adult population is affected by RA, based on the 1958 American College of Rheumatology (ACR) criteria. ${ }^{3}$ The prevalence increases with age, and is higher in women than in men; the overall sex ratio is about $2-3$ to $1 .^{4-6}$

RA is a systemic autoimmune disorder of unknown cause with features that differ between individual patients but may also vary from time to time within one single patient. ${ }^{7.8}$ Its major distinctive feature is chronic, symmetrical, and erosive synovitis of peripheral joints, including hands and feet. Although the severity of the joint disease may fluctuate over time, the most common outcome of established disease is progressive development of various degrees of joint destruction, deformity, immobility, pain, fatigue, depression, and anxiety.

Rheumatoid arthritis has a multidimensional impact on peoples' lives, which can result in handicaps and disabilities, such as difficulties in performing activities of daily life, and work loss. ${ }^{9-11}$ Labour force participation (that is, the proportion of people having a paid job) was found to be reduced among patients with RA, even at an early stage of disease, ranging from 40 to $50 \%,{ }^{1,12}$

To assess work history and labour force participation of patients with RA, we conducted a cross sectional study among a representative sample of Dutch patients with RA attending rheumatology outpatient clinics.

\section{Methods}

\section{Sample selection}

The source study group was derived from the nationwide Standardised Diagnosis Register of Rheumatic Diseases (SDR), a representative database of outpatients visiting a rheumatologist. ${ }^{13}$ The SDR database contains information on the patient population of $80 \%$ of all rheumatologists working in the Netherlands. In the SDR, diagnoses of visiting 
patients are recorded every year by rheumatologists. Participating rheumatologists are instructed to apply the 1987 classification criteria of the ACR. ${ }^{3}$ The SDR provides an of registering the seven items of the ACR criteria explicitly, which was done by some of the participants. A geographically representative sample of 35 rheumatologists ( $37 \%$ of all SDR rheumatologists), working in 17 practices (52\% of all SDR practices) throughout the Netherlands was included in this study. From these practices, a random sample of patients diagnosed as having RA, aged 16-59 years in 1996 and registered in 1994 in the SDR, was selected. Because RA is more prevalent in females and in older people, a rated sampling procedure was followed to obtain sufficient numbers of male patients and of younger patients. Therefore, the sampling procedure for men was inclusion of all patients aged 1650 years, and a random selection of $75 \%$ of the patients aged 51-59. For the women all patients aged 16-40 were included, and a random selection of $50 \%$ of the patients aged 41-50 and of $40 \%$ of those aged 51-59. In total, 1693 patients with RA were selected for our study (635, men and 1058 women).

All patients were sent a letter by their own rheumatologist with information about the study on 'Abilities of persons with rheumatoid arthritis'. They were invited to indicate their willingness to participate by sending a completed form to the TNO Institute adduressing two questions to obtain information on the current work status. Patients not willing to participate were kindly asked to return this form anonymously and to give reasons for non-participation. Only $5 \%$ returned a negative response form, of whom fewer than a quarter gave any reason for non-participation. These methods were approved by the medical ethical committee of TNO and were in accordance with the privacy law in the Netherlands.

After two reminders, a total of 1056 patients. with RA ( $62 \%$ of the initial cohort) returned a completed questionnaire. Those patients are called the participants. Patients who did not respond or who responded negatively are called the non-participants. Seventy three percent of the participants were female with a mean age of 49.0. Age and sex did not differ significantly between participants and non-participants ( $73 \%$ of the non-participants were female with a mean age of 49.1). The SDR data showed that $53 \%$ of both the participants and non-participants satisfied four or more of the ACR criteria.3 For the remaining $47 \%$ of both the participants and the non-participants information on ACR criteria was lacking or incomplete in the SDR. To validate the diagnosis RA, medical files of a random sample of $20 \%$ of the participating patients (201 patients) were checked by rheumatologists for the presence of ACR criteria at time of the study. It was found that 
$152(76 \%)$ had 4 or more of criteria and $165(82 \%)$ were currently using disease modifying antirheumatic drugs.

\section{Data collection}

A self administered questionnaire covering sociodemographics (age, sex, highest attained level of education, type of income), disease characteristics, functional abilities in daily life, general health, and current work situation was completed.

Disease characteristics Disease activity was assessed by a Dutch translation of the Rapid Assessment of Disease Activity in Rheumatology (RADAR), a brief self administered questionnaire, designed to provide valid, interpretable clinical information of patients with RA. ${ }^{14}$ The forward and backward translated RADAR questionnaire contains five questions relevant to disease activity (arthritis activity today; arthritis activity over the past six months; arthritis pain today; duration of morning stiffness; and joint tenderness today). From these five questions an index was calculated, the so-called Rheumatoid Arthritis Disease Activity Index (RADAI). This index was found to be a highly reliable and valid self administered measure of disease activity for clinical, health services, and epidemiological research. ${ }^{15}$ The scores of RADAI may range from 0 to 10 . Higher scores indicate more disease activity.

Patients were also asked about their age at time RA was diagnosed. To assess disease duration, age at diagnosis of RA was subtracted from the age at time of completing the questionnaire.

Work history and labour force participation Work history was assessed on the basis of two variables. Respondents indicated whether or not they had a paid job at time of diagnosis, and indicated what their current work status was (whether they had a paid job at the time of the study, they had left the labour force (because of RA or any other reason), or had never had a paid job). Labour force participation was defined as having a paid job at the time of the study.

Activities in daily life To assess functional abilities, in daily life a validated Dutch version of the Health Assessment Questionnaire was used, ${ }^{16}$ containing 20 items addressing eight dimensions of activities in daily life (dressing and grooming; arising; eating; walking; hygiene; reaching; gripping; other household activities). Each item is scored 0-3 $(0=$ without any difficulty; $1=$ with some difficulty; $2=$ with much difficulty or with help from another person or with a device; $3=$ not able to do). An overall score is calculated as the mean score of the eight scores obtained for the dimensions separately. 
Quality of life Information about health related quality of life was obtained by a validated Dutch translation of the RAND-36, ${ }^{17,18}$ a standardised questionnaire referring to eight dimensions (physical functioning; social functioning; role impairment due to physical functioning; role impairment due to social functioning; mental health; bodily pain; vitality; and general health), and changes in health over the past year. The RAND-36 is quite similar to the internationally widely used SF-36, of which a Dutch translation had not yet been validated at the time of our study. The scores for the separate dimensions of the RAND-36 can vary from 0 to 100 . Lower scores indicate worse outcomes.

\section{Data analysis}

Work history of the total study group was examined to give an overall impression on the working career of people with RA. Furthermore, patient characteristics of the study group were analysed both for working and non-working patients. Statistical differences in means and proportions were tested with use of the CSAMPLE module of the statistical package Epi Info, version $6.02 .{ }^{19}$ The CSAMPLE module computes means or proportions with standard errors and $95 \%$ confidence limits for studies in which the data did not come from a simple random sample.

Next, labour force participation of patients with. RA was studied for the whole group with RA and stratified for age, sex and educational level. The highest attained educational level was separated into three categories: primary, secondary and vocational colleges/university level. Age, sex and educational level are well-known determinants of labour force participation. Therefore, to enable better comparison to reference data of labour force participation for the general Dutch population, we adjusted the age-sex-educational level distribution in the study group ta the distribution in the general Dutch population by using the direct standardisation method. ${ }^{20}$

To study the independent effect of disease duration on the labour force participation, agesex-educational level specific proportions of having work in our study group were compared to those in the general population by using an indirect method of standardisation (based on the method for obtaining the Standardised Morbidity Ratio and its variance). Therefore, we calculated for our study population ratios of the observed (O) and expected (E) number of working people for evenly spaced five-year categories of disease duration. Because of our study design the first category ranges from two to 5 years of disease duration. Expected numbers of labour force participation were computed with the age, sex, educational level labour force participation reference data for the general Dutch population. ${ }^{20}$ The O/E-ratio is the ratio of the observed proportion of patients with RA with a paid job to the proportion expected. This ratio could be interpreted as the relative chance of patients with RA having a paid job compared with the general 
Dutch population, adjusted for age, sex and educational level. A rate ratio of 1.0 indicates that the proportion of patients with RA working is the same as that in the general population. A rate ratio of less than 1.0 indicates that the proportion of patients with RA working is less than that in the general population, and a rate ratio of more than 1.0 indicates that the proportion of patients with RA working is more than that in the general population. To exame statistically significant differences between the group with RA and the general population, we obtained the variances of the O/E-ratios, and estimated their $95 \%$ confidence intervals $(O / E \pm 1.96 * v$ var $(O / E)$ ). If a rate ratio of 1.0 is included in the interval, this implies that the estimate is not statistically significant at the $0.05 \alpha$ level, ${ }^{21,22}$ These analyses were performed with the statistical package SPSS for Windows, release $6.1 .3 .^{23}$

\section{Results}

Figure 3.1 presents the work history of the patients with RA from the year of diagnosis until the time of study in 1996. At the time of diagnosis of RA, the work situation was unknown for $11.6 \%$ of the patients. Overall, $68.2 \%$ of the study group had. a paid job at least temporarily, at some time after being diagnosed with RA. In 1996, 35.7\% still held a paid job, $54.7 \%$ of the total population stopped working " of whom $40 \%$ stopped working because of RA (this is $22.7 \%$ of the total group with RA), and $9.6 \%$ had never had a paid job. The mean disease duration of the population is 11.9 years, varying from two years to 32 years. The mean duration of working after being diagnosed with RA is 7.2 years, varying from 0 years until 32 . 
Figure 3.1 Work history of 1056 patients with RA

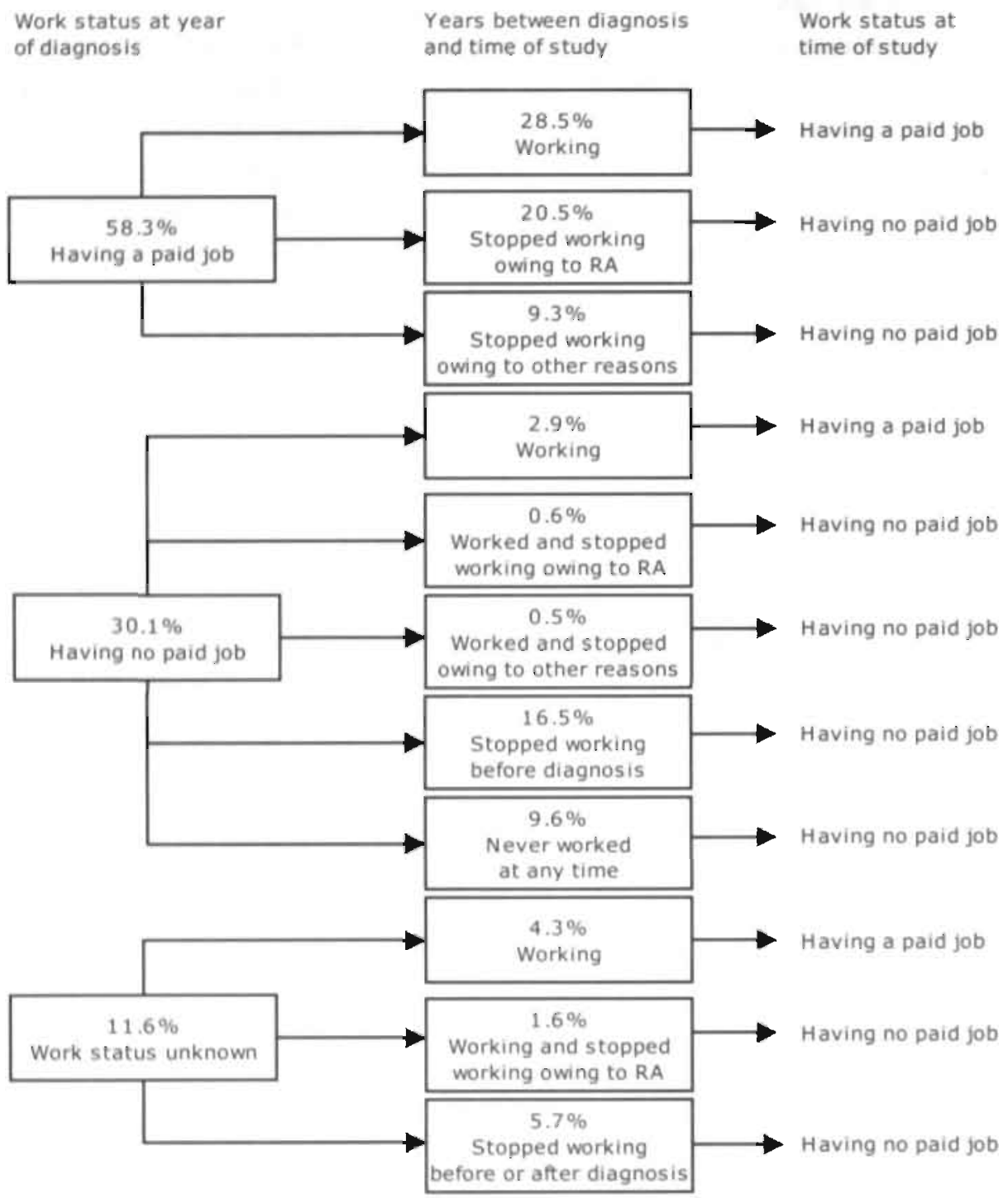


Table 3.1 presents patient characteristics, disease status, and outcome of the total study group, and of the working and non-working study group.

Table 3.1 Patient characteristics, disease status and outcome of 1056 patients with rheumatoid arthritis

\begin{tabular}{|c|c|c|c|}
\hline & $\begin{array}{l}\text { Total RA } \\
\text { population } \\
(n=1056)\end{array}$ & $\begin{array}{l}\text { Patients with RA } \\
\text { with a paid job } \\
(35.7 \%)\end{array}$ & $\begin{array}{l}\text { Patients with RA } \\
\text { without a paid } \\
\text { job }(64.3 \%)\end{array}$ \\
\hline Age (years), mean (95\% C1) & $49.0(48.5$ to 49.5$)$ & $45.8(45.0$ to 46.7$)$ & 50.7 (50.1 to 51.3$)$ \\
\hline Men, $\approx(95 \% \mathrm{Cr})$ & $27.7(25.2$ to 30.1$)$ & $43.9(39.2$ to 48.7$)$ & $18.6(15.8$ to 21.4$)$ \\
\hline High vocational school/university, $\%(95 \% \mathrm{Cl})$ & $12.1(10.1$ to 14.2$)$ & $20.2(16.2$ to 24.1$)$ & $7.5(5.4$ to 9.8$)$ \\
\hline Disease duration (years), mean ( $95 \% \mathrm{C1}$ ) & $11.9(11.4$ to 12.5$)$ & $9.9(9.2$ to 10.6$)$ & $12.9(12.3$ to 13.8$)$ \\
\hline Disease activity (RADAr, 0-10), mean (95\% CI) & $4.2(4.1$ to 4.4$)$ & $3.5(3.3$ to 3.7$)$ & $4.6(4.5$ to 4.8$)$ \\
\hline Disability score (HaQ, 0-3), mean (95\% CI) & $1.00(0.96$ to 1.05$)$ & $0.70(0.60$ to 0.72$)$ & $1.20(1.13$ to 1.26$)$ \\
\hline \multicolumn{4}{|l|}{ Quality of life (RAND-36, 0-100), mean (95\% C) } \\
\hline Physical functioning & $49.2(47.2$ to 50.8$)$ & $62.2(59.7$ to 64.6$)$ & $42.0(40.0$ to 44.1$)$ \\
\hline Physical role functioning & $44.5(41.9$ to 47.3$)$ & $60.0(55.7$ to 64.2$)$ & $34.9(31.1$ to 38.7$)$ \\
\hline Social functioning & $72.5(70.9$ to 74.0$)$ & $80.2(76.1$ to 62.2$)$ & $68.1(66.1$ to 70.2$)$ \\
\hline Emotional role functioning & $74.6(71.9$ to 77.3$)$ & $84.9(81.6$ to 88.1$)$ & $68.4(64.5$ to 72.3$)$ \\
\hline Mental heaith & $72.2(71.0$ to 73.4$)$ & $77.0(75.3$ to 78.6$)$ & $69.5(68.0$ to 71.1$)$ \\
\hline Vitality & $53.4(52.2$ to 54.7$)$ & $58.3(56.5$ to 60.1$)$ & $50.7(49.0$ to 52.4$)$ \\
\hline Bodily pain & $55.7(54.3$ to 57.0$)$ & $63.7(61.7$ to 65.7$)$ & $51.2(49.4$ to 53.0$)$ \\
\hline General health & $49.7(48.4$ to 51.1$)$ & $55.3(53.3$ to 57.2$)$ & $46.6(44.8$ to -48.4$)$ \\
\hline Changes in heaith over past year & $38.8(37.6$ to 39.9$)$ & $41.6(39.9$ to 43.4$)$ & $37.1(35.6$ to 38.7$)$ \\
\hline
\end{tabular}

It was found that on average patients whit: RA who were younger, male, or more highly educated were more likely to be working $(p<0.05)$. In this group of patients RA was more recently diagnosed and disease activity was significantly less than among patients. without a paid job. Working patients had significantly fewer disabilities and a better quality of life than patients who did not work-their physical functioning was better and their role impairment due to physical functioning was less.

The crude labour force participation of patients with RA was $35.7 \%$ (56.7\% in men and $27.7 \%$ in women) (table 3.2). To assess the labour market position of patients with RA in the Netherlands we compared our study group with the general Dutch population of working age (16-59 years). Our study group had a higher mean age, and contained more women and fewer higher educated people. This was to be expected because the peak incidence of RA occurs between the ages of 40 and 60 , and because of the higher prevalence of RA in women than in men. 
Table 3.2 Labour force participation (LFP) and 95\% confidence intervals (CI) among 1056 patients with RA compared with reference data from the general Dutch population ${ }^{20}$

\begin{tabular}{|c|c|c|c|c|c|}
\hline $\begin{array}{l}\text { Highest educational } \\
\text { level }\end{array}$ & $\begin{array}{l}\text { Age } \\
\text { category } \\
\text { (years) }\end{array}$ & $\begin{array}{l}\text { LFP rate of } \\
\text { men with RA } \\
(95 \% \text { CI) }\end{array}$ & $\begin{array}{l}\text { LFP rate of } \\
\text { general } \\
\text { male } \\
\text { population }\end{array}$ & $\begin{array}{l}\text { LFP rate of } \\
\text { females with RA } \\
(95 \% \mathrm{CI})\end{array}$ & $\begin{array}{l}\text { LFP rate of } \\
\text { general } \\
\text { female } \\
\text { population }\end{array}$ \\
\hline Overall (crude) & All & $56.7(51.8$ to 61.7$)$ & & $27.7(24.3$ to 31.2$)$ & \\
\hline $\begin{array}{l}\text { Overall } \\
\text { (standardised) }\end{array}$ & Ail & $74.3(64.3$ to 84.3$)$ & 81.0 & $47.6(43.2$ to 52.1$)$ & 50.1 \\
\hline \multirow[t]{4}{*}{ Primary school } & $20-29$ & 0 & 66.3 & $22.2(0.0$ to 49.1$)$ & 26.6 \\
\hline & $30-39$ & $77.8(50.9$ to 100$)$ & 71.6 & $20.0(6.5$ to 33.5$)$ & 27.4 \\
\hline & $40-49 i$ & $55.2(45.2$ to 65.0$)$ & 70.4 & $23.9(16.6$ to 31.2$)$ & 28.7 \\
\hline & $50-59$ & $33.7(28.2$ to 39.2$)$ & 55.1 & $12.4(8.3$ to 16.5$)$ & 16.5 \\
\hline \multirow[t]{4}{*}{ Secondary school } & $20-29 i$ & $75.0(32.7$ to 100$)$ & 76.2 & $78.8(65.3$ to 92.3$)$ & 65.7 \\
\hline & $30-39$ & $84.2(68.3$ to 100$)$ & 92.0 & $45.2(36.2$ to 54.2$)$ & 50.2 \\
\hline & $40-49$ & $85.5(77.3$ to 93.7$)$ & 90.0 & $46.3(37.9$ to 54.7$)$ & 47.6 \\
\hline & $50-59$ & $59.3(51.0$ to 67.5$)$ & 72.1 & $12.4(5.7$ to 19.1$)$ & 27.7 \\
\hline \multirow{4}{*}{$\begin{array}{l}\text { High vocational } \\
\text { colleges/university }\end{array}$} & $20-29$ & $50.0(0.0$ to 100$)$ & 71.1 & $66.7(29.9$ to 100$)$ & 68.6 \\
\hline & $30-39$ & $80.0(45.1$ to 100$)$ & 94.0 & $75.0(59.5$ to 90.5$)$ & 78.9 \\
\hline & $40-49$ & $89.5(76.7$ to 100$)$ & 92.6 & $54.8(40.9$ to 68.7$)$ & 72.1 \\
\hline & $50-59$ & $78.8(67.6$ to 90.0$)$ & 81.7 & $3.4 .6(16.4$ to 52.8$)$ & 54.9 \\
\hline
\end{tabular}

When the overall standardised labour force participation rates for male and female patients with RA were calculated it was shown that the sex-specific labour force participation rates were not statistically significant lower than the same rates for the general Dutch population. Therefore, the overall standardised labour force participation of the group with RA was not significantly different from that of the general Dutch population. The overall standardised labour force participation of RA was $61.2 \%$ ( $95 \%$ CI $55.7 \%$ to $66.7 \%$ ) compared with $65.5 \%$ for the general Dutch population. However, clear differences were seen when educational levels were taken into account.

For patients with RA with a primary level of education, labour force participation was significantly reduced for men in the age categories 20-29, 40-49 and 50-59 compared with the general population. For both male and female patients with a secondary school level of education, it was found that labour force participation was significantly reduced in the highest age category. For patients with RA with a high level of education, labour force participation was significantly reduced for women in the age categories 40-49 and 50-59.

Figure 3.2 shows the relation between disease duration and labour force participation in patients with RA as rate ratios and their $95 \% \mathrm{CI}$. It shows that patients with RA with disease duration of six years or more have significantly fewer paid jobs than people in the general Dutch population of the same age, sex and educational level. The proportion of working people in patients with RA with a disease duration of 6 to 10 years is 1.1 times less than in the general population, 1.3 times less in patients with a disease duration of 11 
to 15 years, 1.6 times less in patients with disease duration of 16 to 20 years, and 1.8 times less in patients with disease duration of 21 years or more.

Figure 3.2 Relation between labour force participation (LFP) and duration of disease among patients with RA, standardised for age, sex, and educational level and expressed as rate ratios

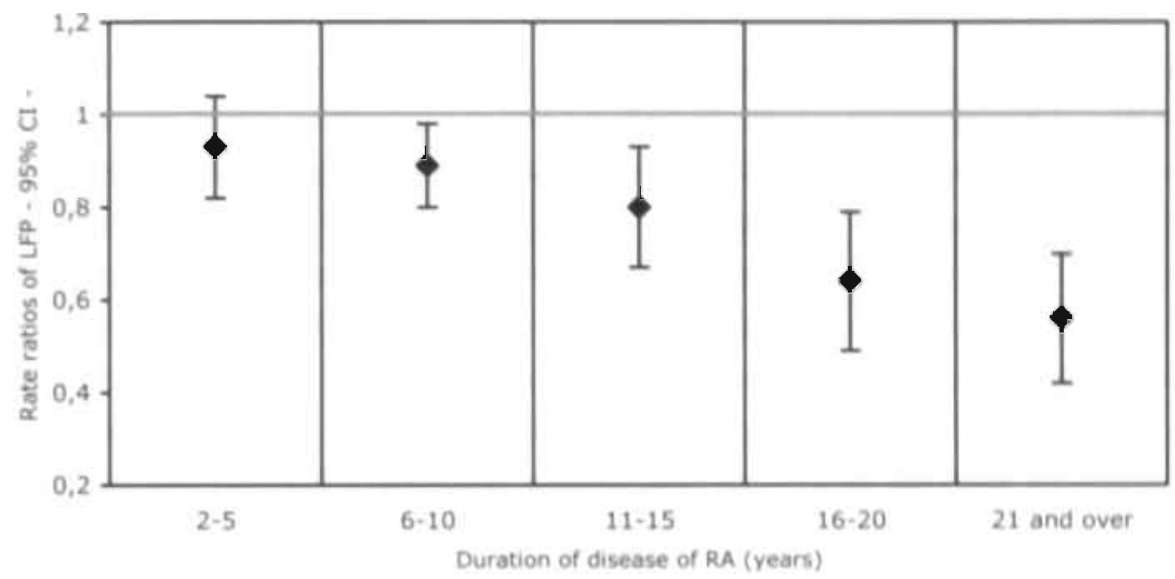

\section{Discussion}

Our study indicates that the labour force participation of patients with RA in the Netherlands is largely comparable with that of the general population, when confounding effects of age, sex and educational level are considered. Still, it was found that disease duration of six years and more was negatively associated with labour force participation. In contrast with our study, most other reports on RA and labour force participation dea! with groups with a work history and focus merely on early withdrawal from the labour force among patients with recently diagnoșed RA, ${ }^{1,12.24-26}$ except for one. ${ }^{27}$ In this last study, labour force participation was $41 \%$ among patients with RA with a mean disease duration of 12 years, which is consistent with our study. Yelin et al. (1987) studied labour force participation and disease duration and found that $50 \%$ of patients with RA with some work experience stopped working, within a decade after diagnosis, $60 \%$ within 15 years, and $90 \%$ within 30 years. In the Netherlands, Doeglas et al. (1995) found that $40 \%$ of patients with RA withdrew from the labour force within four years after diagnosis. ${ }^{12}$ Our study shows a lower reduction in labour force participation in relation to disease duration. It should be noted, however, that in our study we also considered patients without a work 
history, because they potentially can enter the labour force. Moreover, we also controlled for common risk factors of labour force participation, such as age, sex, and education. To compare our labour force participation rates with those patients with RA in other countries, it is also important to consider other work dynamics such as the demand for labour, which can fluctuate over time and differ between countries, and the differences in social insurance legislation systems.

Our study has a number of limitations. Firstly, selection bias (non-response bias) may have affected the observed results. To reduce selective response of patients with a paid job, we introduced the study to the patients as a survey of abilities of people diagnosed with. RA. After sending two reminders the response rate was $62.4 \%$, which, although not high, is an average rate for studies with postal questionnaires in the Netherlands. A randomisedi trial of various design and mailing routines for questionnaires in an open population showed even lower response rates (40-56\%). ${ }^{28}$ Few non-participating patients indicated a reason for refusing to participate and because of privacy legislation in the Netherlands we could not perform an extensive non-response analysis. When the SDR was examined we found no significant differences of age, sex and the registration of ACR criteria between participants and non-participants.

Secondly, we only validated the diagnosis for a randomly selected sample of the participating patients with RA (that is, $20 \%$ of the total population). Based on that sample it can be concluded that $75.6 \%$ of the population fulfilled the 1987 ACR criteria. This might seem to be drawback of this study. However, ACR criteria are intended for classification and are not suited for diagnosis. Moreover, it is well known that at one moment patients with RA can satisfy the ACR criteria and no longer satisfy them at another time. This is especially the case in patients with early RA, self limited RA, and patients with slowly progressive RA during a period of low disease activity. ${ }^{29,30}$ In addition, all patients were diagnosed as having RA by a rheumatologist, and these patients had difficulties in their social contacts, even when they do not meet the classification criteria. Therefore, we believe that our study group is representative of the clinical RA population in rheumatology practices. On the basis of the SDR, it is estimated that rheumatologists treat $25 \%$ of the total group of patients with RA in the Netherlands. ${ }^{13}$ It is reasonable to assume that patients treated by a rheumatologist have worse disease and a poorer outcome than patients not treated by a rheumatologist. Therefore, we conclude that our results are not representative of the total RA population in the Netherlands. In addition, labour force participation of the total RA population in the Netherlands will be higher then that of the RA population treated by a rheumatologist. 
Thirdly, data were collected by a self administered questionnaire, and were not confirmed by objective measures. However, the questionnaire comprised several well validated instruments to assess disease status and outcome. ${ }^{14-16}$ Although the year of diagnosis of RA by a rheumatologist was assessed retrospectively, we believe that this event has such an impact on patients' lives, that it is unlikely that this is substantially and systematically affected in any direction by recall bias.

In summary, this study shows that labour force participation among patients with RA in the Netherlands is not as strongly reduced as is often assumed. To enable comparability between populations, it is important to control for the common risk factors age, sex and educational level.

It should be noted that holding a paid job does not imply that the work situation (working part-time, changing jobs) of working RA-patients is comparable with that of the general Dutch working population. A previous study found that for working Dutch patients with RA there were negative influences on their working capabilities, and also on their social participation and household activities. ${ }^{31}$ Other studies have shown that disease related factors, psychosocial factors as well as work related (such as physical job demand, job autonomy, type of job, and job satisfaction) contribute also to the work capacity of RApatients. ${ }^{1,25,32-35}$ 


\section{References}

1. Yelin E, Henke C, Epstein W. The work dynamics of the person with rheumatoid arthritis. Arthritis Rheum 1987;30:507-12.

2. Warr P. Work, unemployment and mental health. Oxford: Clarendon Press, 1987.

3. Arnett FC, Edworthy SM, Bloch DA, McShane DJ, Fries JF, Cooper NS, Healey LA, Kaplan SR, Liang MH, Luthra HS, Medsger TA Jr; Mitchell DM, Neustadt DH, Pinals RS, Schaller JG, Sharp JT, Wilder RL, Hunder GG. The American Rheumatology Association 1987 revised criteria for the classification of rheumatoid arthritis. Arthritis Rheum $1988 ; 31: 315-24$.

4. Blécourt Jj de. 'Screening' of the population for rheumatic diseases. Ann Rheum Dis $1954 ; 13: 338-40$.

5. Graaff $R$ de. Rheumatoid arthritis in the Netherlands [De reumatoide arthritis in Nederland]. Assen: Van Gorcum, 1962.

6. Valkenburg HA, Laar A van, Hofman A. Epidemiology of rheumatic diseases in the Netherlands [Epidemiologie van reumatische aandoeningen in Nederland: de omvang van reumatische klachten en aandoeningen in een open Nederlandse bevolkingsgroep]. In: Rasker JJ, Festen JJM. Reumatologie in perspectief (Van. Hoytema cursus). Ensichedè: Technische Hogeschool Twente, 1980.

7. Utsinger PD, Zvaifler NJ, Ehrlich GE. Rheumatoid arthritis, etiology, diagnosis, and. treatment. Philadelphia: JB Lippincott CO, 1985:1-984.

8. Harris ED Jr. Mechanisms of disease: Rheumatoid arthritis-pathophysiology and implications for therapy. New Engl J Med 1990;322:1277-89.

9. Felts W, Yelin E. The economic impact of the rheumatic diseases in the United States. J Rheumatol 1989;16:867-84.

10. Yelin E, Feschbach D, Meenan R, Epstein W. Social problems, services and policy for persons with chronic disease: the case of rheumatoid arthritis. Soc Sci Med 1979; 13C:13-20.

11. Katz PP, Yelin EH. Life activities of persons with rheumatoid arthritis with and without depressive symptoms. Arthritis Care Res 1994;7:69-77.

12. Doeglas D, Suurmeijer T, Krol B, Sandermann R, Leeuwen M van, Rijswij̄k M van. Work disability in early rheumatoid arthritis. Ann Rheum Dis 1995;54:455-60.

13. Miedema HS, Linden SM van der, Rasker JJ, Valkenburg HA. A national database of patients visiting rheumatologists in The Netherlands: the Standard Diagnosis Register of Rheumatic Diseases. A report and preliminary analysis. $\mathrm{Br} J$ Rheumatol 1998;37:555-61. 
14. Mason JH, Anderson J, Meenan RF, Haralson KM, Lewis-Stevens D, Kaine $\mathrm{J}$. The Rapid Assesment of Disease Activity (RADAR) questionnaire: Validity and sensitivity to change of a patient self-report measure of joint count and clinical status. Arthritis Rheum 1992;35:156-62.

15. Stucki G, Liang MH, Stucki S, Brühlmann P, Michel BA. A self-administered rheumatoid arthritis disease activity index (RADAI) for epidemiologic research. Arthritis Rheum $1995 ; 38: 795-98$.

16. Bijlsma JWJ, Oude Heuvel CHB, Zaalberg A. Development of the Dutch questionnaire capacities of daily life (VDF) of patients with rheumatoid arthritis. J Rehabilitation Sciences $1990 ; 2: 71-4$.

17. Brook RJ, Ware JE, Davies-Avery A, Stewart AL, Donald CA, Rogers WH, Williams KN, Johnston SA. Overview of adult health status measures fielded in RAND's Health insurance study. Medical Care 1979;15:724-35.

18. Zee KI van der, Sandermann R. Het meten van de gezondheidstoestand met de RAND-36: een handleiding. Northern Centre for Health Care Research: University of Groningen, 1993.

19. Centers for Disease Control and Prevention/World Health Organization. Epi Info (version 6.02) 1994.

20. Statistics Netherlands (CBS). Survey of general population in the working age 1996. The Hague: CBS, 1997.

21. Armitage P, Berry G. Statistical methods in medical research (second edition). Great Britain: Blackwell Scientific. Publications 1987.

22. Rothman KJ, Greenland S. Modern epidemiology. Second edition. Philidelphia: Lippincott-Raven Publishers, 1998.

23. SPSS (Inc.). SPSS for Windows (release 6.1.3), 1995.

24. Mau W, Bornmann M, Weber H, Weidemann HF, Hecker H, Raspe HH. Prediction of permanent work disability in a follow-up study of early rheumatoid arthritis: results of a tree structured analysis using RECPAM. Br J Rheumatol 1996;35:652-9.

25. Fex E, Larsson B-M, Nived K, Eberhardt K. Effect of rheumatoid arthritis on work status and social and leisure time activities in patients followed 8 years from onset. J Rheumatol 1998;25:44-50.

26. Sokka T, Kautiainen $H$, Mottonen T, Hannonen P. Work disability in rheumatoid arthritis 10 years after the diagnosis. J Rheumatol 1999;26:1681-5.

27. Mason JH, Simms, RW, Goldenburg DL, Meenan RF. The impact of fibromyalgia on work: a comparison with RA. Arthritis Rheum 1989;32(suppl):S46. 
28. Eaker S, Bergström R, Bergström A, Adami H-O, Nyren O. Response rate to mailed epidemiologic questionnaires: a population-based randomized trial of variations in design and mailing routines. Am J Epid 1998;147;74-82.

29. Symmons DPM, Barrett EM, Bankhead CR, Scott DGI, Silman AJ. The incidence of rheumatoid arthritis in the United Kingdom: results from the Norfolk Arthritis register. Br J Rheumatol 1994;33:735-9.

30. Wolfe F, Ross K, Hawley DJ, Roberts FK, Cathey MA. The prognosis of rheumatoid arthritis and undifferentiated polyarthritis syndrome in the clinic: a study of 1141 patients. J Rheumatol 1993;20:2005-9.

31. Jaarsveld $\mathrm{CH}$ van, Jacobs JW, Schrijvers AJ, Albada-Kuipers GA van, Hofman DM, Bijlsma JW. Effects of rheumatoid arthritis on employment and social participation during the first years of disease in the Netherlands. Br J Rheumatol 1998;37:848-53.

32. Yelin E, Meenan R, Nevitt M, Epstein W. Work disability in rheumatoid arthritis: effects of disease, social and work factors. Ann Intern Med 1980;93: 551-56.

33. Fifield J, Reisine ST, Grady K. Work disability and the experience of pain and depression in rheumatoid arthritis. Soc Sci Med 1991;33:579-85.

34. Reisine S, McQuillan J, Fifield J. Predictors of work disability in rheumatoid arthritis patients. Arthritis Rheum 1995;38:1630-7.

35. Allaire SH, Anderson J3, Meenan RF. Reducing work disability associated with rheumatoid arthritis: identification of additional risk factors and persons likely to benefit from intervention. Arthritis Care Res 1996;9:349-57. 
Employment, work disability, and work days lost in patients with ankylosing spondylitis: a cross sectional study of Dutch patients 


\section{Abstract}

\section{Objectives}

To evaluate employment status, work disability, and work days lost in patients with ankylosing spondylitis (AS).

\section{Methods}

A questionnaire was sent to 709 patients with AS aged 16 to 59 . The results of 658 of the patients could be analysed.

\section{Results}

After adjusting for age, labour force participation was decreased $15.4 \%$ in male patients and $5.2 \%$ in female patients. compared with the general Dutch population. Work disability (all causes) was $15.7 \%$ and $16.9 \%$ higher than expected in the general population for male and female patients respectively. In particular, the proportion of those with a partial work disability pension was increased. Patients with a paid job lost $5.0 \%$ of work days as the result of having AS, accounting for a mean of 10.1 days of sick leave due to AS per patient per year in addition to the national average of 12.3 disease unspecific days of sick leave.

\section{Conclusions}

This study on work status in AS provides data adjusted for age and sex, and the differences from the reference population were significant. The impact of AS on empioyment and work disability is considerable. Work status in patients with AS needs more attention as an outcome measure in future research. 


\section{Introduction}

In a broader concept of patient outcomes in chronic diseases, psychosocial and economic end points need to be considered in addition to traditionally defined outcome measures. Important economic end points are health resource utilisation and labour force participation. Labour force participation is important from a societal point of view because it is a major determinant of the economic burden of illness. From the patient's point of view, it is also relevant because of its influence on social contacts and self-esteem and therefore on quality of life. ${ }^{1}$ It is known that musculoskeletal disease is the leading cause of work disability in the United States. ${ }^{2-6}$. The same is true in the Netheriands, where. musculoskeletal diseases and neuropsychiatric disorders are the most important causes of sick leave and work disability, each accounting for $29 \%$ of all causes of prolonged sick leave and permanent work disability at the time of the study. ${ }^{7}$ Much less is known about the relative contributions of different subgroups of musculoskeletal disease to the total work disability. For rheumatoid arthritis, several studies on labour force participation and its determinants are published." ${ }^{k 1}$ For ankylosing spondylitis (AS), however, few and inconsistent data on labour force participation exist, ${ }^{22-36}$ and no data are available in the Netherlands. The prevalence of AS in the Netherlands is estimated to be 0.08 to $0.1 \%$, accounting for about 11700 patients with AS. ${ }^{37}$ The disease is about three times more common in men than women and usually starts in the third decade of life. ${ }^{37}$ It may lead to major functional limitations not only because of spinal disease but also because of extraspinal disease manifestations such as peripheral arthritis, inflammatory bowel disease, and uveitis. In this study, we investigated cross sectionally prevalent employment, work disability, and sick leave in patients aged 16-59 years with AS who regularly visit a rheumatologist.

\section{Methods}

\section{Patients}

Patients were selected from the nationwide Dutch Standard Diagnosis Register of Rheumatic Diseases (SDR) in which more than $37(66 \%)$ of all Dutch theumatology practices ( $80 \%$ of rheumatologists) participate. ${ }^{30}$ Rheumatologists register all outpatients once a year. On the basis of the proportion of rheumatologists participating in the SDR, the number of patients in the SDR with the diagnosis AS, and an estimated number of patients with AS in the Netherlands of 11700 , probably $40-50 \%$ of patients with AS under care of a rheumatologist. A geographically representative sample of 15 practices were 
invited to participate in this study and all agreed. Two of the eight Dutch academic practices were included. This number of practices was chosen in order to obtain a large enough sample of patients. Selected patients had consulted their rheumatologist in 1995 or 1996, had to be between 16 and 59 years of age, and had to have the diagnosis of AS.

\section{Questionnaire}

In September 1997 patients received a postal questionnaire on sociodemographic, disease related, and work related variables. Sociodemographic factors comprised sex, age, race, marital status, family situation, education, profession, income, and work status. Disease related questions assessed age at diagnosis, comorbidity, medication, extra-articular manifestations of AS, the BASFI measuring functional status, ${ }^{39}$ the BASDAI measuring disease activity, ${ }^{40}$ the BASG measuring patient. global assessment, ${ }^{41}$ and the Self Assessment Joint Score. ${ }^{42}$ Questions about career history and characteristics of the present job were also asked. Jobs were classified by the system used by Statistics Netherland into agricultural, industrial, transportation, administrative, marketing and sales, servicing, and specialists or managerial. ${ }^{39}$ For statistical purposes, jobs were classified as manual or non-manual. Jobs in agricultural, industrial and transport sector were considered to be manual. Finally, module I of the Health and Labour Questionnaire was included. This questionnaire assesses at one point in time the absence from paid work during the preceding two weeks. Construct validity and feasibility of module I of the questionnaire were tested in the general Dutch population and in patients with various chronic diseases. ${ }^{43}$

\section{Definition of endpoints on work status}

Employment or labour force participation in this study refers to: the ability to perform paid work. This study does not look at the ability to perform unpaid work or the quality of paid work. Full time work was defined as working 32 hours a week or more. Work disability was defined as official disability under the Dutch social security system. Six categories of work disability exist, and work disability of $80-100 \%$ is regarded as full work disability, while the other categories are considered as partial work disability. The reported work disability is from "all causes" and not exclusively attributable to. AS. Unemployment is defined as receiving official unemployment benefit. Sick leave for those with a paid job was assessed by the Health and Labour Questionnaire at one point in time and was defined as absence for at least half a day from paid work because of AS. 


\section{Description of the social security system in the Netherlands}

The Dutch social security benefit programme applies to all people below 65 years who are in employment. In the Netherlands, as in many other European countries, but in contrast with the situation in the United States, a distinction is made between sick leave (work incapacity but the patient has an employment contract) and work disability (employment contract stops). The Dutch social security benefit programme is administered by the employer in collaboration with occupational health and safety organisations for the first 52 weeks of sick leave and by public social security associations for the work disability. For the entire first year of sick leave, the employer is responsible for the provision of the sickness benefit, which may vary between $70-100 \%$ of the former gross wage. Medical certification is not required to claim sickness benefit. After three months of continuous sick leave, the occupational health and safety organisation of the employer is legally obliged to evaluate whether a rehabilitation programme is possible. Part time work can be part of the rehabilitation plan.

After one year of continuous sick leave, the social security association must decide on eligibility for a work disability pension, which can be full or partial, and ranges from 0 to $100 \%$. In august 1993 the eligibility criteria changed. Work disability is allowed if the patient has objective medical restrictions in performing any type of work, independent of age and profession. If the percentage of the disability exceeds $15 \%$, a benefit will be allowed ranging from 25 to $70 \%$ of the former gross wage. Benefits are financed through social contributions from employees and employers. Persons who do not have income compensation from work disability pensions may receive a social benefit allowance.

\section{Comparison with the general Dutch population}

Data on sociodemographic characteristics, labour force participation and unemployment of the Dutch population were retrieved from Statistics Netherlands (CBS). ' Datai on work disability in the Dutch population were retrieved from the National Organization of Social Security Associations (LISV). ${ }^{44}$ Because in our study the upper age limit for inclusion was set at 59 years, whereas in the general population the age of retirement is 65 years, we recalculated the CBS and. LISV data for ages up to 59. Data on sick leave in the study population were compared with the results of a cross sectional study with the same instrument in the general Dutch population. ${ }^{43}$ Reference data for the Dutch population were from 1997 for labour force participation and work disability and from 1996 for data on sick leave. 


\section{Statistical methods}

We aimed to show a difference in employment of at least $10 \%$ and in work disability of at least $5 \%$ in comparison with the Dutch population. By using formulae for comparison of proportions $^{45}$, the required sample size was 247 and 338 patients for employment and work disability respectively. With an assumed response rate of at least $50 \%$, we decided to select at least 1000 patients with AS to participate. Data were analysed using SPSS 8.0 or Excel software. Proportions were calculated for fully completed questions. Job classification was adjusted for age and sex. The data on employment and disability were adjusted by indirect standardisation and presented as adjusted ratios and as adjusted rates. ${ }^{45}$ For the adjusted ratios, the $95 \%$ confidence intervals were calculated.

\section{Results}

\section{Response rate}

The correct address of 152 of the 1092 patients could not be retrieved. Of the 940 remaining patients 709 agreed to participate and received the questionnaire, which was completed by 658 patients. This accounts for a total response rate of $70 \%$. Participants did not differ in age and sex from non-participants. Mean age was 43.5 years and 42.3 years and proportions of male patients $70 \%$ and $69 \%$ for participants and non-participants respectively.

\section{Description of the patient population}

Table 4.1 shows the sociodemographic and disease characteristics of the study group. In a subgroup of patients $(n=137)$ belonging to two of the participating centres, the diagnosis AS as stated in the SDR was confirmed according to the radiologic New York criteria for sacroilitis by an independent reader in $99.3 \%$ of these patients. ${ }^{46}$ The sex ratio of the study population compares well with other existing data. ${ }^{47}$ The prevalence of inflammatory bowel disease and peripheral arthritis is more difficult to compare with results in the literature because different definitions are used and different populations studied. Our results fall within the reported figures: ${ }^{25,26,47-49}$ On the basis of Statistics Netherlands job classification, the age adjusted proportion of patients with AS who had a manual job was higher than in the general Dutch population. 
Table 4.1 Patient characteristics for the total group and by sex compared with the general population

\begin{tabular}{|c|c|c|c|c|}
\hline Patient characteristics & $\begin{array}{l}\text { General } \\
\text { population } \\
16-59 \\
\text { years }\end{array}$ & $\begin{array}{l}\text { Total group } \\
18-59 \text { years } \\
(n=658)\end{array}$ & $\begin{array}{l}\text { Men } \\
18-59 \text { years } \\
(n=461)\end{array}$ & $\begin{array}{l}\text { Women } \\
19-59 \text { years } \\
(n=197)\end{array}$ \\
\hline Men, \% & 50.9 & 70.0 & & \\
\hline Age (years), mean (SD) & 39.0 & $43.5(9.4)$ & $44.0 \quad(9.3)$ & $42.5(9.4)$ \\
\hline Disease duration (years), mean (SD) & Na & $12.2(8.0)$ & $12.4 \quad(8.4)$ & $10.0 \quad(7.5)$ \\
\hline Living with a partner, * & 79.8 & 83.1 & 81.8 & 86.3 \\
\hline Peripheral arthritis*, * & NA & 25.8 & 34.0 & 22.2 \\
\hline Total hip replacement, $\%$ & NA. & 3.6 & 2.8 & 5.6 \\
\hline $1 B D \pi, \%$ & NA & 4.3 & 5.2 & 3.5 \\
\hline BASFI $\approx(0-10)$, mean $(S D)$ & NA & $3.4(2.5)$ & $3.5(2.5)$ & $3.9(2.4)$ \\
\hline BASDAIs (0-10), mean (SD) & NA & $3.9 .(2.4)$ & $3.7 \quad(2.4)$ & $4.4 \quad(2.4)$ \\
\hline BASGY $(0-10)$, mean (SD) & NA & 4.1 $(2.6)$ & $4.0 \quad(2.6)$ & $4.3 \quad(2.6)$ \\
\hline$>12$ years formal education, 16 & 25.5 & 19.3 & 22.6 & 11.8 \\
\hline Mạnual workers, \% & 18.2 & 22.4 & 35.6 & 9.3 \\
\hline
\end{tabular}

- At least one joint on the Self Assessment Joint Score (swollen joints), $\pi$ IBD, Active inflammatory bowel disease for preceding three months for which drug treatment was needed; \# BASFI, Bath ankylosing spondylitis functional index, higher scores indicate worse function; \$ BASDAI, Bath ankylosing spondylitis disease activity index, higher scores indicate more disease activity; $\vee$ BASG, Bath ankylosing spondylitis global assessment, higher scores indicate worse global assessment; NA, not applicable

\section{Work status}

Altogether, $4.1 \%$ of the patients (3.0\% of male patients and $6.6 \%$ of female patients) had never had a job. The unemployment rate was. $4.4 \%$ for both male and female patients, and $2.5 \%$ received a social benefit allowance $(2.8 \%$ of male patients and $2.5 \%$ of female patients). In the Dutch population, the unemployment rate for those in working age was $4.1 \%$ (3.8\% of men and $5.2 \%$ of women received unemployment benefit), and $5.4 \%$ received a social benefit allowance. In table 4.2 employment and full employment are presented as proportions of the total group for each age and sex category together with the reference data for the Dutch population. In table 4.3 these figures are shown for work disability and full work disability. Both tables also provide the adjusted ratios with the $95 \%$ confidence intervals and the adjusted rates for patients with AS. Clearly employment is decreased in both male and female patients, but this is only statistically significant in male patients. The decrease in full time employment is greater for men, whereas for female patients with AS the decrease in employment can be attributed to a decrease in part time employment. For both sexes, significant increase in work disability rates was observed. This increase was more pronounced for partial than for full work disability. 
Table 4.2 Percentage and rate ratios of employment/full employment in patients with ankylosing spondylitis (AS) by sex and age category in comparison with the general population

\begin{tabular}{|c|c|c|c|c|c|c|}
\hline $\begin{array}{l}\text { Age category } \\
\text { (years) }\end{array}$ & $\begin{array}{l}\text { Total } \\
\text { population } \\
\text { with AS }\end{array}$ & $\begin{array}{l}\text { Men } \\
\text { with AS }\end{array}$ & $\begin{array}{l}\text { Women } \\
\text { with AS }\end{array}$ & $\begin{array}{l}\text { Total } \\
\text { general } \\
\text { population }\end{array}$ & $\begin{array}{l}\text { Dutch } \\
\text { men }\end{array}$ & $\begin{array}{l}\text { Dutch } \\
\text { women }\end{array}$ \\
\hline$<20$ & $0.0 / 0.0$ & 0.010 .0 & $0 / 0$ & $19.8 / 7.6$ & 21.719 .2 & $17.7 / 5.7$ \\
\hline $20-24$ & $50.0 / 42.9$ & $44.4 / 33.3$ & $60.0 / 60.0$ & $57.4 / 39.7$ & $58.6 / 46.1$ & $56.2 / 33.1$ \\
\hline $25-29$ & $70,4 / 55.8$ & $70.4 / 65.4$ & $70.6 / 41.2$ & $79.6 / 61.4$ & $85.9 / 79.4$ & $73.0 / 42.7$ \\
\hline $30-34$ & $74.2 / 57.8$ & $80.6 / 77.8$ & $57.9 / 10.5$ & $78.5 / 55.8$ & $91.4 / 84.6$ & $62.5 / 25.5$ \\
\hline $35-39$ & $73.1 / 53.9$ & $83.9 / 72.6$ & $57.1 / 25.0$ & $75.6 / 52.4$ & $93.3 / 86.1$ & $57.6 / 17.5$ \\
\hline $40-44$ & $70.2 / 51.5$ & $76.1 / 63.0$ & $53.6 / 21.4$ & $75.3 / 50.2$ & $92.3 / 83.4$ & $57.8 / 16.2$ \\
\hline $45-49$ & $64.5 / 43.9$ & $68.9 / 52.8$ & $52.9 / 20.6$ & $70.3 / 48.8$ & $87.7 / 80.4$ & $52.2 / 15.9$ \\
\hline $50-54$ & $58.6 / 48.5$ & $71.4 / 56.0$ & $18.5 / 7.4$ & $70.6 / 50.1$ & $92.9 / 83.6$ & $47.4 / 15.1$ \\
\hline $55-59$ & $38.0 / 29.7$ & $43.3 / 34.8$ & $24.0 / 16.0$ & $45.2 / 31.8$ & $65.0 / 55.2$ & $25.1 / 7.9$ \\
\hline Overall crude & $62.9 / 46.7$ & $69.5 / 57.8$ & $47.5 / 20.9$ & & & \\
\hline Rate ratio & $0.82 / 0.77$ & $0.80 / 0.74$ & $0.90 / 2.12$ & & & \\
\hline \multirow[t]{2}{*}{$(95 \% \mathrm{CI})$} & $(0.78$ to 0.87$) /$ & $(0.76$ to 0.85$)$ ( & $(0.77$ to 1.03$) /$ & & & \\
\hline & $(0.71$ to 0.84$)$ & $(0.68$ to 0.80$)$ & $(0.81$ to 1.42$)$ & & & \\
\hline Overall* & $54.2 / 35.5$ & $63.4 / 51.8$ & $46.9 / 23.4$ & $65.2 / 47.1$ & $78.8 / 70.1$ & $52.2 / 21.0$ \\
\hline
\end{tabular}

Values behind the slash are percentages of each age category that are fully employed. * Rates derived through indirect standardisation.

Table 4.3 Percentage and rate ratios of work disability/full work disability in patients with ankylosing spondylitis (AS) by sex and age category in comparison with the general population

\begin{tabular}{|c|c|c|c|c|c|c|}
\hline $\begin{array}{l}\text { Age category } \\
\text { (years) }\end{array}$ & $\begin{array}{l}\text { Total } \\
\text { population } \\
\text { with AS }\end{array}$ & $\begin{array}{l}\text { Men } \\
\text { with AS }\end{array}$ & $\begin{array}{l}\text { Women } \\
\text { with AS }\end{array}$ & $\begin{array}{l}\text { Total } \\
\text { general } \\
\text { population }\end{array}$ & $\begin{array}{l}\text { Dutch } \\
\text { men }\end{array}$ & $\begin{array}{l}\text { Dutch } \\
\text { women }\end{array}$ \\
\hline $16-24$ & $0.0 / 0.0$ & $0.0 / 0.0$ & $0.0 / 0.0$ & $1.5 / 1.2$ & $1.8 / 1.3$ & $1.3 / 1.2$ \\
\hline $25-34$ & $15.3 / 6.3$ & $12.2 / 4.1$ & $22.2 / 1.1$ & $3.3 / 2.7$ & $2.9 / 2.4$ & 3.713 .0 \\
\hline $35-44$ & $27.0 / 18.1$ & $28.1 / 14.1$ & $24.6 / 10.1$ & $6.0 / 4.2$ & $6.5 / 4.1$ & $5.6 / 4.3$ \\
\hline $45-54$ & $41.7 / 23.0$ & $44.3 / 24.1$ & $34.4 / 19.7$ & $12.4 / 8.5$ & $15.4 / 9.5$ & 9.217 .4 \\
\hline $55-59$ & $57.6 / 39.1$ & $62.7 / 43.3$ & $44.0 / 28.0$ & $21.7 / 17.4$ & $29.7 / 21.7$ & $13.6 / 11.7$ \\
\hline Overall crude & $33.8 / 18.7$ & $36.1 / 20.2$ & $28.7 / 15.2$ & & & \\
\hline Rate ratio & $3.10 / 2.76$ & $2.88 / 2.41$ & $4.00 / 2.60$ & & & \\
\hline \multirow[t]{2}{*}{$(95 \% \mathrm{CI})$} & $(2.77$ to 3.42$) /$ & $(2.53$ to 3.22$) /$ & $(3.12$ to 4.87$)$ ) & & & \\
\hline & $(2.32$ to 3.20$)$ & (1.97 to 2.85) & $(1.74$ to 3.46$)$ & & & \\
\hline Overall* & $21.8 / 12.6$ & $24.1 / 13.7$ & $22.6 / 11.9$ & $7.0 / 5.1$ & $8.4 / 5.6$ & 5.614 .6 \\
\hline
\end{tabular}

Values behind the slash are percentages of each age category that have full work disability pension.

- Rates derived through indirect standardisation.

\section{Work days lost}

Module I of the Health and Labour Questionnaire was completed by 389 ( $92.5 \%)$ patients with a paid job. Five questionnaires could not be interpreted, resulting in a total of 385 $(90.9 \%)$ questionnaires that could be analysed. Twenty five $(6.5 \%)$ patients $(5.2 \%$ of male patients and $11.4 \%$ of female patients) reported taking sick leave during the 
preceding two weeks. Of all the work days, $5.0 \%(4.1 \%$ for male patients and $9.1 \%$ for female patients) were lost due to sick leave because of AS. Extrapolating these data to days of sick leave due to AS per year results in 10.1 ( 8.8 days for male patients and 15.3 days for female patients). For the general Dutch population, the mean number of nonspecific days of sick leave per person per year is 12.3 (12.2 days for men and 14.1 days for women). In the Netherlands, employees on continuous sick leave for more than three months are likely to be waiting for a disability assessment, but are still officially registered as employees. When these patients ( 3 men and 4 women) are eliminated from the analysis, $4.3 \%$ of men and $6.7 \%$ of women reported an episode of sick leave, and $3.3 \%$ of possible work days were lost due to AS. Extrapolating these data to the number of days of sick leave would result in 6.5 extra days of sick leave per patient per year (6.9 for male patients and 5.7 for female patients).

\section{Discussion}

Among Dutch patients with AS, labour force participation is reduced, work disability increased, and extra sick leave substantial. We think that $11 \%$ decrease in employment and $15 \%$ increase in work disability are relevant from the clinical and societal point of view. The reduction in labour force participation is more pronounced for men than for women. Sick leave for those with a paid job, however, is more consequential for female patients,

Oụr findings on employment and work disability were obtained after adjusting for age and sex, which was apparently not performed in other studies. In table 4.4, we compare the raw and adjusted rates of labour force participation and work disability and present the difference from the general population for each method. Clearly, total labour force participation fell from $62.9 \%$ to $54.2 \%$ after adjusting for age and sex.

Table 4.4 Percentage employment and work disability as crude rates, adjusted rates after indirect standardisation for age: (and sex), and as difference between the patients and the general population

\begin{tabular}{|c|c|c|c|c|c|c|}
\hline & Total & Difference & Men & Difference & Women & Difference \\
\hline \multicolumn{7}{|l|}{ Employment (\%) } \\
\hline Population & 65.2 & & 78.8 & & 52.2 & \\
\hline Patients; crude & 62.9 & -2.3 & 69.5 & -9.3 & 47.5 & -4.7 \\
\hline Patients; adjusted & 54.2 & -11.0 & 63.4 & -15.4 & 46.9 & -5.2 \\
\hline \multicolumn{7}{|c|}{ Work disability $(\%)$} \\
\hline Population & 7,0 & & 8,4 & & 5.6 & 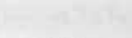 \\
\hline Patients; crude & 33.8 & +26.8 & 36.1 & +27.7 & 28.7 & +23.1 \\
\hline Patients; adjusted & 21.8 & +14.8 & 24.1 & +15.7 & 22.6 & +16.9 \\
\hline
\end{tabular}


Data from the literature on work status in patients with AS are conflicting. Figures on labour force participation vary from $34 \%$ to $96 \%$ 22-26,28,31,33,34,36,50 and for work disability from $3 \%$ to $36 \% .{ }^{22,25-29,31,32,34,35,51}$ The results in the literature, however, are difficult to interpret. Disease characteristics are not always provided and sample sizes are usually small. Moreover, data were never adjusted for age, and sex, and clear reference data on employment for the general population were only provided in one study. ${ }^{50}$

We may have introduced bias to some degree by examining patients with AS who were under the specialised outpatient care of a rheumatologist. This is supported by results in the literature, where employment in patients with AS from a hospital setting ${ }^{26,35}$ is in general lower than in populations obtained from patient associations or community studies. ${ }^{28,29,50}$ Also a study from Norway that compares work status and disease severity between hospital and community patients with $\mathrm{AS}^{24}$ showed that hospital patients with AS had lower employment and more severe disease. It should also be noted that, compared with the Dutch population, our patients were more likely to have manual professions and to be of lower social class based on educational level and job classification. As it has been shown that withdrawal from work as a result of AS is associated with jobs characterised by prolonged standing, ${ }^{27}$ this may have influenced our results. We do not know whether the overrepresentation of manual workers in our group is a true reflection of Dutch patients with AS or is due to the method of sampling. Usually, those who do not respond to questionnaire studies have on average a lower educational level and more manual jobs. ${ }^{52}$. ${ }^{56}$ If this is applied to our findings, it suggests underrepresentation of manual workers and therefore underestimation of the impact of AS on work status. Alternatively, it is also possible that the usual underrepresentation of the lower social class did not occur in our sample, which would result in overestimation of the impact of AS on work status.

It should' be noted that reported work disability in this study is for all causes and not solely attributable to AS. Most studies did not mention whether they recorded disease specific work disability, which contributes to the difficulties in comparing different studies. The Dutch social security system allows a combined (partial) disability pension and a (parttime) job. It seems that patients with AS in the Netherlands often receive a partial disability pension. For female patients, this was not associated with a corresponding increase in part time jobs.

Although the number of AS related days of sick leave for those with a paid job is substantial, our data are not as bad as in other studies. We report 8.8 and 15.3 days sick leave per patient per year for male and female patients respectively, in addition to the non-specific absence of 12 days per year for men and 14 days per year women reported for the general population. ${ }^{43}$ However, a Slovak study ${ }^{35}$ reports 39.5 days of disease 
specific sick leave per patient per year, and a Mexican study 45.8 days per year (for all causes) in the cross sectional part of the study ${ }^{22}$ but only 1 day per patient per month in the prospective study. ${ }^{23}$ Some comments need to be made. Firstly, there is no plausible reason to believe that AS attributable sick leave shows seasonal variation. The questionnaire was sent in September. Continuing studies in our group on weekly variation in disease activity or on sick leave in another cohort show no seasonal influence (unpublished data). Therefore we think the results of the Health and Labour Questionnaire can reliably be extrapolated to one year. Secondly, it is known that sick leave varies with age and is influenced by professional class. As the number of patients taking sick leave in the study group was quite small and as the Health and Labour Questionnaire has no reference data for sick leave by age or profession, we could not adjust for these variables. Because our study population is somewhat older and has an overrepresentation of manual professions, sick leave may be somewhat overestimated. Finally, we instructed patients to provide data on disease specific sick leave. However, one may question whether patients can really distinguish between illness due to AS and other causes. Also, it has not been investigated whether patients with a chronic disease take the same disease non-specific sick. leave as people without chronic disease. Although we are somewhat reluctant to accept relative proportions of disease specific and non-specific sick leave as presented here, it is clear that absence from work in patients with AS is greater than normal. For comparison, sick leave due to migraine is four days a year for women and one day for men. ${ }^{43}$

In contrast with AS, work status in patients with rheumatoid arthritis has received considerable attention over the past two decades. Various studies reported a reduction in labour force participation of $40-50 \%$ after a disease duration of up to 10 . years. ${ }^{11,13,17,19-21,57}$ Also in the Netherlands, labour force participation of patients with rheumatoid arthritis. was reduced after a mean disease duration of 12 years in comparison with the general population. ${ }^{18}$ However, figures on work status in patients with rheumatoid arthritis and AS are difficult to compare. There are major differences in age and sex between the two types of patients, and published results are not adjusted for age and sex.

In the past, work status in AS has received insufficient attention. Our study shows that the impact on this outcome measure is considerable, at least in those patients who are treated by rheumatologists. It is important to assess differences from reference populations. Clearly, prospective studies on work status need to be carried out as well as research into factors influencing this end point. 


\section{References}

1. Warr P. Work, unemployment and mental health. Oxford: Clarendon Press, 1987.

2. Kramer J̦, Yelin EH, Epstein WV. Social and economic impacts of four musculoskeletal conditions. A study using national community-based data. Arthritis Rheum $1983 ; 26: 901-7$.

3. Felts W, Yelin E. The economic impact of the rheumatic diseases in the United States. J Rheumatol 1989;16:867-84.

4. Yelin EH, Henke C], Epstein WV. Work disability among persons with musculoskeletal conditions. Arthritis Rheum 1986;29:1322-33.

5. Yelin E, Callahan LF. The economic cost and social and psychological impact of musculoskeletal conditions. National Arthritis Data Work Groups [see comments]. Arthritis Rheum 1995;38:1351-62.

6. Yelin E. The costs of rheumatoid arthritis: absolute, incremental, and marginal estimates. I Rheumatol Suppl 1996;44:47-51.

7. Centraal Bureau voor Statistiek. Statistisch Jaarboek 1998. Voorburg/Heerlen: CBS, 1998.

8. Yelin E, Meenan R, Nevitt M, Epstein W. Work disability in rheumatoid arthritis: effects of disease, social, and work factors. Ann Intern Med 1980;93:551-6.

9. Reisine ST, Grady KE, Goodenow C, Fifield J. Work disability among women with rheumatoid arthritis. The relative importance of disease, social, work, and family factors, Arthritis Rheum 1989;32:538-43.

10. Pincus T, Callahan LF, Sale WG, Brooks AL, Pạne LE, Vaughn WK. Severe functional declines, work disability, and increased mortality in seventy-five rheumatoid arthritis patients studied over nine years. Arthritis Rheum 1984;27:864-72.

11. Reisine S, McQuillan J, Fifield J. Predictors of work disability in rheumatoid arthritis patients. A five-year followup. Arthritis Rheum 1995;38:1630-7.

12. Reisine S, Fifield J. Family work demands, employment demands and depressive symptoms in women with rheumatoid arthritis: Women Health 1995;22:25-45.

13. Callahan LF, Bloch DA, Pincus T. Identification of work disability in rheumatoid arthritis: physical, radiographic and laboratory variables do not add explanatory power to demographic and functional variables. J Clin Epidemiol 1992;45:127-38

14. Fifield J, Reisine ST, Grady K. Work disability and the experience of pain and depression in rheumatoid arthritis. Soc Sci Med 1991;33:579-85.

15. Pincus T. Long-term outcomes in rheumatoid arthritis. $\mathrm{Br}$ J Rheumatol 1995;34:5973. 
16. Pincus $\mathrm{T}$. The underestimated long term medical and economic consequences of rheumatoid arthritis. Drugs 1995;50:1-14.

17. Doeglas D, Suurmeijer T, Krol B, Sanderman R, van Leeuwen M, van Rijswijk M. Work disability in early rheumatoid arthritis. Ann Rheum Dis 1995;54:455-60.

18. Chorus AMJ, Miedema HS, Wevers CWJ, Linden vd S. Labour force participation among rheumatoid arthritis patients. Ann Rheum Dis 2000;59:549-54.

19. Wolfe F, Hawley DJ. The longterm outcomes of rheumatoid arthritis: Work disability: a prospective 18 year study of 823 patients. J Rheumatol 1998;25:2108-17.

20. Sokka $T$, Kautiainen $H$, Mottonen $T$, Hannonen $P$. Work disability in rheumatoid arthritis 10 years after the diagnosis. J Rheumatol 1999;26:1681-5.

21. Makisara GL, Makisara P. Prognosis of functional capacity and work capacity in rheumatoid arthritis. Clin Rheumatol 1982;1:117-25.

22. Ramos-Remus C, Macias MA, Suarez-Almazor ME, R.E. Prieto RE, Gutierrez-urenam S. Labor status and working-days lost in a consecutive sample of 103 patients with anlylosing spondylitis (AS). Arthritis Rheum [S] 1997:1392.

23. Ramos-Remus C, Prieto-Parra RE, Michel-Diaz J, Gutierrez-Urena S, Suarez-Almazor ME. A five-year cumulative analysis of labor-status and lost working days in patients with ankylosing spondylitis (AS). Arthritis Rheumat [S] 1998:1136.

24. Gran JT, Husby G. Ankylosing spondylitis: a comparative study of patients in an epidemiological survey, and those admitted to a department of rheumatology. J Rheumatol 1984;11:788-93.

25. Gran JT, Ostensen M, Husby G. A clinical comparison between males and females with ankylosing spondylitis. J Rheumatol 1985;12:126-9.

26. Gran JT, Skomsvoll JF. The outcome of ankylosing spondylitis: a study of 100 patients. Br J Rheumatol 1997;36:766-71.

27. Guillemin F, Briancon. S, Pourel J, Gaucher A. Long-term disability and prolonged sick leaves as outcome measurements in ankylosing spondylitis. Possible predictive factors. Arthritis Rheum 1990;33:1001-6.

28. Fellmann ], Kissling R, Baumberger H. [Socio-professional aspects of ankylosing spondylitis in Switzerland]. Z. Rheumatol 1996;55:105-13.

29. Ringsdal VS, Helin P. Ankylosing spondylitis--education, employment and invalidity. Dan Med Bull 1991;38:282-4.

30. Edmunds L, Elswood J, Kennedy LG, Calin A. Primary ankylosing spondylitis, psoriatic and enteropathic spondyloarthropathy: a controlled analysis. J Rheumatol $1991 ; 18: 696-8$.

31. Kaarela K, Lehtinen K, Luukkainen R. Work capacity of patients with inflammatory joint diseases. An eight-year follow-up study. Scand J Rheumatol 1987;16:403-6. 
32. Lehtinen K. Working ability of 76 patients with ankylosing spondylitis. Scand J Rheumatol 1981;10:263-5.

33. McGuigan LE, Hart HH, Gow PJ, Kidd BL, Grigor RR, Moore TE. Employment in ankylosing spondylitis. Ann Rheum Dis 1984;43:604-6.

34. Wordsworth BP, Mowat AG. A review of 100 patients with ankylosing spondylitis with particular reference to socio-economic effects. Br J Rheumatol 1986;25:175-80.

35. Urbanek T, Sitajova H, Hudakova G. Problems of rheumatoid arthritis and ankylosing spondylitis patients in their labor and life environments. Czech Med 1984;7:78-89.

36. Chamberlain MA. Socioeconomic effects of ankylosing spondylitis in females: a comparison of 25 female with 25 male subjects. Int Rehabil Med 1983;5:149-153.

37. Van der Linden SM, Valkenburg HA, de Jongh BM, Cats $A$. The risk of developing ankylosing spondylitis in HLA-B27 positive individuals. A comparison of relatives of spondylitis patients with the general population. Arthritis Rheum 1984;27:241-9.

38. Miedema HS, van der Linden SM, Rasker JJ, Valkenburg HA. National database of patients visiting rheumatologists in the Netherlands: The standard diagnosis register of rheumatic diseases. A report and preliminary analysis. $\mathrm{Br} J$ Rheumatol $1998 ; 37: 555-61$.

39. Calin A, Garrett S, Whitelock H, Kennedy LG, O'Hea J, Mallorie P, et al. A new approach to defining functional ability in ankylosing spondylitis: the development of the Bath Ankylosing Spondylitis Functional Index. J Rheumatol 1994;21:2281-5.

40. Garrett S, Jenkinson T, Kennedy LG, Whitelock. H, Gaisford P, Calin A. A new approach to defining disease status in ankylosing spondylitis: the Bath Ankylosing Spondylitis Disease Activity Index. J Rheumatol 1994;21:2286-91.

41. Jones SD, Steiner A, Garrett SL, Calin A. The Bath. Ankylosing Spondylitis Patient Global Score (BAS-G): Br J Rheumatol 1996;35:66-71.

42. Stucki G, Stucki S, Bruhlmann P, Maus S, Michel BA. Comparison of the validity and reliability of self-reported articular indices. $\mathrm{Br}$ J Rheumatol 1995;34:760-6.

43. Van Roijen L, Essink Bot ML, Koopmanschap MA, Bonsel G, Rutten FF. Labor and health status in economic evaluation of health care. The Health and Labor Questionnaire, Int J Technol Assess Health Care 1996;12:405-15.

44. Kroniek van de sociale verzekeringen. Zoetermeer, 1997.

45. Kirkwood RB. Essentials of Medical Statistics. Oxford: Blackwel Scientific Publications; 1988.

46. Dale K. Radiographic gradings of sacroilitis in Bechterew's syndrome and allied disorders. Scand J Rheumatology 1979;32(S):92-7.

47. Will R, Edmunds L, Elswood J, Calin A. Is there sexual inequality in ankylosing spondylitis? A study of 498 women and 1202 men. J Rheumatol 1990;17:1649-52. 
48. Marks SH, Barnett M, Calin A. Ankylosing spondylitis in women and men: a casecontrol study. J Rheumatol 1983;10:624-8.

49. Dekker Saeys AJ, Keat AC. Follow-up study of ankylosing spondylitis over a period of 12 years (1977-1989). Scand J Rheumatol Suppl 1990;87:120-1.

50. Roussou E, Kennedy LG, Garrett S, Calin A. Socioeconomic status in ankylosing spondylitis: relationship between occupation and disease activity, I Rheumatol 1997;24:908-11.

51. Nissila M, Isomaki $H$, Kaarela K, Kiviniemi P, Martio J, Sarna S. Prognosis of inflammatory joint diseases. A three-year follow-up study. Scand J Rheumatol 1983;12:33-8.

52. Criqui MH, Barrett Connor E, Austin M. Differences between respondents and nonrespondents in a population-based cardiovascular disease study. Am 3 Epidemiol 1978; $108: 367-72$.

53. Gorkin L, Schron EB, Handshaw K, Shea S, Kinney MR, Branyon M, et al. Clinical trial enrollers vs. nonenrollers: the Cardiac Arrhythmia Suppression Trial (CAST) Recruitment and Enrollment Assessment in Clinical Trials (REACT) project. Control Clin Trials $1996 ; 17: 46-59$.

54. Harlan WR, 3rd, Sandler SA, Lee KL, Lam LC, Mark DB. Importance of baseline functional and socioeconomic factors for participation in cardiac rehabilitation. Am J Cardiol 1995;76:36-9.

55. Pietila $A M$, Rantakallio $P$, Laara E. Background factors predicting non-response in a health survey of northern Finnish young men. Scand J Soc Med 1995;23:129-36.

56. Smith $P$, Arnesen $H$. Non-respondents in a post-myocardial infarction trial: characteristics and reasons for refusal. Acta Med Scand 1988;223:537-42.

57. Mau W, Bornmann M, Weber $H$, Weidemann HF, Hecker $H$, Raspe HH. Prediction of permanent work disability in a follow-up study of early rheumatoid arthritis: results of a tree structured analysis using RECPAM. Br J Rheumatol 1996;35: 652-9. 

Work factors and behavioural coping in relation to withdrawal from the labour force among rheumatoid arthritis patients 


\section{Abstract}

\section{Objectives}

To assess separate and combined effects of work factors and behavioural coping in relation to withdrawal from the labour force among patients with rheumatoid arthritis (RA).

\section{Methods}

A cross sectional study was conducted in a Dutch nationwide random sample of 720 patients with RA. Information about work factors and behavioural coping was collected by a self administered postal questionnaire. A broad variety of work factors and coping styles were evaluated separately and in combination using multivariate logistic regression analyses, controlling for sociodemographic and disease related variables. Attributable and preventable fractions were calculated from the combined analyses to assess the relative importance of the contributing factors.

\section{Results}

Additional job training, equal career opportunities, letting the disease influence the choice of the current job position, and informing colleagues about having the disease are negatively associated with withdrawal from the labour force. The most relevant factor in terms of decreasing the risk was adjusting job demands which accounted for $63 \%$ of the patients still in the labour force.

Decreasing activities and diverting attention in order to cope with pain, and pacing in order to cope with limitations were the coping styles which were positively associated with withdrawal from the labour force. The most relevant factor in terms of increasing the risk of withdrawal was pacing which accounted for $67 \%$ of the withdrawals.

\section{Conclusions}

Work factors are potentially important modifiable risk factors for withdrawal from the labour force in patients with RA. Behavioural coping is also relevant. 


\section{Introduction}

Rheumatoid arthritis (RA) is a disease with spontaneous exacerbations and remissions, and its course is largely unpredictable. It may result in pain, morning stiffness, and impairments such as joint destruction, deformities, immobility, and disturbed bodily functions. Impairments may lead to limitations in performing activities, and - in interaction with personal and contextual factors - may restrict patient participation in different areas of life. ${ }^{1}$ Most people who develop: RA are already well established in their working careers. Onset of disease reaches a peak between the ages of 40 and 50 . Over the past two decades, various studies have addressed early withdrawal of patients with RA from the labour force. ${ }^{2-6}$ We have previously reported that participation in the labour force by patients with RA is only slightly lower than for the general working population after controlling for age, sex and educational level.? This implies that, despite active disease, many patients with RA are managing to continue to work.

It has been shown that sociodemographic variables, disease related factors and work characteristics are related to participation in the labour force by patients with RA. Higher age and lower educational level are important sociodemographic risk factors of withdrawal from the labour force by patients with RA. ${ }^{7}$ Pain, deformities, extra-articular disease, and other manifestations of the disease process are important disease related risk factors of withdrawal from the labour force. However, it is also well known that patients with RA with comparable levels of disease activity and impairment may differ greatly in work disability." A recent study has shown that early and aggressive antirheumatic therapy does not seem to reduce early withdrawal from the labour force. ${ }^{5}$ Increasingly, various work factors have been identified as risk factors. A physically demanding job, lack of control over the pace and activities of work, no self-employment status, lack of support by employers and colleagues, and also difficulties in commuting are important factors for leaving the labour force. $^{2.9-12}$ Despite this valuable knowledge, it is still not clear which factors are most important. Some studies point out: that disease related factors are most important, ${ }^{0,12}$ whereas others conclude that work factors are the most important predictors of withdrawal from the labour force. ${ }^{11}$

Another explanation for differences in work disability in RA among otherwise comparable patients might be the way in which patients deal with the biological consequences of their disease, that is, behavioural coping. Coping in RA has been extensively investigated, and it is generally found that what individuals do in relation to the stresses of the disease has potentially important implications for their levels of disability and psychological well being. ${ }^{13}$ Some patients may function to the limit of their capacities while others refrain 
from activities of which they are still capable. Pain, limitations and dependency are identified as the most important chronic stressors of RA. ${ }^{14}$ Limiting the level of activity when faced with the stressors of the disease may have negative effects on future physical functioning. ${ }^{15,16}$ At work a patient's behavioural reaction to these stressors may also be an important factor in determining the patient's work capacity. Nevertheless, the relation between coping and participation in the labour force in RA has, as yet, not been explored.

Both work factors and coping skills are potentially modifiable and could be used to construct vocational interventions to prevent early withdrawal from the labour force. ${ }^{8,17}$ The purpose of this study is to explore modifiable factors other than disease modifying: factors which could prevent or postpone early withdrawal from the labour force. We therefore examined a variety of work factors and behavioural coping styles in a representative Dutch sample patients with RA who had held a paid job anytime after being diagnosed with RA. The study aimed to assess the effects of work factors and behaviourall coping on withdrawal from the labour force by patients with RA, controlling for confounding effects of sociodemographic and disease related factors.

\section{Methods}

\section{Patients and materials}

The study was conducted in a nationwide group of 1056 patients with RA aged 20-59 years diagnosed by a rheumatologist. Eligible patients were identified using the national Standardised Diagnosis Register of Rheumatic Diseases. (SDR), a representative database with information about diagnoses of the patient population from $80 \%$ of all! rheumatologists in the Netherlands ${ }^{18}$ From this database a random sample of patients with RA aged 16-59 years, was selected from à geographically representative sample of 35 rheumatologists ( $37 \%$ of all SDR: rheumatologists) in 17 practices ( $52 \%$ of all SDR practices) throughout the Netherlands. All patients were contacted by mail by their own rheumatologist and $1056(62 \%)$ agreed to participate in the study. At the time of the study, three quarters of the patients fulfilled four or more of the 1987 ACR criteria and. more than $80 \%$ were receiving DMARD therapy. All patients filled out a self administered questionnaire containing several standardised instruments. Data was obtained on sociodemographic factors, disease characteristics, functional abilities, health related quality of life, present and past working conditions, and coping with the disease. The design of the study has also been described in detail elsewhere.? 
For the present analysis, the study group was limited further to include only those patients with paid employment at the time of diagnosis or at any time after being diagnosed with RA ( $n=720,68.2 \%)$. The other 336 patients had either stopped working before diagnosis. $(n=235,22.2 \%)$ or had no work history $(n=101$ patients, $9.6 \%)$ and were therefore not included in the analysis.

\section{Sociodemographic variables and disease characteristics}

Age, sex, educational level, disease duration and disease activity are important risk factors for leaving the labour force. Since the present study focused on work factors and coping styles, sociodemographic variables and disease characteristics were considered to be confounding factors in the relation between work factors or coping styles and withdrawal from the labour force. Educational level was separated into three categories based on the Dutch school system (primary education (0-8 years), secondary education (9-16 years), and higher vocational education/university $(17+$ years $)$ ). An index for disease activity was constructed from five questions of the Rapid Assessment of Disease Activity in Rheumatology (RADAR) instrument, ${ }^{19}$ using the method described by Stucki et al. This index, the Rheumatoid Arthritis Disease Activity Index (RADAI), may vary from 0 to 10 and higher scores, indicate higher disease activity. ${ }^{20}$

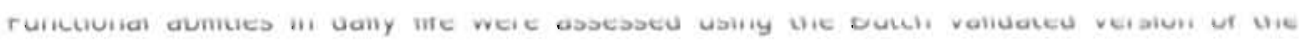
Health Assessment Questionnaire containing 20 items addressing eight dimensions of activities of daily life. An overall score was calculated as the mean score of the individual mean scores for the items in the eight dimensions. ${ }^{21}$

\section{Work factors}

All patients reported on their work history using a Dutch generic structured instrument, the Vocationa! Handicap Questionnaire (VHQ), which had been validated in previous studies in chronically ill Dutch people. ${ }^{22-24}$ This questionnaire assesses present occupational situation, vocational handicaps and past working career. Data was therefore collected for the year of first real paid job, size of company, job demands, accessibility of the work place and transportation mobility, job adjustments, relationship with people in the workplace and career opportunities. Patients who had withdrawn from the labour force were asked to indicate whether they had left the labour force for work related reasons, disease related reasons, or other personal reasons.

\section{Behavioural coping}

Behavioural coping styles were assessed by the validated Coping with Rheumatic Stressors (CORS) instrument which was originally drafted in Dutch. ${ }^{14,25}$ The CORS measures eight 
coping styles for the most important chronic stressors of RA-that is, pain, limitations and dependence. Three coping scales refer to pain: comforting cognitions ( 9 items), decreasing activities ( 8 items), and diverting attention ( 8 items). Three scales measure styles of coping with limitations: optimism (5 items), pacing-for example, adapting one's level of activity (10 items), and creative solution seeking (8 items). Two scales refer to dependence: making an effort to accept one's dependence (6 items), and showing consideration (7 items). For every item, patients, report how often they made use of that particular coping tactic (seldom or never, sometimes, often, very often).

\section{Data analysis}

Sociodemographic and disease characteristics were analysed by $\chi^{2}$ tests to determine proportional variance between the groups and $t$ tests were: conducted in order to analyse differences between group means for patients who had withdrawn from the labour force and patients who still had paid employment at the time of the study.

The relative risk of withdrawal from the labour force associated with specific work related factors and coping strategies was estimated by comparing variables of the patients who had withdrawn from the labour force with those of the patients who had not, adjusted for confounding effects of sociodemographic and disease characteristics. We therefore performed unconditional logistic regression analysis to calculate odds ratios (ORs) and their $95 \%$ confidence intervals (CI) for each work related factor and coping strategy separately. An OR of 1.0 indicates that the exposure to a certain factor by patients with RA who have withdrawn from the labour force is similar to that of patients who still have paid employment; an OR of $<1.0$ indicates that patients whit RA who have withdrawn from the labour force are less exposed to a certain factor those who still have paid employment; and an OR of $>1.0$ indicates that patients with RA who have withdrawn from the labour force are more often exposed to a certain factor than patients who still have paid employment. The $95 \%$ confidence interval indicates whether the differences between the two groups are statistically significant for a certain factor. If an OR of 1.0 is included in the interval, this implies that the estimate is not statistically significant at the $\propto=0.05$ level. ${ }^{26,27}$ In evaluating the association between withdrawal from the labour force and several work factors, we compared the characteristics of the present jobs of patients with the characteristics of the last job of patients who had withdrawn from the labour force. For each work factor we calculated odds. ratios in separate logistic regression models, together with their $95 \%$ confidence intervals, adjusted for age, sex, educational level, disease 
activity and disease duration. The same was done to evaluate the relation between withdrawal from the labour force and several coping strategies. For clinical interpretation, we treated variables of different coping strategies as dummy variables. The total score for each coping scale was therefore divided by the total number of items it included and the scores were then divided into two categories (scores 1.0-2.5 $=$ never and sometimes; $2 \cdot 5-4.0=$ often and very often).

In addition, we performed a logistic regression analysis to assess the importance of work factors and coping styles in the relationship with withdrawal from the labour force in a multivariate context. With a forward stepwise procedure, all work related variables and variables for coping styles were admitted to the regression model after variables for age (as a continuous variable), sex (male versus female), educational level (high versus primary/secondary versus primary), disease duration (as a continuous variable) and disease activity (as a continuous variable) had been entered in the first regression model without selection using statistical thresholds. A variable for work or coping was entered into the equation when the alpha level of rejecting the null hypothesis was 0.20 . This level was chosen to ensure adequate power. Based on the final logistic regression model of the stepwise procedure, attributable fractions and preventable fractions were subsequentiy calculated to estimate the overall proportion of withdrawals from the labour force that could be either attributed to, or prevented by, work factors and coping styles. The adjusted attributable fraction is the proportion of withdrawals from the labour force which is attributed to exposure by that factor. It is calculated as the exposed proportion of patients withdrawn from the labour force multiplied by (aOR-1)/aOR where aOR is the odds ratio for that risk factor adjusted for all other factors in the final model. The adjusted preventable fraction is the proportion of withdrawais in a situation of non-exposure that could be prevented by exposure to that factor and is calculated as the unexposed proportion of patients withdrawn multiplied by (1-aOR). ${ }^{27}$

To examine possible recall bias, we performed the same stepwise forward multivariate regression analysis with a subsample of patients who had, withdrawn from the labour force during the six years before to the study. The cut off point of six years was chosen to ensure adequate power. ${ }^{27}$

All statistical analyses were performed with SPSS for Windows, version 10.0.7. 


\section{Results}

Of the 720 patients, $343(47.6 \%)$ had withdrawn from the labour force after a mean disease duration of 4.8 years; $69.8 \%$ of these patients indicated that they had stopped working as a consequence of RA. Table 1 lists the sociodemographic characteristics and disease specific variables of the study group. At the time of the study patients who had left the labour force had a mean age of 50.1 years, whereas patients with a paid job had a mean age of 45.8 years $(p<0.05)$. A significantly higher proportion of patients who had left the labour force were female and they were less highly educated than patients who still had paid employment. Furthermore, patients who had withdrawn from the labour force experienced significantly higher disease activity, longer disease duration, and more disabilities than the working patients. These variables are considered as important confounders in evaluating the relation between work factors and withdrawal from the labour force and evaluating coping and withdrawal from the labour force in patients with RA.

The mean age at diagnosis of RA was 36.4 years for patients who had withdrawn from the labour force and 36.0 years for patients who still had paid employment. More than $40 \%$ of the patients who had withdrawn from the labour force did so within the first year after diagnosis, and $74.6 \%$ of them indicated that RA was the reason for leaving. Most of the patients $(94,4 \%)$ who had withdrawn from the labour force were officially recognised. as being fully or partially disabled for work purposes since they received a government work disability pension. Partial work dișability was recognised in $14 \%$ of the patients who still had paid employment. The social security system of the Netherlands entitles employees who are on full or partial sick leave for more than one year to a work disability pension, after work disability is officially recognised on the basis of a medical and ergonomic examination. This pension provides income compensation up to a maximum of $70 \%$ of the last income for a maximum period of five years. At the end of that period, the person's work ability has to be reassessed. The level of compensation is dependent on age, number of working years, and the level of work ability. Those whose ability to work is impaired by $80-100 \%$ are entitled to a full work disability pension while those whose ability to work is impaired by $15-80 \%$ are entitled to a partial work disability pension. In the Netherlands it is therefore possible to receive a work disability pension and to remain in employment, usually on a part-time basis. 
Table 5.1 Characteristics of patients withdrawn from the labour force after diagnosis and patients still in paid employment

\begin{tabular}{|c|c|c|c|}
\hline Variables. & Category & $\begin{array}{l}\text { RA patients } \\
\text { withdrawn } \\
\text { from labour } \\
\text { force after } \\
\text { diagnosis } \\
(n=343)\end{array}$ & $\begin{array}{l}\text { RA patients in } \\
\text { paid } \\
\text { employment } \\
\text { at time of } \\
\text { study } \\
(n=377)\end{array}$ \\
\hline Sex*, $\%$ & Men & 29.9 & 43.9 \\
\hline \multirow[t]{4}{*}{ Age at time of study* $\%$} & $20-29$ years & 1.8 & 6.2 \\
\hline & $30-39$ years & 10.2 & 14,9 \\
\hline & $40-49$ years & 27.5 & 42.7 \\
\hline & $50-59$ years & 60.2 & 36.2 \\
\hline \multirow[t]{3}{*}{ Educational level*, \% } & Primary & 52.0 & 32.5 \\
\hline & Secondary & 39.9 & 47.3 \\
\hline & High vocational colleges/university & 8.1 & 20.2 \\
\hline \multirow[t]{5}{*}{ Age at diagnosis of RA, \% } & Younger than 20 vears & 8.2 & 9.6 \\
\hline & $20-29$ & 21.9 & 19.5 \\
\hline & $30-39:$ & 28.5 & 32.3 \\
\hline & $40-49$ & 30.2 & 30.9 \\
\hline & $50-59$ & 11.2 & 7,6 \\
\hline \multirow[t]{5}{*}{ Disease duration at time of study ${ }^{*}, \%$} & 2.5 years & 19.3 & 32.4 \\
\hline & $6-10$ years & 23.9 & 32.8 \\
\hline & $11-15$ years & 17.8 & 17.3 \\
\hline & $16-20$ years & 17.0 & 9.5 \\
\hline & More than 20 years & 22.0 & 8.4 \\
\hline Disease activity*, mean & RADAI (range: $0-10$ ) & 4,9 & 3.5 \\
\hline Functiona! ability*, mean & HAQ (range: 0-3) & 1.3 & 0.7 \\
\hline \multirow{5}{*}{$\begin{array}{l}\text { Duration of labour force participation } \\
\text { after diagnosis*, } \%\end{array}$} & $0-1$ years & 45.4 & 1.7 \\
\hline & $2-4$ years & 18.5 & 23.0 \\
\hline & $5-7$ years & 13.3 & 26.0 \\
\hline & $8-12$ years & 11.3 & 25.0 \\
\hline & More than 12 years & 11.5 & 24,3 \\
\hline \multirow[t]{2}{*}{ Work disability pension, \% } & $280 \%$ disabled & 68.9 & NA \\
\hline & $<80 \%$ disabled* & 25.5 & 14.4 \\
\hline
\end{tabular}

* Differences between group means and distributions are statistically significant $(D<0,05)$. NA =not applicable

\section{Work factors}

Table 5.2 lists the results of the logistic regreșion analyses estimating the risk of withdrawal from the labour force associated with each work factor in separate models. All models were adjusted for confounding effects of age, sex, educational level, disease duration and disease activity. Since functional ability was highly correlated. to disease activity $(r>0.6)$, we chose to enter only the variable for disease activity into the models to prevent colinearity, Variables for the field of work show that patients who had withdrawn from the labour force worked 3.2 times more often in manual or industrial trades than patients who still had a paid job. They were also 3.3 times less likely to have worked in 
Table 5.2 Distribution and odds ratios of withdrawal from the labour force by patients with rheumatoid arthritis for various work factors

\begin{tabular}{|c|c|c|c|c|}
\hline Work factors & Category & $\begin{array}{l}\% \text { of RA } \\
\text { patients } \\
\text { withdrawn } \\
\text { after } \\
\text { diagnosis } \\
(n=343)\end{array}$ & $\begin{array}{l}\% \text { of RA } \\
\text { patients at } \\
\text { time of study } \\
(n=377)\end{array}$ & OR* $(95 \% \mathrm{CI})$ \\
\hline \multirow[t]{7}{*}{ Field of work } & Administrative & 16.9 & 23.3 & 1.0 \\
\hline & Agricultural & 1.9 & 3.3 & $0.9(0.3$ to 3.0$)$ \\
\hline & Manual/industrial & 22.1 & 14.1 & $3.2(1.6$ to 6.4$)$ \\
\hline & Transport & 3.8 & 3.6 & $2.1(0.7$ to 6.2$)$ \\
\hline & Commercial & 13.4 & 11.8 & $1.6(0.8$ to 3.0$)$ \\
\hline & Service/sales & 24.8 & 16.5 & $1.8(1.0$ to 3.2$)$ \\
\hline & Professional & 17.1 & 27.5 & $1.2(0.6$ to 2.4$)$ \\
\hline \multirow{2}{*}{$\begin{array}{l}\text { Size of company } \\
\text { (no. of employees) }\end{array}$} & $<100$ & 69.1 & 59.3 & $1.3(0.9$ to 2.0$)$ \\
\hline & 2100 & 30.9 & 40.7 & 1.0 \\
\hline \multirow[t]{2}{*}{ Temporary job position } & No & 93.3 & 92.2 & 1.0 \\
\hline & Yes & 6.7 & 7.8 & $1.5(0.8$ to 3.0$)$ \\
\hline \multirow{2}{*}{ Executive position } & No & 74.6 & 68.3 & 1.0 \\
\hline & Yes & 25.4 & 31.7 & $1.0(0.6$ to 1.5$)$ \\
\hline \multirow{2}{*}{ Number of working hours } & $32 \mathrm{hrs} /$ week & 38.8 & 47.3 & $0.3(0.2$ to 0.5$)$ \\
\hline & $232 \mathrm{hrs} /$ week & 61.2 & 52.7 & 1.0 \\
\hline \multirow{2}{*}{$\begin{array}{l}\text { Additional job training } \\
\text { after diagnosis }\end{array}$} & No. & 54.9 & 32.3 & 1.0 \\
\hline & Yes & 45.1 & 67.7 & $0.5(0.4$ to 0.8$)$ \\
\hline \multirow{2}{*}{$\begin{array}{l}\text { Changed field of activity } \\
\text { after diagnosis }\end{array}$} & No & 80.2 & 73.7 & 1.0 \\
\hline & Yes & 19.8 & 26.3 & $0.7(0.5$ to 1.1$)$ \\
\hline \multirow{2}{*}{$\begin{array}{l}\text { RA influenced choice on } \\
\text { last/present job position }\end{array}$} & No & 79.3 & 68.7 & 1.0 \\
\hline & Yes & 20.7 & 31.3 & $0.5(0.4$ to 0.8$)$ \\
\hline \multirow{2}{*}{ Accessibility of work place } & Good & 76.5 & 93.4 & 1.0 \\
\hline & Bad & 23.5 & 6.6 & $4.8(2.6$ to 9.1$)$ \\
\hline \multirow[t]{2}{*}{ Transportation mobility } & Not reduced & 83.5 & 95.7 & 1.0 \\
\hline & Reduced & 16.5 & 4.3 & $5.0(2.5$ to 10.0$)$ \\
\hline \multirow{2}{*}{ Adjusted working hours } & No & 86.2 & 72.5 & 1.0 \\
\hline & Yes & 13.8 & 27.5 & $0.3(0.2$ to 0.5$)$ \\
\hline \multirow[t]{2}{*}{ Adjusted job demands } & No & 84.9 & 69.6 & 1.0 \\
\hline & Yes & 15.1 & 30.4 & $0.3(0.2$ to 0.5$)$ \\
\hline \multirow[t]{2}{*}{ Technical adjustments. } & No & 93.6 & 82.8 & 1.0 \\
\hline & Yes & 6.4 & 17.2 & $0.3(0.2$ to 0.6$)$ \\
\hline \multirow{2}{*}{ Dependent on colleaggues } & No & 53.5 & 62.3 & 1.0 \\
\hline & Yes & 46.5 & 37.7 & $1.1(0.8$ to 1.6$)$ \\
\hline \multirow{2}{*}{$\begin{array}{l}\text { Attitude of colleagues } \\
\text { towards patient }\end{array}$} & Normal/positive & 89.7 & 94.8 & 1.0 \\
\hline & Negative & 10.3 & 5.2 & $1.8(1.0$ to 3.6$)$ \\
\hline \multirow[t]{2}{*}{ Support of colleagues } & Sufficient & 73.7 & 94.8 & 1.0 \\
\hline & Insufficient & 26.3 & 5.2 & 4.9 (2.7 to 8.9$)$ \\
\hline \multirow[t]{2}{*}{ Cofleagues well informed on RA } & No & 22.2 & 9.7 & 1.0 \\
\hline & Yes & 77.8 & 90.3 & $0.3(0.2$ to 0.5$)$ \\
\hline \multirow[t]{2}{*}{ Coaching of management } & Sufficient & 64.4 & 91.8 & 1.0 \\
\hline & Insufficient & 35.6 & 8.2 & $5.8(3.3$ to 9.9$)$ \\
\hline \multirow{2}{*}{$\begin{array}{l}\text { Career opportunities } \\
\text { within company }\end{array}$} & Equal to colleagues & 60.5 & 70.3 & 1.0 \\
\hline & Less than colleagues & 39.5 & 29.7 & $1.6(1.1$ to 2.4$)$ \\
\hline
\end{tabular}

*All odds ratios (ORs) and their $95 \%$ confidence intervals (CI) were adjusted for age, sex, educational level, disease activity, and disease duration. Bold printed ORs indicate statistically significant differences between the groups. 
part time jobs ( $<32$ hours a week) in their last job. Patients who still had a paid job reported 2.0 times more often that they had completed additional job training and 2.0 times more often that the disease had influenced their choice of last job position. Difficult access to the workplace and reduced transport mobility were found to be 5.0 times more prevalent among patients who had withdrawn from the labour force, whereas job adjustments at the workplace such as changes in working hours, adjusted job demands, or technical adjustments were reported 3.3 times less by those patients. In addition, relationships with people at work are important in terms of withdrawal from the labour force. Insufficient support from colleagues, colleagues not being well-informed about the disease, and insufficient coaching were reported 3-5 times more often by patients who no longer worked.

Table 5.3 Distribution and odds ratios of withdrawal from the labour force by patients with rheumatoid arthritis for various coping styles

\begin{tabular}{|c|c|c|c|c|}
\hline Coping styles & Category & $\begin{array}{l}\% \text { of RA } \\
\text { patients } \\
\text { withdrawn } \\
\text { after } \\
\text { diagnosis } \\
(n=343)\end{array}$ & $\begin{array}{l}\% \text { of } \\
\text { employed RA } \\
\text { patients at } \\
\text { time of study } \\
(n=377)\end{array}$ & OR* $(95 \% \mathrm{Cl})$ \\
\hline \multicolumn{5}{|l|}{ Pain } \\
\hline \multirow[t]{2}{*}{ Comforting cognition } & Never/sometimes & 12.6 & 13.3 & 1.0 \\
\hline & (very) often & 87,4 & 86.7 & $0.8(0.5$ to 1.4$)$ \\
\hline \multirow[t]{2}{*}{ Decreasing activity } & Never/sometimes & 32.9 & 69.1 & 1.0 \\
\hline & (very) often & 67.1 & 30.9 & $3.6(2.5$ to 5.3$)$ \\
\hline \multirow[t]{2}{*}{ Diverting attention } & Never/sometimes & 56.0 & 66.0 & 1.0 \\
\hline & (very) often & 44.0 & 34.0 & $1.6(1.1$ to 2.3$)$ \\
\hline \multicolumn{5}{|l|}{ Limitations: } \\
\hline \multirow[t]{2}{*}{ Optimism } & Never/sometimes & 15.3 & 14.1 & 1.0 \\
\hline & (very) often & 84.7 & 85.9 & $0.6(0.4$ to 1.0$)$ \\
\hline \multirow[t]{2}{*}{ Pacing } & Never/sometimes, & 14.9 & 46.2 & 1.0 \\
\hline & (very) often & 85.1 & 53.8 & $3.8(2.5$ to 5.7$)$ \\
\hline \multirow[t]{2}{*}{ Creative solutions } & Never/sometimes & 34.9 & 44.9 & 1.0 \\
\hline & (very) often & 65.1 & 55.1 & $1.3(0.9$ to 1.8$)$ \\
\hline \multicolumn{5}{|l|}{ Dependence } \\
\hline \multirow[t]{2}{*}{ Accepting } & Never/sometimes & 53.9 & 62.1 & 1.0 \\
\hline & (very). often & 46.1 & 37.9 & $1.2(0.9$ to 1.8$)$ \\
\hline \multirow[t]{2}{*}{ Consideration } & Never/sometimes & 27.2 & 32.7 & 1.0 \\
\hline & (very) often & 72.8 & 67.3 & $0.8 .(0.5$ to. 1.1$)$ \\
\hline
\end{tabular}

*All odds ratios (ORs) and their $95 \%$ confidence intervals (CI) were adjusted for age, sex, educational level, disease activity, and disease duration. Bold printed ORs indicate statistically significant differences between the groups. 


\section{Coping styles}

The relations between various coping styles and withdrawal from the labour force are shown in table 5.3. In order to cope with pain, patients who had withdrawn from the labour force were 3.6 times more likely to have reduced activity than patients who still had a paid job. They also reported diverting attention 1.6 times more often. In order to cope with limitations, pacing-for example, adapting one's level of activity-was reported 3.8 times more often by patients who had withdrawn from the labour force. With respect to dependence, no significant differences in coping styles were observed between patients with RA who had withdrawn and those still in the labour force.

Table 5.4 Importance of work factors and coping variables for withdrawal from the labour force among RA, taking into account age, sex, educational level, disease activity, and disease duration; attributable (AF) and preventable fractions (PF)

\begin{tabular}{|c|c|c|c|c|c|c|}
\hline Factor & exposed $v$ non-exposed" & aORף & $\begin{array}{l}\text { Proportion } \\
\text { of RA } \\
\text { patients } \\
\text { withdrawn } \\
\text { exposed } \\
\text { to the } \\
\text { factor }\end{array}$ & AF & $\begin{array}{l}\text { Proportion } \\
\text { of RA } \\
\text { patients } \\
\text { withdrawn } \\
\text { not } \\
\text { exposed to } \\
\text { the factor }\end{array}$ & PF \\
\hline $\begin{array}{l}\text { Pain coping style: } \\
\text { decreasing activities }\end{array}$ & (very) often $v$ sometimes never & 3.2 . & 0.67 & $46 \%$ & & \\
\hline Adjusted job demands & yes $v$ no & 0.26 & & & 0.85 & $63 \%$ \\
\hline Coaching of management & insufficient $v$ sufficient & 4.1 & 0.64 & $48 \%$ & & \\
\hline $\begin{array}{l}\text { Colleagues well informed } \\
\text { on RA }\end{array}$ & yes $v$ no & 0.24 & & & 0.22 & $18 \%$ \\
\hline $\begin{array}{l}\text { Limitations coping style: } \\
\text { pacing }\end{array}$ & (very) often $v$ sometimes never & 4.6 & 0.85 & $67 \%$ & & \\
\hline Number of working hours & $32 \mathrm{~h} / \mathrm{w} v \geq 32 \mathrm{~h} / \mathrm{w}$ & 0.31 & & & 0.61 & $42 \%$ \\
\hline Mobility in transportation & reduced $\mathrm{v}$ not reduced & 3.6 & 0.17 & $12 \%$ & & \\
\hline Accessibility of workplace & Bad $v$ good & 3.5 & 0.24 & $17 \%$ & & \\
\hline $\begin{array}{l}\text { Additional job training } \\
\text { after diagnosis }\end{array}$ & yes $v$ no & 0.46 & & & 0.55 & $29 \%$ \\
\hline $\begin{array}{l}\text { RA influenced choice of } \\
\text { last/present position }\end{array}$ & yes $v$ no & 0.39 & & & 0.79 & $48 \%$ \\
\hline $\begin{array}{l}\text { Career opportunities. } \\
\text { within company }\end{array}$ & less equal to colleagues $v$ equat & 1.6 & 0.40 & $15 \%$ & & \\
\hline $\begin{array}{l}\text { Limitations coping style: } \\
\text { optimism }\end{array}$ & (very) often $v$ sometimes never & 0.56 & & & 0.15 & $6 \%$ \\
\hline Temporary job position & yes $v$ no & 2.1 & 0.07 & $4 \%$ & & \\
\hline
\end{tabular}

\# If a factor is positivily associated with withdrawal from the labour force the proportion of patients with RA withdrawn exposed to that factor and the atrributable fraction is presented; if a factor is negatively associated then the proportion of patients with RA withdrawn from the labour force not exposed to that factor and the preventable fraction is presented; "Variables are listed in order of their entry into the regression; $\uparrow$ aOR=adjusted odds ratio (controlled for all variables presented in the table including age, sex, educational level, disease activity, and disease duration). 


\section{Work factors and coping styles combined}

Table 5.4 lists the results of the stepwise forward logistic regression for the combined effect of all work factors and coping styles adjusted for age, sex, education, disease duration, and disease activity. The variables are listed in order of their entry into the regression. Overall, the model shows that coping styles as well as work factors, particularly relationships with the management and colleagues and also organisational factors, contribute substantially to withdrawal from the labour force.

When the proportion of patients who had withdrawn from the labour force was calculated in terms of each factor, it emerged that pacing in order to cope with limitations accounted for $67 \%$ of the withdrawals from the labour force. The highest preventable risk fraction was found for adjusted job demands; it was found that $63 \%$ of the withdrawals could have been prevented from leaving the labour force. Other important factors which showed high attributable fractions were insufficient coaching $(48 \%)$ and decreasing activity in order to cope with pain (46\%). Factors that showed high preventable fractions were: "the disease had influenced the choice of the last job position" (48\%) and working part time $(42 \%)$.

Analysis of a subsample of patients who had withdrawn from the labour force within six: years before the study showed similar results. The factor with the highest preventable fraction was adjusted job demands (accounting for $50 \%$ of the patients still in the labour force). The factor "decreasing activities" in order to cope with pain showed the highest attributable fraction for withdrawal from the labour force (accounting for $46 \%$ of the withdrawals) (no further data shown).

\section{Discussion}

The findings of the study support the evidence of others that work related factors are. important in the relation between RA and withdrawal from the labour force, ${ }^{2,9-11}$ and add a new element to previous studies of this relation by identifying behavioural coping as a potential risk factor which is as important as work factors. Adjusting job demands seems. to be the most important factor negatively associated with withdrawal from the labour force. Pacing in order to cope with limitations, that is, adapting one's level of activity seems to be the major positively correlated factor. Only a few earlier studies have: examined the independent effect of behavioural coping, on illness outcome in RA, and only one study found that RA patients used behavioural coping strategies more frequently than cognitive coping strategies when dealing with problems at work. ${ }^{2 n}$ Although the other studies did not specifically focus on work, our findings on coping in relation to work 
underline their findings that limiting the level of activity when facing the stressors of the disease is negatively associated with physical functioning. ${ }^{13,15,16}$

Although our study shows that disease-related variables differ significantly between patients who had withdrawn and patients who still had a paid job, it does not provide answers to the question of whether disease related factors, work factors or social factors are the most predictive for leaving the labour force. In contrast with other studies, we dealt with disease related factors as confounding variables in the relationship between RA and withdrawal from the labour force. ${ }^{9,11}$ It may be obvious that disease related factors are important and that medical treatment could have a positive influence on labour force participation. However, to maximise the reduction of early withdrawal from the labour force in patients with RA it is also important to examine modifiable factors at work and the psychosocial context. Our study therefore provides useful information for the implementation and evaluation of vocational rehabilitation programmes. ${ }^{9}$

Some of the work factors may seem easy to modify, but altering working conditions requires the cooperation of employers, colleagues, occupational health care, and financial incentives from employers, insurance companies or the government. This cooperation is probably easier to achieve in times of economic growth than in times of recession. ${ }^{29}$ Little is known about the effect of modifying work related factors among patients with RA. One study by Allaire et al. showed that younger patients with a relative short duration of disease could benefit from interventions aimed at adjusting physically demanding jobs, commuting difficulties, and altering job type. ${ }^{9}$ Modifying coping behaviour, on the other hand, requires the full cooperation of the employees themselves. Cognitive-behavioural coping interventions usually emphasise control of pain by understanding the interaction of emotions and cognition with the physical and behavioural aspects of pain. Controlled clinical trials of cognitive-behavioural coping interventions demonstrated improvements in active coping skills in patients with RA and found positive effects on clinical outcome and well being. However, the effects on work status have not yet been studied. ${ }^{17,30-32}$

It should be pointed out that our study has some methodological limitations. Data were collected by a self-administered questionnaire and we did not validate this data using objective measures. However, the questionnaire included several well validated instruments for assessing disease activity and outcome independent of work status. ${ }^{14,20,22-}$ ${ }^{25}$ It is therefore unlikely that our results were substantially and systematically affected in any direction by differential misclassification-that is, patients who had withdrawn would 
rate their disease activity and outcome systematically different from patients who still had a paid job.

Although data about work were collected retrospectively, we think that considerable recall bias is less likely because we found that work related factors and behavioural coping were also equally important in a subsample of patients who had recently withdrawn from the labour force.

With respect to coping, the cross sectional design of our study does not allow us to state that the explanatory variables have a causal relationship with withdrawal from the labour force. Our study does not rule out the competing explanation that withdrawal from the labour force invokes passive coping styles such as "decreasing activities" as a way of coping with pain and "pacing" as a way of coping with limitations. It is possible that behavioural coping and withdrawal from the labour force may be reciprocally interrelated, meaning that passive coping styles may induce withdrawal from the labour force which, in turn, will facilitate deleterious effects on behavioural coping. On the other hand, research on coping found that patients with RA may already develop a coping style early in the illness and use their favourite strategies when confronted with the stressors of iliness. ${ }^{13,33}$ A more longitudinal approach is needed to assess whether the association between behavioural coping and withdrawal from the labour force is one of effect rather than cause and, furthermore, the extent to which coping skills are modifiable in relation to withdrawal from the labour force.

In summary, in addition to disease related factors, work related factors and behaviour coping styles should be considered in vocational rehabilitation for patients with RA as they are major determinants of withdrawal from the labour force. 


\section{References}

1. World Health Organization. ICIDH-2: International Classification of Functioning and Disability, Beta-2 draft, Full Version. Geneva: World Health Organization, 1999.

2. Yelin E, Henke C, Epstein W. The work dynamics of the person with rheumatoid arthritis. Arthritis Rheum 1987;30:507-12.

3. Doeglas D, Suurmeijer T, Krol B, Sanderman R, van Leeuwen M, van Rijiswijk M. Work disability in early rheumatoid arthritis. Ann Rheum Dis 1995;54:455-60.

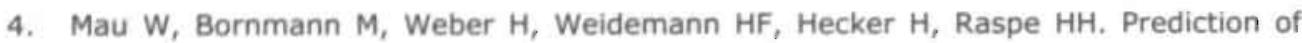
permanent work disability in a follow-up study of early rheumatoid arthritis: results of a tree structured analysis using RECPAM. Br J Rheumatol 1996;35:652-9.

5. Sokka T, Kautiainen H, Mottonen T, Hannonen P. Work disability in rheumatoid arthritis 10 years after the diagnosis. J Rheumatol $1999 ; 26: 1681-5$.

6. Wolfe F, Hawley DJ. The longterm outcomes of rheumatoid arthritis: Work disability: a prospective 18 year study of 823: patients. J Rheumatol 1998;25:2108-17.

7. Chorus AMJ, Miedema HS, Wevers CWJ, Linden SM vd. Labour force participation among rheumatoid arthritis patients. Ann Rheum Dis 2000;59:549-54.

8. Cochrane GM. Rheumatoid arthritis: vocational rehabilitation. Int Rehabil Med $1982 ; 4: 148-53$

9. Allaire SH, Anderson JJ, Meenan RF. Reducing work disability associated with rheumatoid arthritis: identification of additional risk factors and persons likely to benefit from intervention. Arthritis Care Res 1996;9:349-57.

10. Reisine S, McQuillan J, Fifield J. Predictors of work disability in rheumatoid arthritis patients.Arthritis Rheum 1995;38:1630-7.

11. Yelin E, Meenan R, Nevitt M, Epstein W. Work disability in rheumatoid arthritis: effects of disease, social, and work factors. Ann Intern Med 1980;93:551-6.

12. Reisine S, Grady K, Goodenow C, Fifield J. Work disability among women with rheumatoid arthritis. Arthritis Rheum 1989;32:538-43.

13. Newman SP, Revenson TA. Coping with rheumatoid arthritis. Bailliere's Clin Rheumatol $1993 ; 7: 259-80$.

14. Van Lankveld W, Naring G, van der Staak C, van 't Pad Bosch P, van de Putte L. Stress caused by rheumatoid arthritis: relation among subjective stressors of the disease, disease status, and well-being. J Behav Med 1993;16:309-21.

15. Van Lankveld W, Naring G, van 't Pad Bosch P', van de Putte L. Behavioral coping and physical functioning: the effect of adjusting the level of activity on observed dexterity. J Rheumatol 1999;26:1058-64. 
16. Van Lankveld W, Naring G, van't Pad Bosch P, van de Putte L. The negative effect of decreasing the level of activity in coping with pain in rheumatoid arthritis: an increase in psychological distress and disease impact. J Behav Med 2000;23:377-91.

17. Bradley LA, Alberts KR. Psychological and behavioral approaches to pain management for patients with rheumatic disease. Rheum Dis Clin North Am 1999;25:215-32.

18. Miedema HS, Linden SM vd, Rasker J3, Valkenburg HA. A national database of patients visiting rheumatologists in the Netherlands: The Standard Diagnosis Register of Rheumatic Diseases. A report and preliminary analysis. Br J Rheumatol 1998;37:55561.

19. Mason JH, Anderson JJ, Meenan RF, Haralson KM, Lewis-Stevens D, Kaine JL. The rapid assessment of disease activity (RADAR) questionnaire: Validity and sensitivity to change of a patient self-report measure of joint count and clinical status. Arthritis Rheum 1992;35:156-62.

20. Stucki G, Liang MH, Stucki S, Brühimann P, Michel BA. A self-administered rheumatoid arthritis disease activity index (RADAI) for epidemiologic research. Arthritis Rheum 1995;38:795-8.

21. Bijlsma JWJ, Oude Heuvel CHB, Zaalberg A. Development of the Dutch questionnaire capacities of daily life (VDF) of patients with rheumatoid arthritis. J Rehabilitation Sciences $1990 ; 2: 71-4$.

22. Andries F, Wevers CW, Wintzen AR, Busch HF, Howeler CJ, de Jager $A E$, et al. Vocational perspectives and neuromuscular disorders. Int ] Rehabil Res 1997;20:25573.

23. Wevers CW, Brouwer OF, Padberg GW, Nijboer ID, Job perspectives in facioscapulohumeral muscular dystrophy. Disabil Rehabil 1993;15:24-8.

24. Nijboer ID, Wevers C]. Vocational rehabilitation of young adults with a disability of one arm or hand. Int J Rehabil Res 1993;16:45-7.

25. Van Lankveld W, van't Pad B, van de Putte L, Naring G, van der Staak C. Diseasespecific stressors in rheumatoid arthritis: coping and well-being. $\mathrm{Br} J$ Rheumatol 1994;33:1067-73.

26. Armitage P, Berry G. Statistical methods in medical research. 2nd ed. Oxford: Blackwell Scientific Publications, 1987.

27. Rothman KJ, Greenland S. Modern Epidemiology. 2nd ed. Philidelphia: LippincottRaven, 1998.

28. Blalock SJ, DeVellis BM, Holt K, Hahn PM. Coping with rheumatoid arthritis: is one problem the same as another? Health Educ Q 1993;20:119-32.

29. Shanahan EM, Smith MD. Rheumatoid arthritis, disability and the workplace. Baillieres Best Pract Res Clin Rheumatol 1999;13:675-88. 
30. Hawley DJ. Psycho-educational interventions in the treatment of arthritis. Baillieres Clin Rheumatol 1995;9:803-23.

31. Scholten C, Brodowicz T, Graninger W, Gardavsky I, Pils K, Pesau B, et al. Persistent functional and social benefit 5 years after a multidisciplinary arthritis training program. Arch Phys Med Rehabil 1999;80:1282-7.

32. Keefe FJ, Van Horn Y. Cognitive-behavioral treatment of rheumatoid arthritis pain: maintaining treatment gains. Arthritis Care Res 1993;6:213-22.

33. Evers AW, Kraaimaat FW, Geenen R, Bijlsma JW. Psychosocial predictors of functional change in recently diagnosed rheumatoid arthritis patients. Behav Res Ther 1998;36:179-93. 


\section{Employment perspectives of patients}

with ankylosing spondylitis 


\section{Abstract}

\section{Objectives}

To assess the labour market position of patients with ankylosing spondylitis (AS) in relation to disease duration and to identify, potential factors in relation to withdrawal from the labour force.

\section{Methods}

A cross sectional mail survey was conducted among 658 patients with AS. Participation in the labour force was defined as having a paid job. The independent effect of duration of disease was examined by an indirect method of standardisation. A broad variety of risk factors were examined separately and in a combined analysis, including sociodemographic factors, disease related variables, coping styles, and work related factors. Attributable and preventable fractions were calculated from the combined analyses to assess the relative importance of the contributing factors.

\section{Results}

Probability of participation in the labour force was similarly reduced in patients with AS with different durations of disease. Pacing to cope with limitations was the most relevant factor in increasing the risk of withdrawal from the labour force, accounting for $73 \%$ of withdrawals. Coping with limitations by often seeking creative solutions, high disease activity, increased age, and insufficient support from colleagues or management were also positively associated with withdrawal from the labour force. Technical or ergonomic adjustments of the workplace, working in large companies, and coping with dependency. style through frequent acceptance were negatively associated. Of these factors, technical or ergonomic adjustment was the most relevant in terms of reducing the risk.

\section{Conclusions}

Sociodemographic factors, disease related factors, coping styles, and work related factors contribute simultaneously to withdrawal from the labour force. 


\section{Introduction}

Ankylosing spondylitis (AS) is a chronic systemic inflammatory rheumatic disorder that primarily affects the axial skeleton, with sacroilitis as its hallmark. Involvement of the limb joints other than hips and shoulders is present in $30 \%$ of patients. Clinical manifestations of the disease usually begin in late adolescence or early adulthood. Onset after the age of 40 is rare. The disease has both skeletal and extraskeletal manifestations and is clinically three times more common in men than in women. Pain, stiffness, and fatigue are the most often reported symptoms of patients with AS. ${ }^{1,2}$ As in most rheumatic diseases, the severity of symptoms varies greatiy among patients and varies over time in individual patients.

After rheumatoid arthritis (RA), ankylosing spondylitis is the major type of inflammatory rheumatic disease. By contrast with RA, knowledge about the burden of illness in AS is less well established. Generally, AS is considered to be a disease in which relatively good functional capacity and working ability are maintained. Previous studies of working ability among patients with AS reported employment rates of between $34 \%$ and $96 \%$ after mean duration of disease of 12 years or more. ${ }^{1,3.4}$ Despite this, none of the studies investigated the independent effect of duration of disease on participation in the labour force. As age, sex, education, and demand in the labour market may influence the likelihood of people stopping work, it is important to consider these factors when studying work disability. In patients with AS educational level may be influenced by the onset of the disease at a relatively young age. So in a previous study we controlled for age and sex and found that participation in the labour force was decreased by $11 \%$ compared with reference data for the general population of working age. The comparison with reference data of the same time period for the general population allowed for an indirect control for demand in the labour market. ${ }^{4}$

Most studies of risk factors for work disability in patients with AS have considered a limited range of possible risk factors. Factors found to be associated with continued employment include younger age, higher socioeconomic status, prolonged standing, vocational counselling, and indicators of less disease activity. ${ }^{1.5}$ Only two studies are known which use multivariate statistical techniques to determine the independent effect of different sociodemographic and work factors on the risk of work disability. ${ }^{6,7}$ One study, by Barlow et al., found that anxious and depressed mood and lower self esteem were associated with work disability in patients with AS. ${ }^{B}$ In a previous study, behavioural coping was identified as a relatively new potential risk factor in relation to work. ${ }^{\text {? }}$

The purpose of this study was to explore the employment prospects for patients diagnosed with AS by exploring modifiable factors, which could be used to construct vocational 
interventions to prevent or postpone early withdrawal from the labour force. We therefore examined the influence of disease duration on participation in the labour force compared with the general Dutch population. We also studied a broad range of work related variables in relation to withdrawal from the labour force and we assessed the relative importance of work related factors in combination with sociodemographics, disease related factors, and coping styles.

\section{Methods}

\section{Sample selection}

The present study was conducted in a Dutch nationwide study group of 658 patients aged 18-59 years diagnosed by a rheumatologist. Eligible patients were identified using the national Standardised Diagnosis Register of Rheumatic diseases (SDR), a representative database with information on diagnoses of the patient population of $80 \%$ of all rheumatologists in the Netherlands. ${ }^{9}$ From this database a random sample of patients with AS aged 16-59 years was selected from a geographically representative sample of 34 rheumatologists (34\% of all rheumatologists participating in the SDR, $27 \%$ of all rheumatologists in the Netherlands), working in 15 practices ( $42 \%$ of all SDR practices) throughout the Netherlands. All patients were contacted by mail by their own rheumatologist, and $658(60.3 \%$ of the initial cohort, $70.0 \%$ of the patients traceable) agreed to participate in the study. All patients filled out a self administered questionnaire adjusted to their current employment status (having a paid job, having no paid job but: had a paid job in the past, and never had a paid job) and containing several standardised instruments. Data were obtained on sociodemographics, disease characteristics, functional abilities, health related. quality of life, present and past working conditions, and coping with the disease, We limit our description of variables to those which were assessed to address our present study purpose. The design of the present study has been described in detail elsewhere. ${ }^{4,7}$

\section{Sociodemograhic variables}

Year of birth, sex and highest attained level of education were identified as sociodemographic variables. Attained educational level was separated into three categories based. on the Dutch educational system (primary education (0-8 years), secondary education ( $9-16$ years), and higher vocational education/university (17 years and more)). 


\section{Disease characteristics}

Disease activity was assessed using a Dutch version of the Bath ankylosing spondylitis disease activity index (BASDAI) ${ }^{10}$ containing six questions focussing on fatigue (one item), axial pain (one item), peripheral pain (one item), enthesopathy (one item), and morning stiffness (two items). Each question is scored on a Visual Analogue Scale (VAS). The BASDAI score $(0-10)$ was calculated as the mean value of the mean of the first four items and the mean of the last two items referring to morning stiffness. A higher score indicates more disease activity. Patients were asked about the year in which AS was diagnosed. Furthermore, patients reported their current use of medication, whether they had total hip replacement and whether they suffered from AS related comorbidity and other chronic disorders.

\section{Activities in daily life}

To assess functional abilities in daily life, a Dutch version of the Bath ankylosing spondylitis functional index (BASF1) was used. This contains eight questions on function in AS and two questions reflecting the patients' ability to cope with everyday life. ${ }^{11}$ Each question was scored on a VAS, the mean of which gives the BASFI score (0-10). A higher score indicates worse outcome.

\section{Employment situation}

All patients reported on their employment history using a Dutch generic structured instrument, the vocational handicap questionnaire (VHQ), which had been validated in previous studies among Dutch chronically ill people. ${ }^{12-14}$ This instrument assesses present occupational situation, vocational handicaps, past employment history, and income compensation by work disability pensions. Data were also collected on the year of the first real paid job and job changes. To describe the present or last job, data were collected on field of work, job demands, adjustments, size of company, accessibility of the workplace, and transportation mobility, job adjustments, social support from colleagues, and management in the workplace. Patients who had withdrawn from the labour force were asked to indicate in which year they stopped working and whether they had left for work related reasons, disease related reasons, or other personal reasons. For patients who left the labour force after being diagnosed, the duration of employment after diagnosis was calculated.

\section{Coping}

Behavioural coping styles were assessed using the disease specific coping with rheumatic stressors (CORS) instrument. ${ }^{15,16}$ The CORS measures eight coping styles directed at the 
most important chronic stressors of inflammatory rheumatic diseases-that is pain, limitations, and dependence. Three scales refer to pain: comforting cognitions (nine items), decreasing activities (eight items), and diverting attention (eight items). Three scales measure styles of coping with limitations: optimism (five items), pacing-that is, adapting one's level of activity (10 items)- and creative solution seeking (eight items). Two scales refer to dependence: making efforts to accept one's level of dependency (six items), and showing consideration (seven items). For each item, patients report how often they made use of that particular coping strategy (seldom or never, sometimes, often, very often).

\section{Global wellbeing}

The instrument used to assess global wellbeing was the disease specific Dutch verșion of the Bath ankylosing spondylitis global health index (BASG), containing two questions on the impact of AS on global wellbeing in the past week and in the past six months. ${ }^{17}$ Each question was scored on a VAS, the mean of which gave the BASG score (0-10). A higher score indicates more impact of the disease on the global wellbeing of the patient.

\section{Data analysis}

The influence of disease duration on the participation in the labour force of patients with AS was studied by comparing age and sex specific levels of employment in our AS population with those in the general population using an indirect standardisation method. We therefore calculated, for our study group, ratios of the observed $(O)$ and expected $(E)$. number of working people for evenly spaced five year categories of disease duration. Our study design meant that the first category ranges from one to five years of disease duration. Expected levels of participation in the labour force were computed using reference data for the general Dutch population relating to age and sex specific levels of employment. ${ }^{18}$ The $\mathrm{O} / \mathrm{E}$ ratio can be interpreted as the relative chance of patients with AS having a paid job compared with the general population, adjusted for age and sex. A rate ratio of 1.0 indicates an equal chance, a rate ratio of less than 1.0 a decreased chance, and a rate ratio of more than 1.0 an increased chance. To examine statistically significant differences between the AS group and the general population, we obtained the variances of the $\mathrm{O} / \mathrm{E}$ ratios, and estimated their $95 \%$ confidence intervals $(\mathrm{O} / \mathrm{E} \pm 1.96 \times \sqrt{\mathrm{var}}(\mathrm{O} / \mathrm{E}))$. If a rate ratio of 1.0 is included in the interval, then the estimate is not statistically significant at the a level of $0.05 .^{19}$

In evaluating sociodemographics, disease related variables, coping styles, and various work related factors in relation to withdrawal from the labour force, we compared. characteristics of patients who had withdrawn from the labour force any time after being 
diagnosed with AS and patients still employed at the time of the study. For employment factors, we examined the characteristics of the last job position of the patients who had withdrawn and the characteristics of the present job of the employed patients. Firstly, all variables were subjected to univariate analysis using $\chi^{2}$ tests to determine proportional variance between groups and $t$ tests were conducted to analyse differences between group means. In addition, we assessed the relative importance of sociodemographic, disease related factors and work related factors in the relationship with withdrawal from the labour force in a multivariate context. A multiple logistic regression analysis with a forward stepwise procedure was therefore performed to assess the simultaneous associations of those sociodemographic, disease related and work related factors that were found to be significant at the ps 0.05 level, when tested by univariate analysis. A variable was entered into the equation when the a level for rejecting the null hypothesis was 0.20 . This level was chosen to ensure adequate power for the selection of variables to have acceptable performance for statistical testing. ${ }^{19}$ For implementation of the results in practice, each continuous variable was dichotomised at the median score of the total group of patients who performed a job any time after diagnosis.

On the basis of the final logistic regression model of the stepwise procedure, attributable fractions and preventable fractions were subsequently calculated to estimate the overall proportion of withdrawals from the labour force that could be either attributed to, or prevented by, sociodemographic, disease related or work related factors. The adjusted attributable fraction is the proportion of withdrawals from the labour force, which is attributed to exposure by that factor. It was calculated as the exposed proportion of patients withdrawn from the labour force multiplied by (aOR-1)/aOR where aOR is the odds ratio for that risk factor, adjusted for all other factors in the final model.

The adjusted preventable fraction is the proportion of withdrawals in a situation of nonexposure that could be prevented by exposure to that factor. It is calculated as the unexposed proportion of patients withdrawn multiplied by (1-aOR).

To examine possible recall bias, we performed the same stepwise forward multiple regression analysis with a subsample of patients who had withdrawn from the labour force during the five years before the study and a subsample of patients with five or fewer years of disease. The cut off point of five years was chosen to ensure adequate statistical power for the logistic regression. ${ }^{19}$ All statistical analyses were performed using SPSS for Windows, version 10.0.7. 


\section{Results}

Overall participation in the labour force in this cohort of patients with AS with a mean disease duration of 12.4 years, standardised for age and sex, was $54.2 \%$ (63.4\% in males and $46.9 \%$ in females), which is a significant reduction of $11.0 \%$ (15.4\% in males and $5.2 \%$ in females) compared to the Dutch general population of working age. Data about overall participation in the labour force has been presented extensively in a previous paper. ${ }^{4}$ In further exploring the labour market position of these patients, we studied whether disease duration had an effect on the chance of having a paid job among patients with AS compared with the chance of having a paid job given a patient's age and sex according to reference data from the general population in the working age range. Figure 6.1 shows rate ratios and their $95 \%$ confidence intervals for the relative chance of labour force participation in patients with AS for five year categories of duration of disease. It was found that all of the rate ratios were significantly reduced, which implies that the probability of participating in the labour market was reduced in patients with a relatively short disease duration as well as in patient with long disease duration. Moreover, rate ratios of patients with longer disease duration did not differ significantly from patients with short disease duration-that is, having the disease influences the probability of holding a paid job, but the duration of the disease has no additional influence.

Figure 6.I Relation between labour force participation (LFP) and ouration of disease among patients with AS, standardised for age and sex and expressed as rate ratios

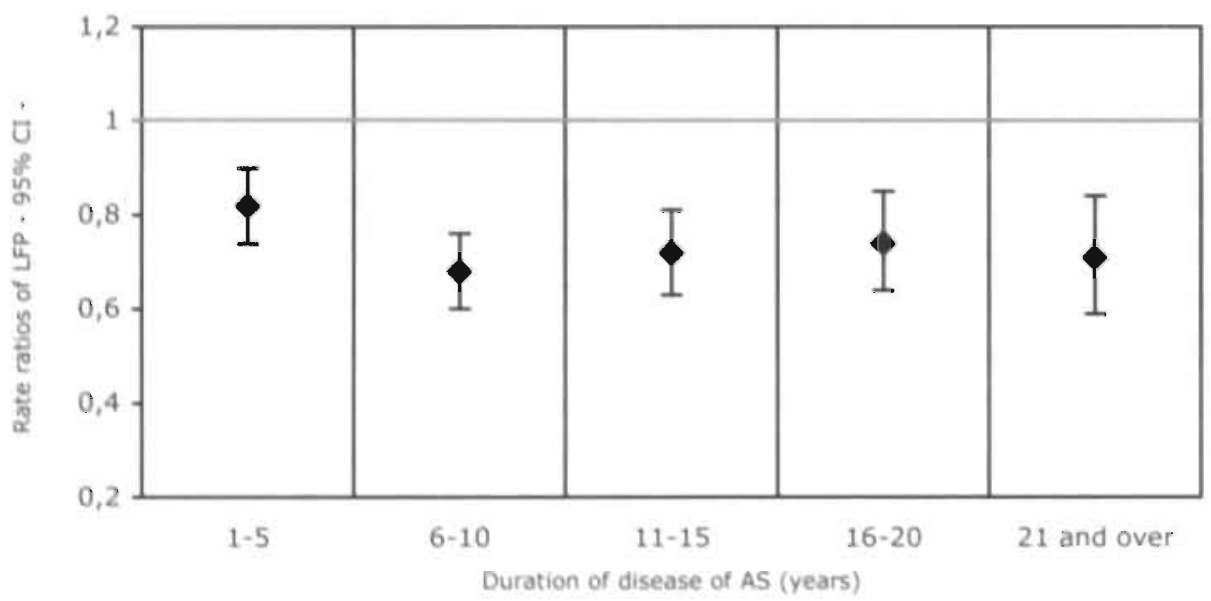


Of the total study group of 658 patients, 81 (12.3\%) had either stopped working before diagnosis $(n=41$ patients $(6.2 \%))$, or had no work history at all $(n=27$ patients $(4.1 \%))$, or had an unknown work history ( $n=13$ patients $(2.0 \%)$ ), whereas 577 patients $(87.7 \%)$ held a paid job, at least temporarily, at some time after being diagnosed with AS. Work history of the total study group has previously been described in more detail.?

For studying determinants of withdrawal from the labour force, we restricted our study group to those 577 patients with a paid job sometime after diagnosis. Of these patients, $156(27.0 \%)$ had withdrawn from the labour force after a mean disease duration of 6.3 years; $94.9 \%$ of these patients indicated that they stopped working for medical reasons. Most cited AS related reasons for withdrawal were physical limitations $(86.1 \%$ of the patients withdrawn due to AS) and being fatigued at work $(77.4 \%$ of the patients withdrawn due to AS). Only $3.2 \%$ of the withdrawals had stopped working because of retirement. Table 6.1 presents patient characteristics, disease status, and outcome of the group of patients that stopped working at any time after being diagnosed with AS compared with the group that was working at the time of assessment.

On the basis of univariate comparisons, it was found that, on average, patients with AS who were younger, male, or more highly educated were more likely to be employed at the time of assessment, a trend similar to that in the general population in the same working age range. Patients who had withdrawn from the labour force had significantly longer disease duration, showed higher disease activity, experienced more disabilities in daily life and used more medication, and more often had total hip replacement. In general, the group of patients who had withdrawn had different coping strategies and experienced less favourable global wellbeing compared with patients who were still in employment.

More than three quarters of the patients who had withdrawn from the labour force had been officially recognised as work disabled as to some extent, as they received income compensation in the form of a work disablement benefit. In the Dutch social security system, employees who are on full or partial sick leave for more than one year are entitled to a work disablement benefit after work disability has been officially recognised on the basis of a medical and ergonomic examination. This pension provides income compensation up to a maximum of $70 \%$ of the last income earned, for a maximum period of five years. At the end of that period, the person's ability to work has to be reassessed. The level of compensation is dependent on age, number of years worked, and levels of work disablement. People whose ability to work is impaired by $80-100 \%$ are entitled to full work disablement benefit. People whose ability to work is impaired by $15-80 \%$ are entitled to partial work disablement benefit. In the Netherlands, it is therefore possible to receive work disablement benefit and to remain in employment, usually on a part time basis. In 
our study population, $18.3 \%$ of the patients with a paid job had been officially recognised as having a work disablement.

Table 6.1 Patient characteristics and disease status and outcome of patients with AS withdrawn from the labour force any time after diagnosis compared with patients with a paid job. at assessment

\begin{tabular}{|c|c|c|c|c|c|}
\hline \multirow{2}{*}{$\begin{array}{l}\text { Patient characteristics } \\
\text { Age (years), mean (SE) }\end{array}$} & \multicolumn{2}{|c|}{$\begin{array}{l}\text { AS patients } \\
\text { withdrawn from } \\
\text { the labour force } \\
\text { after diagnosis } \\
(n=156)\end{array}$} & \multicolumn{2}{|c|}{$\begin{array}{l}\text { AS patients with } \\
\text { a paid job at } \\
\text { assessment } \\
(n=421)\end{array}$} & \multirow[t]{2}{*}{$\begin{array}{l}\text { P Value* } \\
<0.001\end{array}$} \\
\hline & 46.6 & $(0.7)$ & 42.3 & $(0.4)$ & \\
\hline Men, \% & 66.7 & & 77.4 & & 0.008 \\
\hline High vocational colleges/University, $\%$ & 9.6 & & 25.2 & & $<0.001$ \\
\hline Age at time of diagnosis (years), mean (SE) & 31.8 & $(0.8)$ & 30.6 & (0.4) & 0.163 \\
\hline Disease duration (vears), mean (SE) & 14.8 & $(0.7)$ & 11.8 & $(0.4)$ & $<0.001$ \\
\hline Disease activity (BASDAI a, 0-10), mean (SE) & 5.1 & $(0.2)$ & 3.3 & $(0.1)$ & $<0.001$ \\
\hline Disability score (BASFIs, 0-10), mean (SE) & 5.3 & $(0.2)$ & 2.9 & (0.1) & $<0.001$ \\
\hline Total hip replacement, $\%$ & 7.7 & & 2.9 & & 0.010 \\
\hline \multicolumn{6}{|l|}{ Medication use at time of assessment, $\%$} \\
\hline Pain medication other than NSAIDw & 32.1 & & 20.0 & & 0.002 \\
\hline NSAID & 73.7 & & 70.8 & & 0.488 \\
\hline DMARD $r$ & 12.2 & & 7.8 & & 0.106 \\
\hline Other non-specified & 7.7 & & 4.5 & & 0.133 \\
\hline \multicolumn{6}{|l|}{ Coping with pain, mean (SE) } \\
\hline Comforting cognition (9-36) & 26.3 & $(0.4)$ & 27.1 & $(0.2)$ & 0.049 \\
\hline Decreasing activity (8-31) & 21.4 & $(0.3)$ & 16.8 & $(0.2)$ & $<0.001$ \\
\hline Diverting attention (8-30) & 18.4 & $(0.4)$ & 17.4 & $(0.2)$ & 0.012 \\
\hline \multicolumn{6}{|l|}{ Coping with limitations, mean (SE) } \\
\hline Optimism (5-20) & 14.7 & $(0.2)$ & 14.9 & $(0.2)$ & 0.432 \\
\hline Pacing $(10-40)$ & 29.6 & $(0.4)$ & 23.5 & (0.3) & $<0.001$ \\
\hline Creative solutions (8-32) & 21.4 & $(0.4)$ & 19.1 & (0.2) & $<0.001$ \\
\hline \multicolumn{6}{|l|}{ Coping with dependency, mean (SE) } \\
\hline Accepting $(6-24)$ & 13.8. & $(0.3)$ & 12.7 & $(0.2)$ & 0.002 \\
\hline Consideration $(7-28)$ & 19.5. & $(0.3)$ & 18.6 & $(0.2)$ & 0.015 \\
\hline Global well-being (BASG\&, 0-10), mean (SE) & 5.8 & $(0.2)$ & 3.6 & $(0.1)$ & $<0.001$ \\
\hline \multirow{2}{*}{\multicolumn{6}{|c|}{$\begin{array}{l}\text { Work disablement pension (Officially } \\
\text { recognised). } \%\end{array}$}} \\
\hline & 63.5 & & NA & & \\
\hline $15-80 \%$ & 13.5 & & 18.3 & & 0.170 \\
\hline
\end{tabular}

* Differences in proportions tested by $\chi^{2}$ test; group means tested by Student's $t$ test; \# BASDAI, Bath ankylosing spondylitis disease activity index; \$ BASFI, Bath ankylosing spondylitis functional index; $\psi$ NSAID, non-specific anti-inflammatory drugs; 1 DMARD, disease modifying anti-rheumatic drugs; \& BASG, Bath ankylosing spondylitis global index; NA, not applicable.

The associations between various employment factors and withdrawa! from the labour force are presented in table 6.2. Patients with AS who had withdrawn from the labour force were more often active in the industrial sector and less active as professionals (for example, physicians, teachers, and policy makers) than currently employed patients. 
Fewer patients who had withdrawn were specially trained for their last job position, fewer of them had followed any job training at all, and more of them had performed a physically demanding job at some time during their working career. Patients who were still in employment worked more often in larger companies and more often had technical or ergonomic work adjustments.

Patients who had withdrawn from the labour force reported difficult access to the workplace and reduced transport mobility at the workplace more often than currently employed patients. With respect to the social environmental factors at the workplace, patients who had withdrawn were much more dependent on their colleagues. Compared with patients still in employment, they also thought more often that attitudes of colleagues and management were negative and that there was insufficient support from both colleagues and management.

Table 6.2 Work related factors of AS patients withdrawn from the labour force any time after diagnosis compared with AS patients. with a paid job at assessment

\begin{tabular}{|c|c|c|c|}
\hline Work related factors & $\begin{array}{l}\% \text { of AS patients } \\
\text { withdrawn from } \\
\text { the labour force } \\
\text { after diagnosis } \\
(n=156)\end{array}$ & $\begin{array}{l}\% \text { of AS patients } \\
\text { still hoiding a paid } \\
\text { job at assessment } \\
(n=421)\end{array}$ & p Value* \\
\hline \multicolumn{4}{|l|}{ Job characteristics } \\
\hline \multicolumn{4}{|l|}{ Field of activity } \\
\hline Administrative & 17.3 & 18.5 & 0.736 \\
\hline Transport & 7.1 & 5.2 & 0.402 \\
\hline Marketing and sales & 12.8 & 12.6 & 0.941 \\
\hline Service & 14.7 & 14.3 & 0.881 \\
\hline Industrial & 35.2 & 25.2 & 0.006 \\
\hline Professionals & 12.2 & 24.0 & 0.022 \\
\hline Part time job & 21.6 & 27.6 & 0.154 \\
\hline Special training for the present/last job position & 46.2 & 55.6 & 0.044 \\
\hline Additional job training after diagnosis & 50.0 & 67.0 & $<0.001$ \\
\hline Changed field of activity after diagnosis & 49.4 & 55.5 & 0.189 \\
\hline AS influenced choice on last/present job position & 25.6 & 30.6 & 0.241 \\
\hline Executive job position & 30.1 & 34.9 & 0.279 \\
\hline Ever performed a physically demanding job & 69.2 & 55.1 & 0.002 \\
\hline Ever performed a mentally demanding job & 51.9 & 57.7 & 0.213 \\
\hline Size of company ( $<100$ employees) & 68.2 & 48.9 & $<0.001$ \\
\hline \multicolumn{4}{|l|}{ Work adjustments } \\
\hline Adjusted working hours & 17.9 & 20.4 & 0.507 \\
\hline Adjusted job demands & 13.5 & 14.3 & $0.80 \theta$ \\
\hline Technical/ergonomic adjustments & 8.3 & 17.6 & 0.006 \\
\hline \multicolumn{4}{|l|}{ Physical and social environmental factors } \\
\hline Difficult access to work place & 13.7 & 3.3 & $<0.001$ \\
\hline Reduced transportation mobility at the work place & 14.1 & 2.4 & $<0.001$ \\
\hline Colleagues informed on AS & 69.2 & 76.0 & 0.098 \\
\hline Dependent on colleagues & 49.4 & 23.5 & $<0.001$ \\
\hline Negative attitude of colleagues towards patient & 24.4 & 7.6 & $<0.001$ \\
\hline Negative attitude of management towards patient & 17.3 & 3.6 & $<0.001$ \\
\hline Insufficient support colleagues or management & 41.0 & 12.8 & $<0.001$ \\
\hline
\end{tabular}

- Differences in proportions tested by $x^{2}$ test 
Table 6.3 lists the results of the stepwise forward logistic regression for the combined effect of sociodemographic and disease related factors and work related factors. Because functional ability, use of medication, and global wellbeing were highly correlated with disease activity, and field of activity correlated highly with educational level ( $r>0.6)$, we chose to enter only the variables for disease activity and educational level into the models to prevent colinearity.

Table 6.3 Importance of risk factors for early withdrawal from the labour force among patients with AS: attributable (AF) and preventable fractions (PF)E

\begin{tabular}{|c|c|c|c|c|c|c|}
\hline Factor & exposed $v$ non-exposed* & aOR & $\begin{array}{l}\text { Proportion } \\
\text { of AS } \\
\text { patients } \\
\text { withdrawn } \\
\text { exposed } \\
\text { to the } \\
\text { factor }\end{array}$ & AF & $\begin{array}{l}\text { Proportion } \\
\text { of AS } \\
\text { patients } \\
\text { withdrawn } \\
\text { not } \\
\text { exposed to } \\
\text { the factor }\end{array}$ & PF \\
\hline \multicolumn{7}{|l|}{ Coping with limitations: } \\
\hline pacing & (very) often v sometimes/never & 6.3 & 0.87 & $73 \%$ & & \\
\hline $\begin{array}{l}\text { Support of colleagues/ } \\
\text { management }\end{array}$ & insufficient $v$ sufficent & 3.4 & 0.41 & $29 \%$ & & \\
\hline $\begin{array}{l}\text { Transportation mobility } \\
\text { at the workplace }\end{array}$ & reduced $v$ not reduced & 4.1 & 0.14 & $11 \%$ & & \\
\hline $\begin{array}{l}\text { Technical/ergonomic } \\
\text { adjustments }\end{array}$ & yes $v$ no & 0.2 & & & 0.92 & $73 \%$ \\
\hline Disease activity & BASDAI5 $>3.7 v<3.7$ & 1.8 & 0.71 & $32 \%$ & & \\
\hline Attitude management & negative $\mathrm{v}$ normal/positive & 5.3 & 0.17 & $14 \%$ & & \\
\hline $\begin{array}{l}\text { Additional job training } \\
\text { after diagnosis }\end{array}$ & yes $v$ no & 0.5 & & & 0.50 & $25 \%$ \\
\hline \multicolumn{7}{|l|}{ Coping with limitations: } \\
\hline creative solutions & (very) often $v$ sometimes/never & 2.1 & 0.68 & $36 \%$ & rat & \\
\hline Size of company & $2100 v<100$ employees & 0.5 & & & 0.68 & $34 \%$ \\
\hline Age & $245 v<45$ years & 2.0 & 0.63 & $32 \%$ & & 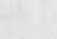 \\
\hline \multicolumn{7}{|l|}{ Coping with dependency: } \\
\hline accepting & (very) often $v$ sometimes/never & 0.5 & & & 0.64 & $32 \%$ \\
\hline Access to workplace & difficult $v$ not difficult & 2.7 & 0.14 & $9 \%$ & & \\
\hline \multicolumn{7}{|l|}{ Coping with pain: } \\
\hline decreasing activity & (very) often v sometimes/never & 1.6 & 0.65 & $24 \%$ & & \\
\hline Disease duration & $\geq 11.5 v<11.5$ years & 1.5 & 0.55 & $18 \%$ & & \\
\hline \multicolumn{7}{|l|}{ Coping with pain: } \\
\hline comforting cognition & (very) often $v$ sometimes/never & 0.6 & & & 0.19 & $8 \%$ \\
\hline
\end{tabular}

E. If a factor is positively associated with withdrawal from the labour force the proportion of AS patients withdrawn from the labour force exposed to that factor and the attributable fraction is pressented, if a factor is negatively associated then the proportion of AS patients withdrawn from the labour force not exposed to that factor and the preventable fraction is presented. " Variables are listed in order of their entry into the regresșion; \$ BASDAI, Bath ankyloșing spondylitis disease activity index; $\uparrow$ aOR, adjusted Odds Ratio (controlled for all variables in the table presented) 
Variables listed in table 6.3 were entered into the final regression model in sequence as presented. The following variables, which were significant by univariate analysis, were excluded during the forward stepwise procedure: sex, educational level, diverting attention in order to cope with pain, special training for the last job position, and performed a physically high demanding job at some time during working career. Overall, the model shows that coping styles and disease related, sociodemographic and work-related factors contribute substantially to withdrawal from the labour force.

When the proportion of patients who had withdrawn from the labour force was calculated in terms of each factor, it ernerged that pacing in order to cope with limitations accounted for $73 \%$ of the withdrawals from the labour force. On the other hand, it was found that $73 \%$ of the withdrawals could still have been employed if technical or ergonomic adjustments of the workplace had been arranged. Other important factors increasing the risk were often/very often seeking of creative solutions to cope with limitations ( $36 \%$ ), a high disease activity (32\%), older age (32\%) and insufficient support from colleagues or management $(29 \%)$. Other important factors, which reduced the risk, were working in a large company (34\%) and frequent/very frequent acceptance to cope with dependency $(32 \%)$.

In subsample analyses of patients who had withdrawn from the labour force within five years before the study and of patients with five or fewer years of disease, the same factors were identified. The following variables were stronger in the subsample of patients with five or fewer years of disease compared with patients in the full sample or in the subsample of patients withdrawn within five years before the study: pacing to cope with limitations, dișease activity, attitude of the management, and access to workplace.

\section{Discussion}

Despite the fact that the overall participation in the labour force of the patients with AS under study was lower compared to the general population, ${ }^{4}$ the present study indicates that the probability of participating in the Dutch labour force is already reduced in patients with AS with relatively short disease duration, and participation in the labour force is not additionally influenced by duration of disease. By contrast with our study, most other reports on participation in the labour force and disease duration among patients with AS deal with groups with a work history, and found employment rates which still ranged from $79 \%$ to $85 \%$ after 20 years of AS, and from $53 \%$ to $81 \%$ after 30 years of AS.20-22 Our study also considered patients without a work history and controlled for the common risk 
factors of participation in the labour force: age and sex. Therefore, our results give a deeper understanding of the position in the labour market of patients with AS among the general working population in relation to their duration of disease.

We report that sociodemographic factors, coping styles, disease related factors, and various work related factors substantially contribute to withdrawal from the labour force in patients with AS. In a previous study we already identified coping as an important factor related to work among patients with AS. ${ }^{7}$ In this study, we further explored behavioural coping simultaneously with other factors. Pacing to cope with limitations-that is, adapting the level of activity indicated by "I take more time for my activities", "I stop doing my activities in time", or "I take full account of my limitations" was the major positively correlated factor. This implies that a passive way of coping with the limitations is associated with withdrawing the labour force. Moreover, we found that five of the eight different coping styles assessed in this study significantly contributed to withdrawal from the labour force. With the exception of our previous study, we know of no earlier study that has covered the effect of behavioural coping in relation to employment in patients with AS. A recent study by Barlow et al. investigated cognitive coping in relation to work in patients with AS." In fact, for patients with rheumatic diseases in general, only a few studies have examined the independent effect of behavioural coping on outcome of illness, and only two studies in rheumatoid arthritis found that patients use behavioural coping strategies when dealing with problems at work. ${ }^{23-26}$ Earlier studies indicated that patients with AS use adaptive coping mechanisms to cope with stressful situations and that these patients were comparable with patients with other rheumatic diseases in the use of active or passive coping mechanisms. ${ }^{27.28}$ Therefore, our findings in patients with AS stresses the importance of behavioural coping in relation to employment in patients with rheumatic diseases in general and in patients with AS in particular.

The major employment factor negatively associated with withdrawal from the labour force was. technical or ergonomic adjustment of the workplace. One: earlier study by Fellman et al. found that $62 \%$ of patients with AS had pain when working which was induced by a wrong or monotonous posture, long working times, and unfavourable climatic factors at. work. ${ }^{29}$ Guillemin et al, found that exposure to cold conditions and prolonged standing increased the risk of long term work disability: ${ }^{6}$ Yelin et al., on the other hand, found no relation between getting equipment and the improvement of employment status of persons with musculoskeletal conditions. Compared with our study, Yelin et al. found a relatively low frequency of people getting special equipment $(5.3 \%)$ in a relatively old population with various musculoskeletal conditions. ${ }^{30}$ On the basis of those earlier studies. 
and our study, we conclude that the ergonomic and climatic conditions at the workplaces of patients with AS specifically should be analysed at an early stage and adjusted to the needs of these patients to prevent problems at work.

Other major work related factors with negative correlation were working in a large company and additional job training after diagnosis, whereas insufficient support from colleagues or management, reduced transportation mobility at the workplace, difficult access to the workplace, and negative attitude of the management were positively correlated. Only a few of these factors have been previously investigated in a multivariate context among patients with $A S .^{5}$ In line with our finding, vocational counselling and job training had already been identified as a protective factor against long term disability by Guillemin et al. ${ }^{\circ}$

It should be pointed out that our study has some methodological limitations. Data were collected by a self administered questionnaire and we did not validate these data using objective measures. However, the questionnaire included several well validated instruments for assessing disease activity and outcome independently of employment status. ${ }^{10-17}$ So it is not likely that our results were substantially and systematically affected in any direction by differential misclassification; in other words there was no systematic difference in rating of disease activity and outcome between patients who had withdrawn and patients who still had a paid job.

Although data about employment were collected retrospectively, we think that considerable recall bias is less likely, because we found that work related factors were equally important in a subsample of patients who had recently withdrawn from the labour force.

With respect to coping, the cross sectional design of our study does not allow us to state that the explanatory variables have a causal relationship with withdrawal from the labour force. Our study does not rule out the competing explanation that withdrawal from the labour force invokes passive copingl styles such as "pacing" as a way of coping with limitations or that behavioural coping and withdrawal from the labour force is reciprocally interrelated. On the other hand, research on coping in AS found that the coping mechanisms used did not: vary with the duration of AS, ${ }^{1}$ meaning that AS patients may develop a coping style early in the illness and use their favourite strategies to deal with stressful situations. A more longitudinal approach is needed to assess whether the association between coping and withdrawal from the labour force in AS is one of effect rather than cause. 
To provide information on the extent to which withdrawal from the labour force is due to a specific factor, and to estimate potential maximum effect of intervention programmes in the light of these factors, we calculated attributable and preventable fractions. Application of this technique is relatively new in this field of research. It is only found in two other studies in RA patients. ${ }^{24,31}$ Considering our results with respect to, for instance, pacing to cope with limitations (accounting for $73 \%$ of the withdrawals) and disease activity (accounting for $32 \%$ of the withdrawals), it can be calculated that the sum of the fractions exceeds $100 \%$. Despite being aware that any withdrawal from the labour force could be caused or prevented by various factors, there might be a tendency to believe that the sum of these fractions should be $100 \%$. In fact, separate components of the underlying mechanism are not mutually exclusive. Therefore, the upper limit of the total of all fractions of all the components is not $100 \%$ but infinity. Only a fraction of withdrawal from the labour force attributable to or preventable from a single component cannot exceed $100 \%{ }^{19}$ This is also the case in our study.

In summary, our findings show that it is important to consider sociodemographic factors, disease related factors, behavioural coping styles, and work related factors in both research and vocational management of patients with AS. Research on the subject should give more attention to the study of behavioural coping and attitudes towards work depending on the nature and conditions of the work and on the social work environment and their effects on employment. Therefore, we emphasise that developers of intervention programmes dealing with work problems in patients with AS should consider and evaluate the involvement of a multidisciplinary team of professionals with medical, paramedical, psychosocial, and occupational health expertise. Furthermore, we think that cooperation from employers and from colleagues, is important to achieve maximum reduction in early withdrawal from the labour force among these patients. In practice, patients should be encouraged to remain active despite the stressors of their disease. Moreover, patients should be encouraged and guided to recognise and develop their talents, and if possible, should extent their education. In general, companies should be encouraged to promote positive attitudes towards people with disabilities.

\section{Acknowledgements}

For helping to recruit patients we gratefully thank all rheumatologists and their assistants at the following rheumatology centres: Sint Antoniusziekenhuis Nieuwegein, Rode Kruisziekenhuis Den Haag, Bosch Medicentrum Den Bosch, Sint Laurentiusziekenhuis 
Roermond, Sint Jansgasthuis Weert, Groene Hartziekenhuis Gouda, Albert Schweitzerziekenhuis Dordrecht, Kennemer Gasthuis locatie Deo Haarlem, Lievensberg Ziekenhuis Bergen op Zoom, Tweesteden Ziekenhuis Tilburg, Rijnstate Ziekenhuis Arnhem, St. Maartenskliniek Nijmegen, Medisch Spectrum Twente Enschede and Academisch Ziekenhuis Maastricht. We also are thankful to Mr. Cees J Wevers, occupational physician, TNO Work and Employment Hoofddorp for allowing us to use the VHQ. 


\section{References}

1. Ward MM. Quality of life in patients with ankylosing spondylitis. Rheum Dis Clin North Am 1998;24:815-27.

2. Ward MM. Health-related quality of life in ankylosing spondylitis: a survey of 175 patients. Arthritis Care Res 1999;12:247-55.

3. Zink A, Braun J, Listing J, Wollenhaupt J. Disability and handicap in rheumatoid arthritis and ankylosing spondylitis--results from the German rheumatological database. German Collaborative Arthritis Centers. I Rheumatol 2000;27:613-22.

4. Boonen A, Chorus A, Miedema $H$, van der Heijde D, van der Tempel $H$, van der Linden S. Employment, work disability, and work days lost in patients with ankylosing spondylitis: a cross sectional study of Dutch patients. Ann Rheum Dis 2001;60:353-8.

5. Boonen A, de Vet $H$, van Der HD, van Der LS. Work status and its determinants among patients with ankylosing spondylitis. A systematic literature review. J Rheumatol 2001;28:1056-62.

6. Guillemin F, Briancon S, Pourel J, Gaucher A. Long-term disability and prolonged sick leaves as outcome measurements in ankylosing spondylitis. Possible predictive factors. Arthritis Rheum 1990;33:1001-6.

7. Boonen A, Chorus A, Miedema $H$, van Der HD, Landewe R, Schouten $H$ et al. Withdrawal from labour force due to work disability in patients with ankylosing spondylitis. Ann Rheum Dis 2001;60:1033-9.

8. Barlow JH, Wright CC, Williams B, Keat A. Work disability among people with ankylosing spondylitis. Arthritis Rheum 2001;45:424-9.

9. Miedema HS, Linden SM vd, Rasker J], Valkenburg HA. A national database of patients visiting rheumatologists in the Netherlands: The Standard Diagnosis Register of Rheumatic Diseases. A report and preliminary analysis. Br J Rheumatol 1998;37:55561.

10. Calin A, Nakache JP, Gueguen A, Zeidler H, Mielants H, Dougados M. Defining disease activity in ankylosing spondylitis: is a combination of variables (Bath Ankylosing Spondylitis Disease Activity Index) an appropriate instrument? Rheumatology $1999 ; 38: 878-82$.

11. Calin A, Garrett S, Whitelock. H, Kennedy LG, O'Hea J, Mallorie P et al. A new approach to defining functional ability in ankylosing spondylitis: the development of the Bath Ankylosing Spondylitis Functional Index. J Rheumatol 1994;21:2281-5. 
12. Andries F, Wevers CW, Wintzen AR, Busch HF, Howeler CJ, de Jager AE et al. Vocational perspectives and neuromuscular disorders. Int J Rehabil Res 1997;20:25573.

13. Wevers CW, Brouwer OF, Padberg GW, Nijboer ID. Job perspectives in facioscapulohumeral muscular dystrophy. Disabil Rehabil 1993;15:24-8.

14. Nijboer ID, Wevers C]. Vocational rehabilitation of young adults with a disability of one arm or hand. Int J Rehabil Res 1993;16:45-7.

15. Van Lankveld W, van 't Pad Bosch P, van de Putte L, Naring G, van der Staak C. Disease-specific stressors in rheumatoid arthritis: coping and well-being. $\mathrm{Br} J$ Rheumatol 1994;33:1067-73.

16. Van Lankveld W, Naring G, van der Staak C, van 't Pad Bosch P, van de Putte L. Stress caused by rheumatoid arthritis: relation among subjective stressors of the disease, disease status, and well-being. J Behav Med 1993;16:309-21.

17. Jones SD, Steiner A, Garrett SL, Calin A. The Bath Ankylosing Spondylitis Patient Global Score (BAS-G). Br J Rheurnatol 1996;35:66-71.

18. Statistics Netherlands. (CBS). Survey of general population in the working age 1997. The Hague: Statistics Netherlands, 1998.

19. Rothman KJ, Greenland S. Modern Epidemiology. Second ed. Philadelphia: LippincottRaven Publishers, 2000.

20. Ringsdal VS, Helin P. Ankylosing spondylitis--education, employment and invalidity. Dan Med Bull 1991;38:282-4.

21. Lehtinen K. Working ability of 76 patients with ankylosing spondylitis. Scand J Rheumatol 1981;10:263-5.

22. McGuigan LE, Hart HH, Gow PJ, Kidd BL, Grigor RR, Moore TE. Employment in ankylosing spondylitis. Ann Rheum Dis 1984;43:604-6.

23. Blalock SJ, DeVellis. BM, Holt K, Hahn PM. Coping with rheumatoid arthritis: is one problem the same as another? Health Educ Q 1993;20:119-32.

24. Chorus AM, Miedema HS, Wevers CW, van der Linden S1. Work factors and behavioural coping in relation to withdrawal from the labour force in patients with rheumatoid arthritis. Ann Rheum Dis 2001;60:1025-32.

25. Harter M. [Psychosomatic aspects of rheumatic diseases]. Psychother Psychosom Med Psychol 1993;43:100-9.

26. Basler HD, Rehfisch HP. Cognitive-behavioral therapy in patients with ankylosing spondylitis in a German self-help organization. J Psychosom Res 1991;35:345-54.

27. Gunther V, Mur E, Traweger C, Hawel R. Stress coping of patients with ankylosing spondylitis. J Psychosom Res 1994;38:419-27. 
28. Mengshoel AM, Forre O. Pain and fatigue in patients with rheumatic disorders. Clin Rheumatol 1993;12:515-21.

29. Fellmann J, Kissling R, Baumberger $H$. [Socio-professional aspects of ankylosing spondylitis in Switzerland] Sozio-professionelle Aspekte der Spondylitis ankylosans in der Schweiz. Z Rheumatol 1996;55:105-13.

30. Yelin E, Sonneborn D, Trupin L. The prevalence and impact of accomodations on the employment of persons 51-61 years of age with musculoskeletal conditions. Arthritis Care Res 2000;13:168-76.

31. Allaire SH, Anderson JJ, Meenan RF. Reducing work disability associated with rheumatoid arthritis: identification of additional risk factors and persons likely to benefit from intervention. Arthritis Care Res 1996;9:349-57. 
Labour force participation, career related problems, and job handicaps in adults with juvenile chronic arthritis 


\section{Abstract}

\section{Objectives}

To assess labour force participation, career related problems and job handicaps in young adults with juvenile chronic arthritis (JCA).

\section{Methods}

A random sample of 104 patients with JCA from 17 rheumatology practices was examined. They were aged 16-35 years and had a mean duration of disease of 14 years. The response rate was $50 \%$. Data on sociodemographics, disease status, labour force participation, career related issues and job handicaps were obtained with a selfadministered questionnaire. Labour force participation (defined as having a paid job at the time of the study) of patients with JCA was compared with reference data from the general population. A comparison was also made of career related issues and job handicaps between employed patients and patients who had withdrawn from the labour force.

\section{Resuits}

Labour force participation was $37 \%$ down in male patients and $25 \%$ down in female patients compared to peers in the genera! population. Moreover, female patients were significantly more dependent on work disability pensions. Two-thirds of the study group reported problems with school education. Among patients who had withdrawn from the labour force, insufficient support from colleagues and their managers, an exacerbation of symptoms due to working, and problems with mobility activities and with hand or arm movements at the workplace were more common.

\section{Conclusions}

Labour market position of adult patients with JCA was poorer than that of their peers in the general population. Work disability is an important problem, and reported careerrelated problems and job handicaps may be important factors to consider in career counselling in JCA. 


\section{Introduction}

Juvenile chronic arthritis is a collective term for a number of distinct childhood arthritides with unknown aetiology. Prognostic indicators for JCA are type of arthritis (pauciarticular, polyarticular of systemic onset), rheumatoid factor (RF) status, the course of disease, and the response to, and side-effects of, the treatment. The majority of children with JCA achieve permanent remission and therefore have no active symptomatology in the adult years. ${ }^{2}$ However, the effects of the disease may cause long-term disability. Suffering from JCA is a stressful life event and causes further undesirable events such as frequent absence from school. ${ }^{2}$ Furthermore, uncorrected flexion contractures, growth retardation, bone deformity, limb length discrepancies, visual impairment, and developmental delay may cause a lifetime of functional impairment. Peterson et al, concluded that adults who have had JCA during childhood experience long-term physical and psychosocial impairment. ${ }^{3}$

Employment prospects are a major concern for patients and their parents. Paid employment is important in daily life, not only in terms of earnings and social status, but because of the associated social support and social distraction. ${ }^{4}$ Only a few studies have shown that adults with a history of JCA appear to be employed at rates close to peers without illness. ${ }^{5.7}$ Many employed individuals reported difficulties doing their jobs, and $21 \%$ had resigned from a job due to $\mathrm{JCA}^{8}{ }^{8}$ but less is known about restricting and facilitating factors for labour force participation. Such information could contribute to the improvement of vocational counselling and the employment perspectives of patients with JCA. The purpose of this study was therefore to examine labour force participation, careerrelated problems and job handicaps in young adults with JCA.

\section{Methods}

\section{Sample selection}

The source population was taken from the nationwide Standardised Diagnosis Register of Rheumatic Diseases (SDR), a representative database of outpatients visiting a rheumatologist. ${ }^{9}$ The SDR database contains information about the patient population of $80 \%$ of all rheumatologists working in the Netherlands. Diagnoses of visiting patients are recorded annually in the SDR by rheumatologists. An annual average of 400 patients diagnosed with JCA are registered using the EULAR guidelines. ${ }^{10}$ The mean age of this patient group is 25 years, reflecting that it is mostly adolescents and adults with (childhood-onset) JCA, and not children, who visit rheumatologists. In the Netherlands, 
children up to the age of 16 with inflammatory rheumatic disease mostly visit paediatricians, some of whom have specialised in rheumatology. These specialists do not contribute to the SDR.

This study included a geographically representative sample of 35 rheumatologists who participate in the SDR ( $37 \%$ of all SDR rheumatologists), working in 17 practices ( $52 \%$ of all SDR practices) throughout the Netherlands. In 1996, we selected from these practices all 207 patients with JCA aged 16-35 years ( 79 men, 128 women) who had been registered in 1994. Of these patients, $59 \%$ had pauciarticular JCA, 28\% polyarticular JCA and systemic onset of disease was recorded for the remaining $13 \%$.

\section{Questionnaire}

All patients were invited to participate in the study by their own rheumatologists. After informed consent had been obtained, the participants received a postal self-administered questionnaire covering sociodemographics, disease related characteristics, and workrelated items. The sociodemographic variables were age, sex, highest attained level of education, current work status and dependency on social security. The disease-related variables were age at diagnosis, disease activity with the self administrated RADAI, ${ }^{11,12}$ functional status with use of the HAQ, ${ }^{13}$ comorbidity, and visits to a rheumatologist in the past year. The work related characteristics were labour force participation, career related problems, and job handicaps assessed with the Dutch Vocational Handicap questionnaire. ${ }^{14}$ Labour force participation was defined as having a paid job at the time of the study. Career related problems were assessed using various questions, such as experiencing problems during education, feeling restricted in the choice of a job, being excluded from a job, resigned from a job due to the disease, and not being promoted. Job handicaps were measured on the basis of job demands, and patients' abilities, as well as adjustments, at work, on the basis of 5 domains: mobility ( 7 items), communication ( 3 items), menta! abilities ( 3 items), hand/arm movements ( 3 items), and physical strength ( 3 items).

\section{Data analysis}

To assess possible selection bias, non-response analysis was performed for age, sex, and type of disease onset using analysis of variance and chi-square tests. Labour force participation and other socio-economic characteristics of patients with JCA were studied for men and women, and compared with reference data of peers from the general population. ${ }^{15}$ For career related problems, chi-square analysis was used to compare patients in employment at the time of the study and patients who had withdrawn from the labour force. For job handicaps and adjustments at work, we performed analysis of 
variance and chi-square tests comparing employed patients and patients who had withdrawn from the labour force. The level of significance was set at ps0.05.

\section{Results}

Of the 207 patients, 139 agreed to participate and 104 returned a completed questionnaire. This resulted in an overall response rate of $50 \%$. Non-response analysis comparing participants and non-participants showed a few differences (table 7.1). The response rate of women was significantly higher than for men (76 (59\%) of the 128 women and 28 (35\%) of the 79 men in the sample). In addition, the participants included significantly more patients with systemic disease onset and significantly fewer patients with polyarticular JCA compared to non-participants.

Table 7.1 Comparison between participating and non-participating patients with JCA

\begin{tabular}{|lcc|}
\hline Characteristics & Participants $(n=104)$ & Non-participants $(n=103)$ \\
\hline Age at time of study (years), mean (SD) & $24.1 \quad(5.1)$ & $23.9(4.9)$ \\
Sex*, $\%$ women & 73.1 & 50.5 \\
Type of disease onset*, $\%$ & & 59.2 \\
pauciarticular & 58.7 & 35.0 \\
polyarticular & 21.2 & 5.8 \\
systemic & 20.2 & \\
\hline
\end{tabular}

* statistically significant differences between participants and non-participants ( $p \leq 0.05$ )

The majority of our study population consisted of women $(n=76 ; 73.1 \%)$. The disease characteristics of male and female patients are listed in table 7.2.

Men reported higher age at diagnosis and shorter disease duration than women. Although. men had a significantly lower mean HAQ score than women, on average both groups of patients were able to perform daily activities without problems or with only minor problems. Women reported using aids more often than men. No significant difference was found between the sexes for comorbid conditions. The most reported comorbid condition was osteoarthritis. 
Table 7.2 Disease related characteristics of patients with JCA currently between 16-35 years of age

\begin{tabular}{|lrr|}
\hline Disease related characteristics & Men $(n=28)$ & Women $(n=76)$ \\
\hline Age at time of study (years), mean (SD) & $22.5(4.6)$ & $24.7 \quad(5.1)$ \\
Age at diagnosis* (years), mean (SD) & $11.6(4.7)$ & $9.2(5.4)$ \\
Disease duration* (years), mean(SD) & $10.6(6.0)$ & $15.5(7.3)$ \\
Disease activity (RADAI, range 0-10), mean (SD) & $3.6(2.8)$ & $3.9(2.1)$ \\
Activities of daily living* (HAQ range 0-3), mean (SD) & $0.4(0.7)$ & $0.9(0.8)$ \\
Use of assistive devices* (one or more), \% & 42.9 & 38.4 \\
Comorbidity (one or more comorbid conditions), \% & 25.0 & 34.2 \\
Under treatment of rheumatologist past year, * & 92.6 & 93.4 \\
\hline
\end{tabular}

* statistically significant differences between men and women ( $p \leq 0.05)$

\section{Socioeconomic characteristics}

Since socioeconomic characteristics correlate highly to gender, we present sex-specific figures for patients with JCA and of peers in the general population (table 7.3). It was found that employment was significantly lower in patients with JCA compared to peers in the general population, being only $43 \%$ in male patients and $40 \%$ in female patients compared to $68 \%$ and $52 \%$ respectively. This is a relative reduction of $37 \%$ in male patients and $25 \%$ in female patients. Of the patients currently without employment, $56 \%$ of the men and $46 \%$ of the women had withdrawn from the labour force. Most of the patients without working experience were still receiving training (in men $71 \%$ and in women $54 \%$ ). In our population, work disability was officially recognised in $7 \%$ of the male patients and $24 \%$ of the female patients. Compared to peers in the general population, female patients received work disability pensions almost eight times more often. Male patients received pensions almost three times more often.

Table 7.3 Socioeconomic characteriștics of patients with JCA aged 16-35 years in comparison with reference data of peers from the general population

\begin{tabular}{|c|c|c|c|c|}
\hline \multirow[b]{2}{*}{ Socioeconomic characteristics } & \multicolumn{2}{|c|}{ JCA population $(n=104)$} & \multicolumn{2}{|c|}{$\begin{array}{l}\text { Reference data of } \\
\text { peers in the general } \\
\text { population }\end{array}$} \\
\hline & $\begin{array}{l}\% \text { Men }(95 \% \mathrm{Cl}) \\
(\mathrm{n}=28)\end{array}$ & $\begin{array}{l}\% \text { Women }(95 \% \mathrm{CI}) \\
(\mathrm{n}=76)\end{array}$ & $\%$ Men & $\%$ Women \\
\hline $\begin{array}{l}\text { Completed a high vocational college } \\
\text { or university training }\end{array}$ & $10.7(0.0$ to 22.5$)$ & $18.3(9.8$ to 27.0$)$ & 17.7 & 17.4 \\
\hline Receiving a training at time of study & 17.9 (3.4 to 32.4$)$ & $17.1 \quad(8.7$ to 25.5$)$ & 22.7 & 22.6 \\
\hline Employed & $42.9(24.4$ to 61.6$)$ & $39.5 \quad(29.6$ to 48.4$)$ & 67.8 & 52.4 \\
\hline Receiving a work disability pension & $7.0(0.0$ to 22.5$)$ & 23.7 (14.1 to 33.3$)$ & 2.4 & 3.0 \\
\hline
\end{tabular}




\section{Career related problems}

Of the total study population, 66 JCA patients (64\%) reported problems during their educational training as a consequence of their disease. The reasons stated most often were inability to participate optimally in school programs because of pain and a lack of energy ( $36 \%)$, falling behind due to hospitalisation and treatment (35\%), and mobility problems at school such as climbing stairs and moving long distances from one classroom to another $(20 \%)$. There were no significant differences between male and female patients.

In the JCA patients with employment experience ( $n=72 ; 69 \%$ of total sample), we did not find any significant differences between patients currently employed $(n=48)$ and patients who had withdrawn $(n=24)$ in terms of age, sex, education, experiencing problems during school education and problems while searching for jobs. When applying for a job, $43 \%$ of the patients currently employed said they had held back information about their disease, compared to $25 \%$ of the patients who had withdrawn from the labour force ( $p \leq 0.05$ ). Patients who had withdrawn from the labour force perceived significantly less support from their colleagues and significantly less support from managers compared to patients still employed ( $25 \%$ vs. $3 \%$ and $29 \%$ vs. $3 \%$, respectively). Moreover, patients who had withdrawn from the labour force reported significantly more often that disease activity worsened because of job performance compared to currently employed patients ( $43 \%$ vs. $10 \%$, respectively). The main stated reasons for stopping work were that a temporary contract was not followed by a new contract, that no job adjustments were made and that they were too disabled physically to do their jobs adequately.

\section{Job handicaps}

Patients, who had withdrawn from the labour force reported a mean of 6.2 problems with mobility at work out of 7 potential problems. By comparison, the mean number of problems among patients in employment was 3.5 ( $p \leq 0.05$ ). Patients who had withdrawn from the labour force also reported significantly more problems with hand or arm movements during their work (2.7 problems. out of 3 potentiali problems compared to 1.7 ). No significant differences were found for the other domains relating to work handicaps. We did not find any significant differences for specific adjustments at work between employed patients and patients who stopped working ( $29 \%$ versus $23 \%$, respectively). Of the patients who had to stop working, $17 \%$ said specific adjustments would have been appreciated to prevent or postpone their resignation. The most important of these adjustments were greater flexibility in working hours, the adaptation of working hours during the day or the reduction of total working hours. 


\section{Discussion}

Despite comparable levels of educational achievement, labour force participation by young adults with JCA in the Netherlands was lower than by peers in the general population. In male patients, we found a relative reduction of $37 \%$. The reduction for female patients was $25 \%$. Work disability was often officially recognised as a problem, given the fact that the rate of work disability pensions was almost three times higher in men and eight times in women. The literature provides limited information about the long-term social outcome of JCA patients in adulthood. In general, it is stated that social outcome in adulthood of JCA patients is comparable to peers without illness. ${ }^{5}$ Only one earlier study by Peterson et al. reported that JCA patients had lower employment rates, ${ }^{3}$ which is in line with our findings. Moreover, our study also identified career-related problems and job handicaps among these patients. Important career-related problems were a lack of support from colleagues and management and the interaction between disease activity and work performance. Important job handicaps were mobility problems, such as moving from one place to another at the workplace, and arm/hand movements. Although our study did not find direct support for any further need for job adjustrnents to reduce job handicaps, some indications were found that adequate adjustments would have contributed to postponing or preventing early withdrawal from the labour force.

Our findings should be interpreted in the light of our study limitations. First, we relied on data from the nation-wide Standardised Diagnosis Register of Rheumatic Diseases for the diagnosis of JCA. In order to be recorded in the database, a condition must be diagnosed by a rheumatologist, and recorded accurately. In the Netherlands, approximately 1,000 JCA patients with a mean age of 25 years are treated by a rheumatologist. This is $20 \%$ of the total JCA population in the Netherlands. ${ }^{9}$ It is reasonable to assume that patients treated by a rheumatologist have worse disease and outcome than patients not treated by a rheumatologist. Our findings are not fully representative for the total JCA population, but representative for adult JCA patients seeing a rheumatologist.

Second, selection bias (non-response bias) might have affected the observed results. To reduce selective response, we introduced the study to patients as a survey of abilities of people diagnosed with childhood rheumatic disease. The response rate was $50 \%$, which is an average rate among relative young age groups for studies with postal questionnaires in the Netherlands. A randomised trial of various design and mailing techniques for questionnaires in an open population reported comparable response rates. ${ }^{16}$ Few nonparticipating patients indicated a reason for refusing to participate and privacy legislation 
in the Netherlands prevented us performing an extensive non-response analysis. When the SDR data were examined we found that the sex distribution of the participants was slightly different from non-participants. We have therefore presented our results with as much gender-specific information as possible. Patients with systemic onset of disease are also slightiy overrepresented and patients with polyarticular onset underrepresented. Unfortunately, our sample size limited our ability to make further subgroup comparisons. However, prognosis is related more to the disease course than the onset type of JCA. 17, it In our study sample, there were no significant differences in disease activity between different types of JCA onset (data not shown). We do not therefore think that this has substantially or systematically affected our results in any direction.

In conclusion, JCA in childhood has an important impact on labour force participation and work disability rates in adulthood. Most patients with any employment history reported career related problems and job handicaps as a consequence of their childhood disease. Our study supports the view that social support, mobility problems and hand/arm impairments at the workplace are the main important factors to consider in career counselling for these patients. 


\section{References}

1. Erlandson D. Juvenile rheumatoid arthritis. In: Logigian M, Ward J, editors. Pediatric Rehabilitation: A team Approach for Therapists. Boston: Little Brown and Co., 1989.

2. Lovell D, Levinson J. Health care services, school performance and needs in pediatric rheumatology-results of a nationwide survey. Artritis Rheum 1987;30:S35.

3. Peterson LS, Mason T, Nelson AM, O'Fallon WM, Gabriel SE. Psychosocial outcomes and health status of adults who have had juvenile rheumatoid arthritis: a controlled, population-based study [see comments]. Arthritis Rheum 1997;40:2235-40.

4. Warr P. Work, unemployment and mental health. Oxford: Clarendon Press, 1987.

5. Allaire SH. Work disability. In: Wegener ST, Belza BL, Gall E.P., editors. Clinical care in the rheumatic diseases. Georgia: American College of Rheumatology, 1996; 141-5.

6. Hill RH, Herstein A, Walters K. Juvenile rheumatoid arthritis: follow-up into adulthood - medical, sexual and social status. Can Med Assoc J 1976;114:790-6.

7. Miller JJ, Spitz PW, Simpson U, Williams GF. The social function of young adults who had arthritis in childhood. J Pediatr 1982;100:378-82.

8. Muney K, Hanson V, Mukamel M, Boone D. Health status and achievement in adult life of patients diagnosed with juvenile rheumatoid arthritis. Arthritis Rheum, 1987;30:S200.

9. Miedema HS, Linden SM vd, Rasker JJ, Valkenburg HA. A national database of patients visiting rheumatologists in the Netherlands: The Standard Diagnosis Register of Rheumatic Diseases. A report and preliminary analysis. Br J Rheumatol 1998;37:55561.

10. Wood P. Nomenclature and classification criteria of arthritides in children. EULAR Bull $1988 ; 4: 101$.

11. Mason JH, Anderson JJ, Meenan RF, Haralson KM, Lewis-Stevens D, Kaine JL. The rapid assessment of disease activity (RADAR) questionnaire: Valididty and sensitivity to change of a patient self-report measure of joint count and clinical status. Arthritis Rheum 1992;35:156-62.

12. Stucki G, Liang MH, Stucki S, Brühlmann P, Michel BA. A. self-administered rheumatoid arthritis disease activity index (RADAI) for epidemiologic research. Arthritis Rheum $1995 ; 38: 795-8$.

13. Bijlsma JWJ, Oude Heuvel CHB, Zaalberg A. Development of the Dutch questionnaire capacities of daily life (VDF) of patients with rheumatoid arthritis. J Rehabilitation Sciences 1990;2:71-4. 
14. Andries $F$, Wevers CW, Wintzen AR, Busch HF, Howeler $C$, de Jager $A E$ et al. Vocational perspectives and neuromuscular disorders. Int J Rehabil Res 1997; 20:25573.

15. Statistics Netherlands (CBS). Survey of the general population in the working age 1996. The Hague: CBS, 1997.

16. Eaker S, Bergstrom R, Bergstrom A, Adami HO, Nyren O. Response rate to mailed epidemiologic questionnaires: a population-based randomized trial of variations in design and mailing routines. Am J Epidemiol 1998;147:74-82.

17. Hull RG. Outcome in juvenile arthritis. Br J Rheumatol 1988;27:66-71.

18. Schneider R, Passo MH. Juvenile rheumatoid arthritis. Rheum Dis Clin N Am 2002;28:503-30. 


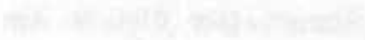


Summary and conclusions 



\section{Introduction}

The study described in this thesis has yielded several important and new findings with regard to work related quality of life, participation in the labour force and its determinants of patients with rheumatoid arthritis (RA), ankylosing spondylitis (AS), and juvenile chronic arthritis (JCA) in the Netherlands. The main results are outlined below in the context of the research questions 1 to 4 posed in the General introduction (Chapter 1), and placed in perspective.

\section{Main results}

1. What is the importance of paid work for the quality of life of patients with rheumatic diseases?

This question was addressed in Chapter 2 for patients with RA and AS, Using stepwise logistic regression, we assessed the contribution of paid work to the physical and mental health related quality of life (QOL), as measured by two. component summary scores of the SF-36. ${ }^{1}$ The expected findings were that work not only provides social status and income, but is also valued for its social support and social distraction outside the family. ${ }^{2}$ Our study shows a positive association between paid work and physical health related. QOL and no association with mental health related $\mathrm{QOL}$ in both patient groups, after controlling for sociodemographics, disease related variables (including disease activity, comorbidity, and disease duration), coping and fatigue. One might argue that being at work is an indicator of functional status of patients. In our samples, functional status, as indicated by the health assessment questionnaire (HAQ) in patients with RA and the Bath ankylosing spondylitis; functional index. (BASFI) in patients with AS, was highly correlated $(r>0.6)$ with the disease activity indicator in both diseases. So by controlling for disease activity in our regression models we also controlled for functional status. We therefore believe that our findings. present evidence for the conclusion that being at work is more than an indicator for functional status, despite: the cross sectional design of our study. Moreover, we conclude that work can positively influence patient's perception of their own physical performance. This conclusion is supported by earlier studies, which have indicated that patients with rheumatic diseases and comparable levels of disease activity can differ greatly in the way they perceive their health. ${ }^{3}$ 
2. To what extent do patients with rheumatic diseases participate in the labour force, and what is their labour market position compared to peers in the general population?

Participation in the labour force is defined as having a paid job at the time of the study. To assess the labour market position of patients with rheumatic diseases, in other words to compare patients with rheumatic diseases to peers in the general population, we have calculated standardised rates to control for differences in age, sex and educational level. This provided new insights into the labour market position of these patients.

The standardised labour force participation rate of patients with RA is $61 \%$ compared to $66 \%$ for the general population, indicating that the labour market position of patients with RA is not significantly different from that peers without disease in the general population. There is a correlation between a significant reduction in labour force participation compared to peers from the general population and a disease duration of six years or more (Chapter 3 ).

For patients with AS, the standardised labour force participation rate is $54 \%$ compared to $66 \%$ of that of peers in the general population (Chapter 4). Furthermore, the probability of participating in the Dutch labour force is already lower in patients with AS of relatively short disease duration, and is not additionally influenced by duration of disease (Chapter 6).

In conclusion, our study reveals that participation in the labour force of patients with RA is only slightly lower than that of peers in the general Dutch population and that participation in the labour force is already lower in patients with AS at a very early stage of disease.

\section{Which determinants of early withdrawal from the labour force can be} identified, and what is the relative importance of some of those

\section{determinants?}

In answer to this question, Chapter 5 looks at determinants for patients with RA and Chapter 6 examines determinants for patients with AS. The study groups were restricted to patients with a paid job some time after the diagnosis, and the analysis focuses on potentially modifiable determinants.

In both patient groups, support of colleagues and management, accessibility to the workplace, transportation mobility at the workplace and additional job training after diagnosis are important work factors. Additionally, in patients with RA only, adjusted job demands, colleagues being well informed about the disease, reduced number of working hours, and allowing the disease to influence job choice are 
associated with a reduction of withdrawal from the labour force. In AS only, technical or ergonomic adjustments and working at a large company are associated with a reduction in withdrawal from the labour force and a negative attitude of the management is associated with an increase. For patients with RA, the most important work factor in terms of decreasing the risk is adjusted job demands. For patients with AS, the factor is technical of ergonomic adjustments of the workplace. Furthermore, in both patient groups, limiting the level of activity when facing the stressors of the disease, in other words behavioural coping, is negatively associated with labour force participation. By identifying behavioural coping as a potential determinant, the present study adds a new element to the discussion about the multifactorial mechanism underlying the relationship between rheumatic diseases and labour force participation.

In conclusion, the results of Chapter 5 and 6 indicate that, alongside sociodemographic factors and disease related factors, various work factors and behavioural coping styles simultaneously play an important role in relation to withdrawal from the labour force in patients with rheumatic diseases.

4. Which problems do adult patients with childhood rheumatic disease have at the labour market?

The reșults of Chapter 7 indicate that the labour force participation rate is lower for adult patients with a history of childhood rheumatic disease onset who are consulting a rheumatologist and that these patients are more dependent on work disability pension than peers in the general population. Although a considerable number of patients had problems with school life, this was not found to be predictive for employment later in life. Important career related problems are insufficient support of colleagues and management and the interaction between disease activity and work performance. Mobility problems, such as problems with transfer from one place to another at the workplace, and hand and arm movements, are important job handicaps. Kulas \& Schanberg ${ }^{4}$ state that many children with JCA experience painful complications such as joint destruction and deformity, osteoporosis, and growth abnormalities, which continue into adulthood. The present study shows that adults with JCA have major disease related. problems with participation in the labour force and that work disability is officially recognised in their cases. 


\section{Methodological considerations}

Many of the methodological strengths and limitations of the study have been discussed in the previous chapters. Some general methodological issues will be dealt with here: patient selection, data collection, and statistical analysis.

\section{Patient selection}

All patients were recruited with the help of a selection of rheumatologists working in rheumatology outpatient clinics. Representative patient selection was facilitated by the Standardised Diagnosis Register of Rheumatic Diseases (SDR), which was founded in 1979. In the mid-nineties, this database contained information relating to $80 \%$ of the patient populations of all rheumatologists working in the Netherlands. This is representative for the total patient population under rheumatological care, and not for patients with rheumatic diseases under the care of general practitioners, orthopaedic or internal medicine specialists. ${ }^{5}$ Rheumatological care in the Netherlands is well dispersed over the country, and therefore easily accessible for rheumatic patients. Since 2002, the SDR database is no longer updated, and is no longer easily accessible anymore for representative patient selection at a national level.

Patients were eligible for this study when recorded in the SDR as having RA, AS or JCA and as being of working age. The diagnoses AS and JCA were not validated. RA was validated using the 1987 ACR criteria. ${ }^{6}$ This might seem a drawback of our study. However, most available criteria are intended for classification and not for diagnosis. In AS, the modified New York criteria are often applied. They were designed as diagnostic criteria but, in retrospect, they appear to be classification criteria.? Internationally, there is still some discussion about activity and severity criteria for $\mathrm{AS}^{8,9}$ There are no universally accepted classification schemes for JCA. ${ }^{4}$ More importantly, even in cases where patients do not meet any criteria, they were clinically diagnosed by a rheumatologist, and therefore labelled as rheumatic patients in their contacts with social security organisations.

In addition, one might argue that patients with rheumatic diseases receiving rheumatological care have worse disease and poorer outcome, but little is known in the Netherlands about patients with similar diagnosis who are not receiving rheumatological care. It is therefore difficult to state whether our results present a more negative picture of the labour force participation for all Dutch patients. However, if we assume that we included patients with worse disease, and therefore patients with poorer outcome, labour force participation rates of the total population with RA, AS, and JCA of working age would be higher than found in our study. More research is needed to establish a complete picture 
of participation rates for the total population with rheumatic diseases, and to make a better assessment of the way in which the labour force participation rates of our study population are influenced.

We attempted to reduce selective patient response to a minimum by introducing the study to the patients as a survey of abilities of patients diagnosed with a rheumatic disease. Privacy legislation in the Netherlands meant that it was not possible to perform a comprehensive non-response analysis. Fortunately, the SDR database provided some anonymised information about the age, sex and diagnosis of patients selected for the study but not willing to participate. In adults with JCA. only, women were significantly overrepresented and patients with polyarticular onset were underrepresented. This was controlled for using sex specific figures. Due to the sample size, we were not able to investigate the problems of adults with different types of JCA onset, or to determine whether this might have affected our results. Since earlier studies have indicated that prognosis in this patient group is more related to disease course than the type of onset, ${ }^{10}$ and since we did not find any significant differences in our study sample between disease activity and types of onset, we assume that the overrepresentation of patients with polyarticular onset has little effect on our conclusion with respect to problems in the labour market for adult patients with childhood rheumatic disease.

The results of our study are, therefore, representative for the clinical outpatient population of rheumatologists, and not for the total patient population with rheumatoid arthritis, ankylosing spondylitis and adults with JCA in the Netherlands.

\section{Data collection}

The design of our study was already established in a broader research line on 'labour force participation and its determinants in patients, with chronic diseases ${ }^{\circ}$. The data are therefore based on self reported measures, and limited resources meant that we were not able to collect more objective measures. To obviate this, our choice of measurement instruments we focused as much as possible at reliable, valid and easily applicable self administered instruments.

The cross sectional design of our study is a major limitation in examining determinants of early withdrawal from the labour force. In fact, it does not allow us to draw conclusions on causality of factors relating to leaving the labour force, specifically with respect to our findings on behavioural coping. It is not clear whether behavioural coping styles are stable and already developed early in the disease process, or whether they are susceptible to 
change over time. In earlier studies, it has been stated that patients with rheumatic diseases develop a coping style early in the illness and use their favourite strategies to deal with stressful situations. ${ }^{11-14}$ In our study, the results on coping in subgroups of patients with short disease duration, and patients who had recently left the labour force, did not influence our conclusions about coping. The results of this study, therefore, indicate that research on the subject should pay more attention to behavioural coping strategies.

In conclusion, the data collected in our study are reliable and valid for exploration of associations of various determinants with early withdrawal from the labour force. In the specific case of coping, a more longitudinal approach would be interesting to explore further the role of behavioural coping strategies in relation to labour force participation in rheumatic diseases.

\section{Statistical analysis}

An important strength of this study is that standardisation methods are used to enable comparison of labour force participation rates between patients with rheumatic diseases and the general population, since age and sex and, in rheumatoid arthritis patients educational achievement are important confounding factors. This has not been done before, but would seem to be important for future research in order to establish a better picture of the labour market position of patient populations. It also leads to a better comparison of international data, because differences in labour force participation rates between countries can be discussed against the backgroud of differences in economic situation and social security systems:

Most of the statistical methods used in this thesis assume that the outcomes for labour force participation of study subjects are independent. If, for instance, participation in the labour force is influenced by the conduct of rheumatologists towards the working ability of patients, all the $p$ values and confidence intervals presented. will usually not give valid results. If this is the case, special statistical analytic techniques are required in which clustering is considered. ${ }^{15}$ A Dutch postal survey of $82 \%$ of all rheumatologists in the Netherlands show that most of the rheumatologists consider reduction of pain and fatigue as their major responsibility in the process of occupational rehabilitation, followed by improving participation in the workforce and quality of work. ${ }^{16}$ It would, therefore, be interesting to study more comprehensively the role of the rheumatologists in relation to labour force participation with different analytical techniques. 
The techniques used for statistical analysis in this thesis are straightforward epidemiological techniques. The standardisation method for these techniques has never been applied before in this field of research.

\section{Final conclusion}

The main conclusion of this thesis is that, at least in the Netherlands, the labour market position of subgroups of patients with chronic rheumatic disease is unfavourable compared to non-diseased peers. Furthermore, it shows that work is an important independent factor of physical health related quality of life in theumatic patients. It also provides various potentially modifiable determinants, both at the individual and the societal levels. These determinants can be used to develop multidisciplinary intervention programmes for rheumatic patients with the aim of preventing problems with entering or staying in the labour force, despite active disease.

In summary, this thesis shows that having a chronic rheumatic disease does not necessarily mean that these patients are unable to work. In patients with rheumatic diseases, who are willing to work, it is important for workload to be adapted to a patient's ability, which can fluctuate over time. Patients who are considering leaving the work force because of disease, should be coached adequately and informed comprehensively about the consequences. Therefore, we hope that this thesis can contribute to more effective vocational intervention strategies that will enable people with rheumatic diseases willing to work to participate in the labour force. Team working between curative and company health care should therefore be the rule. 


\section{References}

1. Ware JEJ, Kosinski M, Bayliss MS, McHorney CA, Rogers WH, Raczek A. Comparison of methods for the scoring and statistical analysis of SF-36 health profile and summary measures: summary of results from the Medical Outcomes Study. Med Care 1995;33:AS264-79.

2. Warr P. Work, unemployment and mental health. Oxford: Clarendon Press, 1987.

3. Cochrane GM. Rheumatoid arthritis: vocational rehabilitation. Int Rehabil Med 1982;4:148-153.

4. Kulas DT, Schanberg L. Juvenile idiopathic arthritis. Curr Opin Rheumatol 2001; 13:392-8.

5. Miedema HS, Linden SM vd, Rasker J3, Valkenburg HA. A national database of patients visiting rheumatologists in the Netherlands: The Standard Diagnosis Register of Rheumatic Diseases. A report and preliminary analysis. Br J Rheumatol 1998;37:55561.

6. Arnett FC, Edworthy SM, Bloch DA, McShane DJ, Fries JF, Cooper NS et al. The American Rheumatology Association 1987 revised criteria for the classification of rheumatoid arthritis. Arthritis Rheum 1988;31:338-24.

7. Goei The HS, Steven MM, van der Linden SM, Cats A. Evaluation of diagnostic criteria for ankylosing spondylitis: a comparison of the Rome, New York and modified New York criteria in patients with a positive clinical history screening test for ankylosing spondylitis. Br J Rheumatol 1985;24:242-9.

8. Linden S van der, Valkenburg HA, Cats A. Evaluation of diagnostic criteria for ankylosing spondylitis. A proposal for modification of the New York criteria. Arthritis Rheum 1984;27:361-8.

9. Braun J, Sieper J. Building consensus on nomenclature and disease classification for ankylosing spondylitis: results and discussion of a questionnaire prepared for the International Workshop on New Treatment Strategies in Ankylosing Spondylitis, Berlin, Germany, 18-19 January 2002. Ann Rheum Dis 2002;61:iii61-7.

10. Hull RG. Outcome in juvenile arthritis. $\mathrm{Br}$ J Rheumatol $1988 ; 27: 66-71$.

11. Ward MM. Quality of life in patients with ankylosing spondylitis. Rheum Dis Clin North Am 1998;24:815-27.

12. Van Lankveld W, van 't Pad Bosch P, van de Putte L, Naring G, van der Staak C. Disease-specific stressors in rheumatoid arthritis: coping and well-being. $\mathrm{Br} J$ Rheumatol 1994;33:1067-73. 
13. Van Lankveld W, Naring G, van der Staak C, van 't Pad Bosch P, van de Putte L. Stress caused by rheumatoid arthritis: relation among subjective stressors of the disease, disease status, and well-being. J Behav Med 1993;16:309-21.

14. Van Lankveld W, Naring G, van 't Pad Bosch P, van de Putte L. The negative effect of decreasing the level of activity in coping with pain in rheumatoid arthritis: an increase in psychological distress and disease impact. J Behav Med 2000;23:377-91.

15. Rothman KJ, Greenland S. Modern Epidemiology. Second ed. Philadelphia: LippincottRaven Publishers, 2000.

16. De Buck PD, van Amstel RJ, Buijs PC, Maasen JH, van Dijk FJ, Hazes JM et al. Communication between Dutch rheumatologists and occupational physicians in the occupational rehabilitation of patients with rheumatic diseases. Ann Rheum Dis 2002;61:62-5. 
Samenvatting 



\section{Reuma en werk in Nederland}

Reuma is een verzamelnaam voor meer dan honderd aandoeningen van het bewegingsstelsel, die niet door een ongeval of blessure zijn veroorzaakt. Veel mensen denken bij reuma aan pijn en beperkingen in de gewrichten die onlosmakelijk verbonden zijn met het ouder worden. Echter, jong en oud kunnen getroffen worden door reuma. Bij kinderen en pubers komt juveniele chronische artritis (JCA) oftewel jeugdreuma voor, Bij mensen van middelbare leeftijd zijn reumatoide artritis (RA) en ankyloserende spondylitis (AS), oftewel de ziekte van Bechterew, veelvoorkomende vormen van reuma.

Mensen met reuma ondervinden vaak veel problemen bij het dagelijks functioneren, zo ook bij het verrichten van betaald werk. Een baan is niet alleen een bron van inkomsten, maar is ook van belang voor de sociale status, de sociale contacten en steun buiten de directe familiekring. Aan de andere kant kan werk voor mensen met reuma ook een extra belasting. met zich meebrengen, die gezondheidsbedreigend kan uitpakken. Het is daarom van belang om een goede balans te vinden tussen de belastbaarheid en de werkbelasting bij mensen met reuma om tijdelijke en permanente arbeidsongeschiktheid te voorkomen.

In Nederland hebben naar schatting 200.000 mensen reuma in de arbeidzame leeftijd. Dit is $2 \%$ van de totale beroepsbevolking. De kosten van reuma in Nederland bedragen $6 \%$ van de totale medische kosten en $15 \%$ van de totale kosten als gevolg van arbeidsongeschiktheid. Reuma is dus ook een belangrijk maatschappelijk probleem.

Slechts weinig wetenschappers in Nederland hebben uitgebreid aandacht besteed aan de problemen die mensen met reuma ondervinden in de arbeidssituatie of bij het verkrijgen van betaald werk. Er zijn wel enkele gegevens uit buitenlandse studies over deze relatie bekend. Deze gegevens zijn echter van beperkte waarde voor de Nederlandse situatie door verschillen in cultuur, economische situaties en sociale zekerheidsstelsels.

Het hoofddoel van dit proefschrift is het bestuderen van de relatie tussen reuma en betaald werk in Nederland (Hoofdstuk 1). Deze relatie is onderzocht aan de hand van de volgende vragen:

1. Wat is het belang van betaald werk voor de kwaliteit van leven van mensen met reuma?

2. Wat is de arbeidsparticipatie van mensen met reuma, en hoe verhoudt deze zich ten opzichte van de totale Nederlandse bevolking?

3. Wat zijn beīnvloedbare determinanten van vroegtijdig stoppen met werken door mensen met reuma?

4. Welke problemen ervaren jongvolwassenen met jeugdreuma op de arbeidsmarkt? 
De antwoorden op deze vragen zijn gebaseerd op gegevens van een landelijk vragenlijstonderzoek. De onderzoeksgroep bestond uit 1056 patiēnten met RA tussen 16 en 59 jaar oud, 658 patiénten met AS tussen 16 en 59 jaar oud en 104 patiênten met JCA tussen de 16 en 35 jaar. Deze patiënten werden willekeurig geselecteerd met behulp van een landelijke registratie van poliklinische patiènten van reumatologen, de zogeheten Standaard Diagnoseregistratie van Reumatische ziekten. Alle patiënten vulden eenmalig een vragenlijst in over hun sociaal-economische achtergrond, de ziektegeschiedenis, de algemene gezondheidstoestand, het arbeidsverleden en de huidige arbeidssituatie.

\section{Het belang van betaald werk voor de kwaliteit van leven}

In Hoofdstuk 2 is het belang van betaald werk voor de kwaliteit van leven bestudeerd voor mensen met RA en AS. Voor beide reumatische aandoeningen is geconstateerd dat betaald. werk gepaard gaat met een betere lichamelijke gezondheidsgerelateerde kwaliteit van leven. Er is geen relatie gevonden tussen betaald werk en mentale gezondheidsgerelateerde kwaliteit van leven. In beide onderzochte relaties is rekening gehouden met de mogelijke invioed van factoren als leeftijd, geslacht, opleiding, ziektestatus, verschillende stijlen van omgaan met reuma en vermoeidheid. Tevens is uitgesloten dat het hebben van werk uitsluitend een indicator is voor functionele status. Het blijkt namelijk dat werk een onafhankelijke bijdrage levert aan de lichamelijke gezondheidsgerelateerde kwaliteit van leven, ook als er rekening is gehouden met de mogelijke invloed van ziekteactiviteit en functionaliteit. Op basis hiervan concluderen we dat het hebben van werk positief kan bijdragen aan de ervaren lichamelijke gezondheidstoestand.

\section{De arbeidsparticipatie}

De arbeidsparticipatie van reumapatiènten in vergelijking met de algemene beroepsbevolking is beschreven in de Hoofdstukken 3, 4 en deels in Hoofdstuk 6. Omdat leeftijd, geslacht en opleiding voor mensen in het algemeen van invloed zijn op de arbeidsparticipatie, is in dit proefschrift hiermee rekening gehouden door te standaardiseren. Door te standaardiseren biedt dit proefschrift nieuwe inzichten in de arbeidsmarktpositie van deze patiënten.

De gestandaardiseerde arbeidsparticipatie van mensen met RA is $61 \%$ en van de algemene beroepsbevolking $66 \%$. Dit verschil is niet statistisch significant. Wanneer de arbeidsparticipatie voor verschillende categorieen van ziekteduur uitgesplitst werd, bleek dat mensen met een ziekteduur van zes jaar of meer een significant lagere arbeidsparticipatie hadden vergeleken met de algemene beroepsbevolking (Hoofdstuk 3). 
De gestandaardiseerde arbeidsparticipatie van patienten met AS is $54 \%$. Dit is $12 \%$ lager dan de arbeidsparticipatie in de algemene beroepsbevolking. Dit verschil is statistisch significant (Hoofdstuk 4). De arbeidsparticipatie van patiènten met AS bleek reeds bij mensen bij wie 1 tot 5 jaren geleden de diagnose was gesteld lager te zijn dan de arbeidsparticipatie van de algemene beroepsbevolking. Deze verlaging van de arbeidsparticipatie bleef constant bij het toenemen van het aantal ziektejaren (Hoofdstuk 6).

\section{Determinanten van vroegtijdig stoppen met werken}

Determinanten van vroegtijdig stoppen met werken zijn beschreven in Hoofdstuk 5 voor patiènten met RA en in Hoofdstuk 6 voor patiènten met AS, De determinanten die in verband werden gebracht met vroegtijdig stoppen met werken zijn sociaaldemografische kenmerken, ziektekenmerken, werkfactoren en stijlen van omgaan met de ziekte. Hierbij is uitgebreid gekeken naar beinvloedbare factoren in de werksituatie.

In beide patièntengroepen waren belangrijke determinanten van vroegtijdig stoppen met werken: onvoldoende steun van collega's en het management, slechte toegankelijkheid van de werkplek, problemen met het verplaatsten op de werkplek en weinig tot geen bijscholing of cursussen voor het verbreden van kennis en vaardigheden als de diagnose eenmaal gesteld is.

Voor patiënten met RA bleken ook determinanten als aanpassingen van werkzaamheden en werktijden, het informeren van collega's over de aandoening en het afstemmen van de laatst uitgevoerde functie op de fysieke mogelijkheden een belangrijke rol te spelen. Voor patiënten met AS bleken ook technische of ergonomische aanpassingen op de werkplek, de bedrijfsomvang en de houding van managers ook belangrijke determinanten te zijn. De belangrijkste werkfactor om stoppen met werken te voorkomen bij RA is het aanpassen van werktaken (zoals het afstoten van taken of het zelf kunnen indelen yan taken), Voor patiënten met. AS is dit het doorvoeren van technische of ergonomische aanpassingen (zoals een aangepaste bureaustoel of werkblad).

Naast werkfactoren is ook het kunnen omgaan met pijn, beperkingen en afhankelijkheid als gevolg van de ziekte in verband gebracht met vroegtijdig stoppen met werken. Dit proefschrift geeft aanwijzingen dat als reumapatiẻnten actief blijven ondanks pijn en beperkingen zij minder geneigd zijn om vroegtijdig te stoppen met werken. Deze relatie werd niet eerder onderzocht en met dit resultaat voegt dit proefschrift een nieuwe risicofactor toe aan de reeds bekende rișicofactoren van vroegtijdig stoppen met werken. In dit proefschrift is verder aangetoond dat factoren in het werk en het kunnen omgaan met de gevolgen van de ziekte een even belangrijke rol innemen in de relatie tussen reuma en werk als sociaaldemografische factoren en ziektekenmerken. 


\section{Problemen van jongvolwassenen met reuma op de arbeidsmarkt}

In Hoofdstuk 7 zijn problemen die jongvolwassenen met jeugdreuma ervaren op de arbeidsmarkt beschreven. De onderzochte patiênten rapporteerden minder vaak een betaalde baan en zijn vaker afhankelijk van een arbeidsongeschiktheidsuitkering dan leeftijd- en geslachtgenoten in de algemene bevolking. Hoewel een aanzienlijk deel van de patiénten problemen had gedurende de opleiding, bleek dit niet voorspellend te zijn voor de kans op het krijgen van een baan. Belangrijke problemen die een carrière kunnen bemoeilijken zijn onvoldoende steun krijgen van collega's en managers en de balans vinden tussen de wisselende ziekteactiviteit en het uitvoeren van het werk. In het dagelijks functioneren op de werkplek werden mobiliteitsproblemen en problemen bij het gebruik van handen en armen als belangrijke beperkingen ervaren door patiênten met jeugdreuma.

\section{Tot slot}

De belangrijkste conclusies van dit proefschrift (Hoofdstuk 8) zijn dat de huidige arbeidsmarktpositie van mensen met reuma minder gunstig is dan die van niet-zieke mensen en dat het hebben van reuma niet hoeft te betekenen dat mensen niet kunnen werken. Voor mensen met reuma die willen werken is het belangrijk dat de werklast is aangepast aan de belastbaarheid. Door het wisselende karakter van de ziekte kan de belastbaarheid per periode verschillen. Mensen die overwegen om te stoppen met werken vanwege de ziekte, zouden adequaat begeleid en uitgebreid geïnformeerd moeten worden over de gevolgen hiervan voor de financiēle positie, maar ook voor de persoonlijke ontwikkeling en de sociale status.

De determinanten van vroegtijdig stoppen met werken die beschreven zijn in dit proefschrift bieden aanknopingspunten voor het ontwikkelen van effectieve interventies die (re-)integratie van mensen met reuma kunnen bevorderen. Een goede samenwerking tussen de curatieve en de bedrijfsgezondheidszorg is hierbij een vereiste. 
Dankwoord 



\section{'First Things First, but not necessarily in that order'}

Iedereen die heeft meegewerkt aan het tot stand komen van dit proefschrift wil ik graag op deze plek bedanken en een aantal van hen wil ik hier graag noemen.

Alle mensen met reuma die belangeloos een vragenlijst hebben ingevuld. Hartelijk dank! Ik hoop dat dit proefschrift niet alleen wetenschappelijk, maar ook maatschappelijk zijn weg zal vinden.

Alle reumatologen en hun assistentes die bereid waren hun patienten uit te nodigen voor deeiname aan het onderzoek. Dit betrof de volgende klinieken: Jan van Breemeninstituut Amsterdam, Sint Antoniusziekenhuis Nieuwegein, Rode Kruisziekenhuis Den Haag, Bosch Medicentrum Den Bosch, Sint Laurentiusziekenhuis Roermond, Sint Jansgasthuis Weert, Groene Hartziekenhuis Gouda, Albert Schweitzerziekenhuis Dordrecht, Kennemer Gasthuis locatie Deo Haarlem, Lievensberg Ziekenhuis Bergen op Zoom, Tweesteden Ziekenhuis Tilburg, Rijnstate Ziekenhuis Arnhem, Medisch Centrum Leeuwarden, St. Maartenskliniek Nijmegen, Medisch Spectrum Twente Enschede, Leids Universitair Medisch Centrum Leiden, Academisch Ziekenhuis Groningen, Gelderse Vallei Wageningen, Ziekenhuis Hilversum, Beatrixziekenhuis Gorinchem en het Academisch Ziekenhuis Maastricht. Allen heel erg bedankt!

Mijn promotor, Professor dr. Sjef van der Linden. Beste Sjef, hartelijk bedankt voor het vertrouwen in mijn werk. Dankzij je snelle en constructieve reacties via de elektronische mail was Maastricht een stuk dichter bij Leiden.

Mijn medeauteurs drs. Harald Miedema, dr. Annelies Boonen en drs. Cees Wevers. Beste Harald, heel erg bedankt dat je me op het promotiepad gezet hebt. Ik weet zeker dat het met de implementatie van de resultaten goed komt. Beste Annelies, hartelijk dank voor de vele, soms felle, doch stimulerende discussies. Beste Cees, heel erg bedankt dat ik de vragenlijst 'Arbeid en Handicap' heb kunnen gebruiken als wezenlijk onderdeel van dit proefschrift.

Mijn werkgever, TNO Preventie en Gezondheid, en in het bijzonder dr. ir. Marijke de Kleijnde Vrankrijker en dr. Marijke Hopman-Rock, die bereid waren mij de ruimte te geven dit promotietraject te starten en tot een goed einde te brengen. Beste Marijkes, hartelijk dank daarvoor! 
De leden van de beoordelingscommissie: Prof. dr. F.J.N. Nijhuis, voorzitter, Prof. dr. J.Th.M. van Eijk, Prof. dr. W. van Mechelen, Prof. dr. J.J. Rasker, Prof. dr. ir. C.P. van Schayck wil ik graag bedanken voor het lezen en beoordelen van mijn proefschrift.

Yolanda Soons, heel erg bedankt voor de steun gedurende het officiële traject van verzoek tot toelating voor promotie aan de Universiteit Maastricht tot de promotie zelf.

Rianne Quak, zonder jou zag mijn proefschrift er lang niet zo mooi uit. Jij 'managed' alles. Heel erg veel dank voor de vele gezellige overuurtjes!

Pete Thomas, thenk joe voor het corrigeren van mijn Engels!

Jan Albert Sterkman. Beste Jas, dankzij jouw journalistieke blik is mijn Nederlandse samenvatting hopelijk ook leesbaar voor niet-ingewijden. Biertje?

Dolph Paulsen, ik was meteen heel erg enthousiast over het ontwerp van de omslag van mijn proefschrift. Het is helemaal mijn stijl: abstract en rustig. Heel erg bedankt voor dit mooie cadeau!

Jaap van der Plas. Veel dank voor je steun bij de reproductie van mijn proefschrift.

Mijn paranimfen, Loes van Herten en Henriëtte Grooten. Als paranimf heb ik bij jullie beiden het 'kunstje' van dichtbij mogen afkijken. Ik ben er trots dat jullie nu aan mijn zijde willen staan. Vriendinnen voor altijd!

Verder wil ik mijn zus, schoonouders, schoonzussen, zwagers, vrienden en collega's bedanken voor de oprechte belangstelling in mijn promotietraject. Dat feestje komt eraan!

Pap en mam, dankzij jullie heb ik alle kans gekregen dat te worden wat ik wilde worden. Maar belangrijker is dat jullie de basis hebben gelegd voor wie ik ben. Ik kan me geen betere en zorgzamere ouders wensen!

Lieve Eric, vandaag is het feest, en morgen ook. Ik ook van jou!

Astrid Chorus

Februari 2004 
About the author 

The author of this thesis, Astrid Chorus was born on June $2^{\text {nd }}, 1967$ in Munstergeleen, The Netheriands. After she graduated from secondary school in 1985, she started her study Human Nutrition at the Agricultural University in Wageningen. Her MSc program was focused on nutrition, epidemiology and statistics. She graduated in 1991. In the same year she was employed as an Epidemiologist at the department of Psychosocial Research and Epidemiology of the Netherlands Cancer Institute/Antoni van Leeuwenhoek hospital in Amsterdam. In 1992 she was officially registered as Epidemiologist A by the Netherlands Epidemiology Society. In 1994 she took up a research appointment at the division of Public Health of TNO Prevention and Health in Leiden. There she is involved in research projects in the field of chronic diseases and participation in society. The study on the labour market position of rheumatic patients was conducted in 1996 and 1997 as part of her work tasks. In 1998 she came in touch with Professor dr. Sj. van der Linden, head of the division of Rheumatology, department of Internal Medicine of the Academic Medical Hospital Maastricht. The idea was born to start a PhD-project on the subject as described in this thesis. Astrid continued her research interests in the field of chronic diseases and participation in society at TNO. Nowadays she is part of the team 'Physical activity and health' and involved in research on physical activity and chronic diseases. 
De schrijver van dit proefschrift, Astrid Chorus, werd geboren op 2 juni 1967 te Munstergeleen, een dorp in Limburg. Na haar middelbare school aan de Albert Schweitzerscholengemeenschap te Geleen, begon ze in 1985 aan haar studie Voeding van de Mens aan de Landbouwuniversiteit te Wageningen. Deze studie werd in 1991 met succes afgerond. Haar hoofdvakken waren Voeding van de Mens, Epidemiologie en Statistiek. In datzelfde jaar kreeg zij een aanstelling als Epidemioloog/Methodoloog bij de afdeling Psychosociaal Onderzoek en Epidemiologie van het Nederlands Kanker Instituut/Antoni van Leeuwenhoekziekenhuis te Amsterdam. Eén jaar later, in 1992, werd zij officieel geregistreerd als Epidemioloog A.

In 1994 werd Astrid aangesteld als wetenschappelijk medewerker bij de toenmalige divisie Volksgezondheid van TNO Preventie en Gezondheid (TNO-PG) te Leiden. Binnen TNO-PG is ze tot op heden betrokken bij onderzoeken op het terrein van chronisch zieken en maatschappelijke participatie. Het onderzoek naar arbeidsparticipatie en arbeidsmogelijkheden van mensen met reuma, dat de basis vormde van dit proefschrift, werd uitgevoerd in 1996 en 1997. In 1998 ontmoette zij Professor dr. Sjef van der Linden, hoofd van de sectie Reumatologie, afdeling Interne Geneeskunde van het Academisch Ziekenhuis Maastricht. Het idee werd geboren om een promotieproject te starten, waarvan dit proefschrift het eindproduct is.

Astrid's onderzoeksinteresses liggen nog steeds op het terrein van chronisch zieken en maatschappelijke participatie. Momenteel maakt zij binnen TNO-PG deel uit van de groep 'Bewegen en Gezondheid', waarbinnen ze zich voornamelijk bezighoudt met het subthema 'Chronisch zieken en bewegen'. 


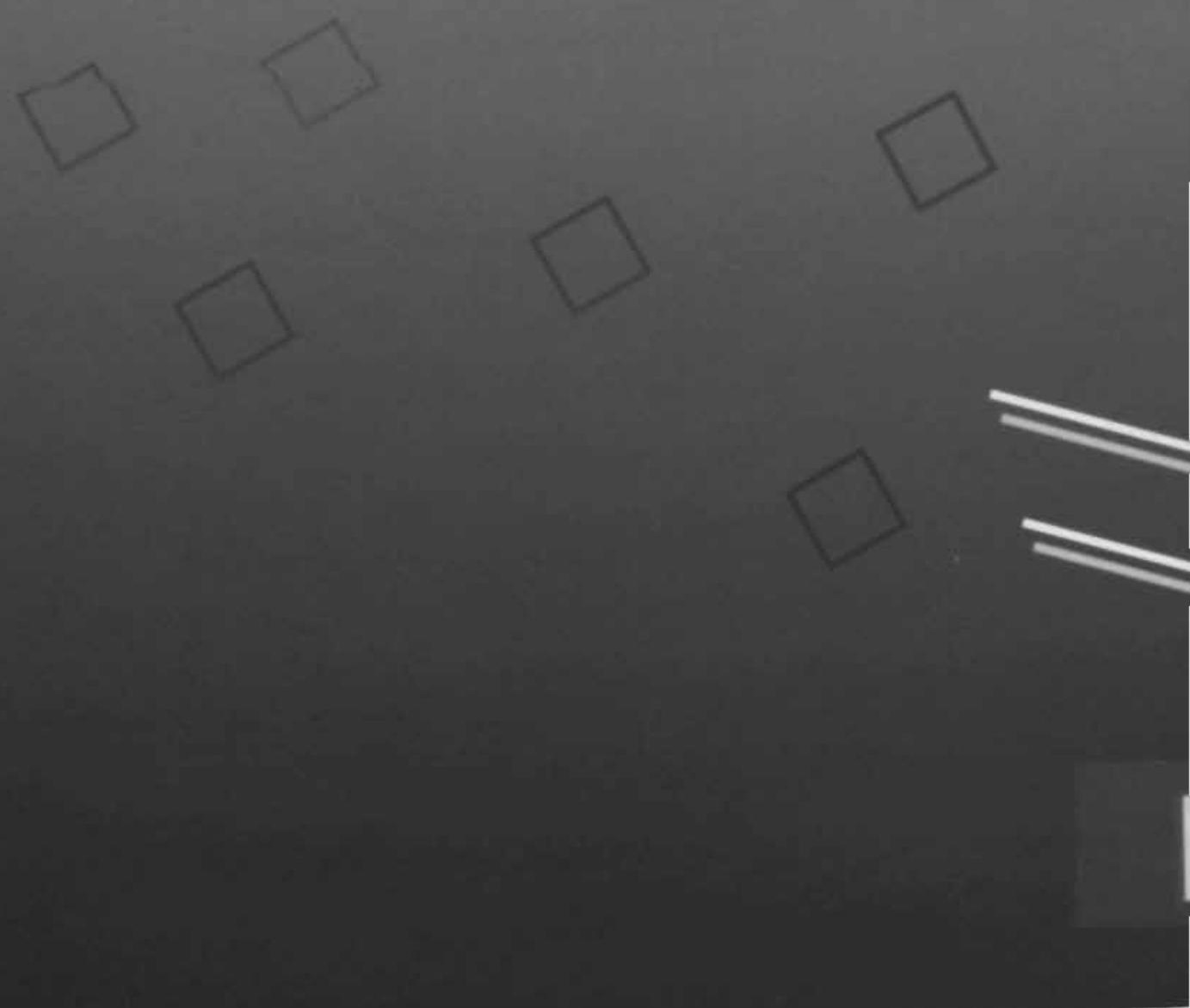